

\title{
THE DESIGN AND USABILITY EVALUATION OF A MONITORING AND FEEDBACK SYSTEM FOR STROKE SURVIVORS
}

\author{
Bart Klaassen
}




\section{Composition of the Graduation Committee:}

\section{Chairperson}

and secretary: Prof. dr. P.M.G. Apers (University of Twente)

Promotors: $\quad$ Prof. dr. ir. H.J. Hermens (University of Twente)

Prof. dr. ir. P.H. Veltink (University of Twente)

Co-promotor: Dr. ir. B.J.F. van Beijnum (University of Twente)

Members: $\quad$ Prof. dr. ir. D. Heylen (University of Twente)

(Internal) Prof. dr. ir. G.J. Verkerke (University of Twente)

Members: $\quad$ Prof. dr. Med. A.R. Luft (University Hospital Zurich, Cereneo A.G.)

(external) Prof. dr. ir. N.M. Maurits (University of Groningen)

Dr. J.B.J. Bussmann (The Erasmus University Medical centre)

Paranymphs: Björn Klaassen

Martijn van Eenennaam

This work was supported by the $\mathrm{FP}_{7}$ project INTERACTION (FP7/ICT project 287351). This work was carried out at the MIRA institute for Biomedical Technology \& Technical Medicine and the CTIT Centre for Telematics and Information Technology, University of Twente.

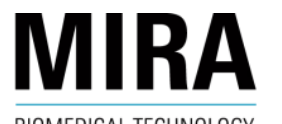

BIOMEDICAL TECHNOLOGY

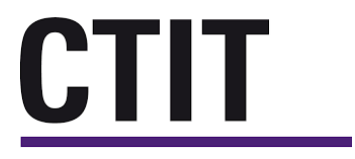

\section{UNIVERSITY OF TWENTE.}

CTIT PhD-thesis number: No. 16-414

ISSN: $1381-3617$

ISBN: $978-90-365-4264-7$

DOI: $10.3990 / 1.9789036542647$

Author: Bart Klaassen

Email: b.klaassen.bmd@gmail.com

Copyright () 2016 Bart Klaassen, Enschede, The Netherlands.

All rights reserved. 


\title{
THE DESIGN AND USABILITY EVALUATION OF A MONITORING AND FEEDBACK SYSTEM FOR STROKE SURVIVORS
}

\author{
DISSERTATION
}

to obtain

the degree of doctor at the University of Twente, on the authority of the rector magnificus, Prof. dr. T.T.M. Palstra,

on account of the decision of the graduation committee, to be publicly defended on Wednesday November 3oth, 2016 at 16:45

by

\section{Bart Klaassen}

born on the $18^{\text {th }}$ of November, 1987 in Goes, The Netherlands 
This dissertation has been approved by:

Promotors: Prof. dr. ir. H.J. Hermens

Prof. dr. ir. P.H. Veltink

Co-promotor: Dr. ir. B.J.F. van Beijnum 


\section{SUMMARY}

The impact of stroke on the world is significant, with high disability rates among survivors and rising costs in healthcare. Therefore, new healthcare strategies and technological solutions should be found in stroke care. Is it possible to reduce healthcare costs, and at the same time make treatment more efficient? It has already been shown that specialized stroke care improves health and economic outcomes. Furthermore, Monitoring patients in their homes, using telemedicine techniques, can lead to better health care at lower costs. Both imply increased demand of new healthcare strategies and technological solutions. If monitoring stroke survivors in their home environment is the solution for a reduction in healthcare cost and a more efficient treatment plan, what information is missing in order to implement such technical solutions in healthcare?

Stroke survivors are trained to recover adequate control over their movements with the objective to optimize their daily-life functional performance. While, the main objective of the rehabilitation program is to maximize the functional performance at home, the actual performance of patients in their home environment is unknown. Therefore, daily-life monitoring of the quality of movement during functional activities of stroke survivors in their physical interaction with the environment is essential for optimal guidance of rehabilitation therapy.

There are several challenges in performing a quantitative and qualitative analysis of daily-life performance using telemedicine technology, compared to clinically assess motor capacity using standardized clinical tests. This includes: the development of new metrics for quantifying movement during daily-life, the absence of context when measuring movements without any visual reference, which is available in clinic but not available in a daily-life setting and finally, the presentation of large amount of movement data to care-professionals. Therefore, there is a need to investigate into how stroke survivors can be monitored during daily-life, which telemonitoring technology to include and what to present to care-professionals. This thesis, supported by the $\mathrm{FP}_{7}$ project INTERACTION, addresses two main objectives: 1) to develop and evaluate a tele-supervision system and intelligent on-body feedback technology for monitoring and coaching stroke survivors in a home environment and 2) develop and evaluate new quality of movement metrics in stroke survivors.

The research presented in this thesis has contributed to both fundamental and applied areas of science and also has an important (potential) societal impact regarding diagnostics and treatment of (stroke) survivors by enabling quantitative 
monitoring during daily-life activities. A literature survey on telemedicine systems presented new insights which can help researchers in optimizing their usability strategies during system development and predicting future trends in usability evaluation strategies. In a multidisciplinary team, with particular focus on the telemonitoring aspects, a full-body inertial sensing system, unobtrusive to wear by stroke survivors during daily-life was realised. This system is named: INTERACTION. This system was used to monitor stroke survivors at home to gain new insights into the performance of these patients during daily-life activities. Clinically relevant Quality of Movement (QoM) metrics were developed, implemented and evaluated, enabling new insights into the differences between in-clinic and outpatient measurements of stroke survivors over longer periods of time. This in turn might assist care-professionals in understanding what is happening with stroke survivors after discharge from the hospital to their homes.

In addition to the INTERACTION system, a reduced sensor system (the "Arm Usage Coach"), capable of monitoring and coaching stroke survivors by giving feedback based on arm movement activity, was designed, implemented and evaluated. This, in turn might engage patients in using their impaired arm more often during daily-life activities. It was found that stroke survivors prefer vibrotactile feedback as a feedback method, which sets the foundation for other researchers in developing assistive technological devices for stroke survivors.

Insights on the opinions given by care-professionals in using inertial motion capture as an assistive technology, including working with QoM metrics as opposed to traditional clinical assessments, was given. Developers in assistive devices for healthcare still face the problem that many care-professionals slowly adapt new technology into their daily-practices. The findings presented in this thesis might help other developers in understanding what is important, in our case related to an inertial motion capture system and associated metrics, and take new approaches in designing and introducing assistive devices into daily practices.

For taking the research presented in this thesis further, it would be interesting to investigate into the optimisation of INTERACTION and the motivational aspects of the patient for performing in clinic and at home. If the INTERACTION system can be less obtrusive to wear by patients and implemented on a larger scale, we can gain more knowledge from a wider variety of stroke patients. Big data approaches can be used to analyse the data, see trends over time and gain more insights into the usage of the system. If so, it might result in a change in therapy of stroke survivors and outpatient, ambulant monitoring and coaching will increase. 


\section{SAMENVATTING}

De wereldwijde impact van beroertes (stroke) is significant gezien het percentage overlevenden met resulterende functie beperkingen en de stijgende kosten in de gezondheidszorg. Daarom moeten er nieuwe strategieën en technische oplossingen gevonden worden voor zorg bij beroertes. Is het mogelijk om de kosten in de gezondheidszorg te reduceren maar tegelijkertijd de behandeling meer effectief te maken? Het is eerder aangetoond dat gespecialiseerde zorg bij beroertes zowel gezondheid en economische uitkomsten verbetert. Daarnaast hebben studies laten zien dat het monitoren van patiënten thuis, met behulp van telemedicine technieken, kan leiden tot betere zorg met lagere kosten. Beiden impliceren een verhoogde vraag naar nieuwe zorg strategieën en technische oplossingen. Als het monitoren van stroke patiënten in hun thuis omgeving een belangrijke bijdrage kan leveren aan een effectiever zorg behandelingsplan en voor een reducering in zorgkosten, is de vraag: wat moet er nog worden uitgezocht om dit soort technologie doelmatig en doeltreffend te kunnen toepassen.

Stroke patiënten worden tijdens de revalidatie getraind om voldoende controle te krijgen over hun bewegingen met het doel om hun functionele prestaties ("functional performance") in het dagelijks leven te optimaliseren. Het hoofddoel van het revalidatie programma focust op het behalen van een maximale "functional performance" thuis. Het blijkt echter dat de daadwerkelijk prestaties tijdens dagelijks leven onbekend zijn. Het monitoren van de bewegingskwaliteit van stroke patiënten tijdens hun activiteiten, waar ze interacteren met hun eigen fysieke omgeving, is daarom essentieel voor een optimale begeleiding in het revalidatie proces.

Er zijn verschillende uitdagingen bij het uitvoeren van een kwantitatieve analyse van prestaties tijdens dagelijks leven met behulp van telemedicine technieken, vergeleken met de huidige methodes in de kliniek waarbij gebruik wordt gemaakt van gestandaardiseerde capaciteit testen voor stroke patiënten. Bijvoorbeeld, het ontwikkelen van nieuwe metrieken voor het kwantificeren van bewegingen tijdens dagelijks leven, de afwezigheid van context wanneer men bewegingen thuis meet zonder visuele referenties (in kliniek is de therapeut aanwezig) en de grote hoeveelheid data die gepresenteerd moet worden. Daarom is uitgezocht hoe deze patiënten thuis gemonitord kunnen worden, welke telemonitoring technologie geschikt is en wat uiteindelijk aan therapeuten gepresenteerd wordt. Dit proefschrift, ondersteunt door het $\mathrm{FP}_{7}$ project INTERACTION, richt zich op twee doelstellingen: 1) het ontwikkelen en evalueren van een tele-supervisie systeem en intelligent on-body feedback systeem voor het monitoren en coachen van stroke patiënten thuis en 2) het 
ontwikkelen en evalueren van nieuwe metrieken voor de bewegingskwaliteit bij stroke patiënten.

Het werk in dit proefschrift bevat zowel fundamentele als toegepaste gebieden in de wetenschap, en heeft een belangrijke (potentiele) maatschappelijke impact wat betreft tot het diagnosticeren en behandelen van (stroke) patiënten door het mogelijk maken van het kwantitatief monitoren van patiënten tijdens activiteiten in het dagelijks leven. Een uitvoerig literatuur onderzoek naar telemedicine systemen en hun bruikbaarheid (usability) resulteerde in nieuwe inzichten welke andere onderzoekers kan helpen in het optimaliseren van usability strategieën tijdens het ontwikkelen van nieuwe systemen en het voorspellen van usability evaluatie trends in de toekomst. In een multidisciplinair team is een volledig inertieel sensor systeem ontwikkeld voor het hele lichaam, met de focus op de telemonitoring aspecten. Dit system is ontworpen om comfortabel gedragen te worden door stroke patiënten tijdens dagelijkse activiteiten. Dit systeem heet: INTERACTION. Het systeem is gebruikt om meerdere stroke patiënten thuis te monitoren en nieuw inzicht te krijgen in de "functionele performance" van deze patiënten tijdens dagelijks leven. Relevante bewegingskwaliteit metrieken zijn ontwikkeld, toegepast en geëvalueerd, waarbij de resultaten nieuw inzicht bieden in de verschillen tussen metingen in de kliniek en thuis over langere tijdsperiode. Dit kan therapeuten ondersteunen in het achterhalen wat er precies gebeurd met patiënten in de thuis situatie.

Naast het INTERACTION systeem is een gereduceerd sensor systeem, genaamd de "Arm Usage Coach", ontwikkeld, toegepast en gevalideerd door stroke patiënten. Dit systeem heeft de mogelijkheid om patiënten te monitoren en coachen door het geven van feedback op basis van arm activiteit. Dit kan als resultaat hebben dat patiënten hun aangedane arm meer gaat gebruiken tijdens dagelijkse activiteiten. Gebleken is dat stroke patiënten voorkeur geven voor vibrotactiele feedback als een feedback methode, wat een goede basis is voor andere onderzoekers in het ontwikkelen van ondersteunende technologieën bij stroke patiënten. De visies van therapeuten, buiten INTERACTION, over de ontwikkelde bewegingskwaliteit metrieken, alsmede het gebruik van een inertieel sensor systeem in de kliniek en thuis zijn geanalyseerd. De resultaten van deze semi-gestructureerde interviews kunnen andere ontwikkelaars helpen om te begrijpen wat belangrijk is voor clinici voor het maken van nieuwe ondersteunende producten gerelateerd aan het monitoren van bewegingen.

Om het onderzoek behandeld in dit proefschrift verder te brengen zou het interessant zijn om te kijken naar de optimalisatie van het INTERACTION systeem, alsmede naar de motivatie aspecten van patiënten in de kliniek en thuis en het effect 
op de "functional performance". Als het INTERACTION systeem zo gemaakt wordt dat het makkelijker draagbaar is en minder opvalt, kan het op een grotere schaal ingezet worden. Daarbij kan meer kennis vergaart worden van een grotere populatie stroke patiënten. Big data strategieën kunnen worden inzetten om de data te analyseren en trends over de tijd te zien, maar ook om meer inzicht te krijgen in het gebruik van het systeem. Als dit mogelijk wordt gemaakt, kan het resulteren in een mogelijke verandering in therapie bij (stroke) patiënten en zal het ambulant monitoren en coachen van patiënten een ruimere toepassing kunnen krijgen. 


\section{ZUSAMMENFASSUNG}

Mit steigenden Kosten sowohl im Gesundheitswesen als auch in der Behandlung, sowie hohen Invaliditätsraten unter den Überlebenden, haben Schlaganfälle tiefgreifende Auswirkungen. Daher sollen neue Gesundheitsstrategien und technologische Lösungen für die Schlaganfallbehandlung gefunden werden. Ist es möglich, Kosten im Gesundheitswesen zu reduzieren und zugleich die Behandlung effizienter zu gestalten? Dass spezialisierte Schlaganfallversorgung gesundheitliche sowie wirtschaftliche Folgen verbessert ist bereits etabliert. Darüber hinaus kann eine Beobachtung von Patienten in ihrer häuslichen Umgebung zu einer verbesserten und günstigeren Gesundheitsversorgung führen. Diese Fakten implizieren einen steigenden Bedarf für neue Gesundheitsstrategien sowie technologische Lösungen. Davon ausgehend dass die Beobachtung von Schlaganfallpatienten im eigenen Zuhause die Lösung für günstigere und effizientere Behandlung darstellt, welche Informationen werden noch für die Realisierung solcher technologischen Lösungen benötigt?

Schlaganfallüberlebenden wird beigebracht angemessene Kontrolle über ihre Bewegungen zurückzuerlangen um ihr Zurechtkommen im Alltag zu verbessern. Während es das Hauptziel eines Rehabilitationsprogramms ist, die Funktionsfähigkeit zu Hause zu maximieren, ist der tatsächliche Fortschritt der Patienten in ihrer häuslichen Umgebung nicht bekannt. Aus diesem Grund ist die Beobachtung der Bewegungsqualität von Schlaganfallpatienten im Umgang mit dem alltäglichen Leben für eine erfolgreiche Rehabilitationstherapie unerlässlich.

Im Vergleich zur klassischen klinischen Beurteilung der Motorik basierend auf standardisierten klinischen Tests gibt es eine ganze Reihe von Herausforderungen wenn es darum geht eine quantitative Analyse der täglichen Lebensleistung mithilfe von Telemedizin durchzuführen. Hierzu gehören: die Entwicklung neuer Metriken zur Quantifizierung von Bewegungen im täglichen Leben, der fehlende Kontext bei der Messung von Bewegungen ohne die visuelle Referenz, die zwar in der Klinik zur Verfügung steht, aber im Alltag nicht verfügbar ist. Nicht zuletzt stellt sich die Frage, wie die Datenmassen für Therapeuten verständlich dargestellt werden können. Daher ist es notwendig zu untersuchen, wie Schlaganfallpatienten im alltäglichen Leben beobachtet werden können, welche Technologien hierfür nützlich sind und wie die gesammelten Daten mit Therapeuten geteilt werden.

Diese These, welche durch das $\mathrm{FP}_{7}$ Projekt INTERACTION unterstützt wird, adressiert zwei Hauptanliegen: 1) Entwicklung und Evaluierung eines Telemonitoring sytems und einer Technologie welche Schlaganfallpatienten intelligentes Coaching 
und Feedback direkt am Körper des Patienten bietet, sowie 2) Entwicklung und Evaluierung von neuen Metriken für die Bewegungsqualität von Schlaganfallüberlebenden. Die Forschung in dieser Arbeit trägt sowohl zu grundlegenden als auch angewandten Bereichen der Wissenschaft bei und hat zudem wichtige (potenzielle) gesellschaftlichen Auswirkungen im Bezug auf Diagnostik und Behandlung von (Schlaganfall) Überlebenden durch die Ermöglichung einer quantitativen Beobachtung im Alltag. Eine Literaturrecherche über Telemedizinsysteme präsentiert neue Erkenntnisse, die Forschern bei der Optimierung ihrer Nutzbarkeitsstrategien während der Systementwicklung und der Vorhersage zukünftiger Trends in Strategien der Bewertung von Benutzerfreundlichkeit helfen kann. In einem multidisziplinären Team mit besonderem Fokus auf Aspekte des Telemonitoring wurde ein Ganzkörper-System basierend auf Inertial sensoren entwickelt. Dieses System, welches für den träger unauffällig im Alltag getragen werden kann, nennen wir das INTERACTION System. Das System wurde verwendet um Schlaganfallpatienten zu Hause zu beobachten und so neue Einsichten über die Bewegungsqualität im Alltag dieser Patienten zu gewinnen. Es wurden klinisch relevante Metriken für Bewegungsqualität entwickelt, implementiert und evaluiert. So konnten neue Einblicke in die Unterschiede zwischen Messungen in der Klinik und ambulanten Messungen an Schlaganfallüberlebenden über längere Zeiträume erlangt werden. Dies könnte Therapeuten helfen zu verstehen, was nach der Entlassung aus dem Krankenhaus mit Schlaganfallpatienten geschieht.

Neben dem INTERACTION System wurde ein reduziertes Sensoren system, welches sich auf Armbewegungen konzentriert (der "Arm Usage Coach"), entwickelt, implementiert und bewertet. Dieses System hat das Potential Patienten zu ermutigen ihren beeinträchtigten Arm im Alltag häufiger zu gebrauchen. Schlaganfallpatienten bevorzugen unseren Ergebnissen nach vibrationsbasiertes taktiles Feedback. Diese Einsicht kann anderen Forschern als Basis für die Entwicklung von Assistenzsystemen für Schlaganfallpatienten dienen.

Die von Therapeuten gehaltenen Meinungen über Intertial bewegungserfassung als assistive Technologie, inklusive des Arbeitens mit Metriken für Bewegungsqualität im Gegensatz zu herkömmlichen klinischen Messungen, wurden eingehend untersucht und in dieser These dargestellt. Entwickler von Assistenztechnologien erfahren häufig dass Therapeuten neue Technologien nur langsam in ihren Arbeitsalltag integrieren. Die hier präsentierten Ergebnisse können anderen Entwicklern helfen, die Gründe hierfür zu verstehen und daraus neue Schlussfolgerungen für zukünftige Designs zu ziehen. 
Um diese These noch zu ergänzen wäre es interessant die Optimierung von INTERACTION und die Motivation von Schlaganfallpatienten in der Klinik und zu Hause zu untersuchen. Darüber hinaus könnte eine noch unaufdringlichere und großflächig angelegte Umsetzung des INTERACTION Systems Ergebnisse von einer größeren Bandbreite von Schlaganfallpatienten liefern. Big Data Ansätze können zur Analyse der gesammelten Daten genutzt werden um Trends zu sehen und Einsichten über die Nutzung des Systems zu erlangen. In diesem Fall könnte die Behandlung von Schlaganfallpatienten tiergehend verändert werden und ambulantes Coaching im Alltag ansteigen. 
I WOULD LIKE TO THANK EVERYONE FOR YOUR SUPPORT

BART 


\section{CONTENTS}

Summary

Samenvatting iii

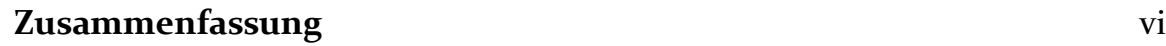

Thank you note ix

Chapter 1: Introduction 1

Chapter 2: Usability in telemedicine systems - A literature survey 9

Chapter 3: A full body sensing system for monitoring stroke patients in a home environment.

Chapter 4: Objective evaluation of the quality of movement in dailylife after stroke.

Chapter 5: Usability evaluations of a wearable sensing system and resulting metrics for stroke survivors by care professionals.

Chapter 6: The development and evaluation of an arm usage coach for stroke survivors.

100

Chapter 7: The usability evaluation of a sensing system combined with vibrotactile feedback in stroke survivors.

Chapter 8: Discussion and conclusion.

References

140

List of Publications

161

INTERACTION

163 


\section{Chapter 1}

\section{INTRODUCTION}

\section{Stroke definition and impact}

Stroke is defined as an episode of acute neurological dysfunction presumed to be caused by ischemia (occlusion of a cerebral artery) or haemorrhage (spontaneous rupture of blood vessels or Aneurysms), persisting over 24 hours or until death. An acute stroke refers to the first 24-hour-period of a stroke. This definition of stroke might be outdated with upcoming technologies resulting in new insights of the human body. A study by Sacco et al, 2013 investigated into a new definition and mentioned the following: a central nervous system infarction based on objective evidence of cerebral, spinal cord or retinal focal ischemic injury in a defined vascular distribution or clinical evidence of the mentioned injuries based on symptoms persisting over 24 hours or until death. This also includes cerebral, intracerebral and subarachnoid haemorrhagic infarctions and cerebral venous thrombosis [1].

Stroke is one of the major causes of adult disability worldwide [2-3]. Many stroke survivors struggle with impairments ranging from moderate to severe. The National Heart, Lung, and Blood Institute's (NHLBI) Framingham Heart Study (FHS) observed that among 108 ischemic stroke survivors who were at least 65 years old, $50 \%$ had some form of hemiparesis, $30 \%$ were unable to walk without some assistance, $26 \%$ were dependent on others for performing activities of daily living and $35 \%$ had depressive symptoms [4]. After discharge from hospital, most stroke survivors continue therapy on an outpatient basis; take multiple, expensive medications; require special adaptive equipment; and are seen by many specialists for follow-up care. Although there are considerable costs associated with the inpatient phase of stroke care (in the hospital), acute-care stays are getting shorter and stroke rehabilitation is increasingly being shifted to an outpatient setting (e.g. in a rehabilitation centre or at home) $[5,6]$. Comprehensive rehabilitative services have been shown to be cost-effective with catastrophic illnesses, such as stroke [7]. Therefore there is a demand for new outpatient, ambulatory, rehabilitation solutions. 


\section{Stroke Therapy}

In acute hospital stay, the primary focus of healthcare is on the stabilization of the patient, the delivery of acute stroke treatments, and the initiation of preventive measures. Before the patient is discharged from the hospital, a formal clinical assessment (conducted by e.g. occupational or physical therapist) will be done on functional and cognitive abilities. The discharge process itself may also involve e.g. social workers and psychologists to assess psychosocial issues that could intervene with the transition from hospital to home. Services provided after discharge are referred to as post-acute care services and are designed to support the transition from hospital to home and to realize the highest level of functioning for these patients possible. The provided rehabilitation care varies widely, depending on the setting, with the most involved rehabilitation care provided in inpatient rehabilitation facilities, followed by skilled nursing facilities, which provide "subacute" rehabilitation (e.g. long-term residential care provided by nursing homes) and long-term acute care hospitals, which delivers post-acute rehabilitation care.

A variety of techniques are currently implemented in stroke patient rehabilitation to regain back selective motor control of affected limbs. If a patient is unable to initiation a movement, strategies may include the usage of exteroceptive, proprioceptive and reflex stimulation techniques combined with the patient's own attempt to control their body [8]. Stroke patient treatment should involve the use of the patient's hemiplegic side in voluntary motor tasks. Treatment plans may include constraintinduced movement therapy [9] bilateral training [10] mental practice with motor imagery [11-14] electromyography biofeedback, vibrotactile stimulation [15-17] robotassisted therapy [18], acupuncture and electrical stimulation [19-20] to name a few. These techniques are implemented into a patient's treatment plan to re-establish voluntary control of motor tasks after a stroke. Physical rehabilitation is shown to be most effective when a therapists combines a mixture of different treatments for individual patients. Evidences shows that no one rehabilitation approach was more effective than any other, therefore a physiotherapist should not limit their practice to a single approach. [21]

For stroke, the rehabilitation and organisation in the US are regulated globally within the health-care system [22]. In Europe, stroke rehabilitation services are also embedded in health care systems, but are constrained by many circumstances with various (dis)incentives. These constraints vary between countries, resulting in differences in the organisation of stroke rehabilitation and therefore remain difficult 
to summarize [23]. For example, one study compared the US with Switzerland and found a distinct difference in time frames for rehabilitation in the United States and Switzerland. Patients remained in an inpatient setting an average of 40 days longer in Switzerland (for the combination of acute care and rehabilitation) and had significantly higher levels of functioning at discharge when compared to their US counterparts [24].

\section{Economic impact}

In the US, healthcare expenditure rises from US\$ 2.9 trillion in 2013 to an estimated US $\$ 4.8$ trillion in 2020. In Europe, a healthcare expenditure exceeding $10 \%$ of the gross domestic product in six member states was found [25]. Health data compiled from more than 190 countries showed that stroke remains the number two global cause of death (after heart disease). The number of people having first and recurrent strokes each year went up, reaching 33 million in 2010 with 16.9 million people having a first stroke worldwide [3]. Most strokes are ischaemic (caused by thrombosis or embolisms) and the rest are haemorrhagic (caused mainly by rupture of blood vessel or aneurysm) [26]. Stroke costs the United States an estimated \$34 billion each year. This total amount includes the cost of health care services, medications to treat stroke, and missed days of work [27]. It is projected, that in 2030 the total costs of stroke in the US will rise to a staggering $\$ 185$ billion, with hospitalisation costs rising the most [3]. In the EU27 countries, the annual economic cost of stroke is estimated to be $€ 27$ billion: $€ 18.5$ billion for direct costs and $€ 8.5$ billion for indirect costs. An additional $€ 11.1$ billion is calculated for the value of informal care [28]. Although costs are rising, stroke mortality has been declining worldwide. This is mainly due to a decreased exposure to risk factors (e.g. hypertension and smoking) and better access to healthcare. In the European Union, hospital discharges for cerebrovascular diseases almost doubled during the last 15 years of the twentieth century. In the United States, the same pattern has been reported for the same period [29].

\section{Technological solutions and limitations}

As of today, many new technological advances have been made. Examples include high-speed internet and smartphones, which are being used in many telemedicine applications (for example, in the MobiGuide project [30-31]) as well as small, lightweight body sensors and actuators to monitor and capture human movement (Xsens MVN [32], fitbit [33]), assist in lower and upper extremity functional training (Hocoma lokomat [34] and Armeo [35]) or for stroke rehabilitation by video gaming 
[36-37]. Motion capture refers to the process of recording the movements of something, for example in humans, horses or objects. Motion capture can be realized by either inertial, optical or video based systems. Inertial based systems utilising small inertial (accelerometer, gyroscope and magnetometer) sensors placed on specific body segments. By implementing a kinematic model, full body $3 \mathrm{D}$ reconstruction can be realised. Alternatively, optical systems, which are more precise then inertial based systems but more expensive, can also be used for motion capture. It requires a specific camera setup area indoors or outdoors, with markers to be placed on the object of interest to be recorded [38-39]. Finally, video images can be used to record and track body movement. The latter is especially popular due to its low costs, easy usage, general acceptance among care-professionals for reviewing patients and implementation in the gaming industry [40-41].

The deployment of motion capture and supporting technology (e.g. telemonitoring systems) for outpatient rehabilitation is limited and delayed by ethical issues (data collection, storage and anonymization), its cost-effectiveness, acceptance by insurances companies, integration into the health-care infrastructure and clinical practice guidelines, and user-acceptance [42-44, 45]. For example, telemedicine regulations are part of the Medicare healthcare program in the US, however in Europe most countries have not set up clear regulatory guidance and only a few telehealth companies have managed to partner with leading organizations within their own countries. Therefore it might take longer before regulations are standardized and technology deployed on a large scale [46].

The impact of stroke on the world is significant, with rising costs in healthcare, treatment and high disability rates among survivors. Besides, stroke therapy is a long process which seem to differ from country to country. Therefore, new healthcare strategies and technological solutions should be found in stroke care. Is it possible to reduce healthcare costs, and at the same time make treatment more efficient? It has already being shown that specialized stroke care improves health and economic outcomes [29]. Furthermore, Monitoring patients in their homes can lead to better health care at lower costs [47-48]. Both imply increased demand of new healthcare strategies and technological solutions. 


\section{Telemedicine and usability}

The World Health organization has adopted the following description of telemedicine: "The delivery of health care services, where distance is a critical factor, by all health care professionals using information and communication technologies for the exchange of valid information for diagnosis, treatment and prevention of disease and injuries, research and evaluation, and for the continuing education of health care providers, all in the interests of advancing the health of individuals and their communities" [49-50]. Research showed that remote patient monitoring significantly reduces the risk of death and hospitalization and that there is direct cost reduction for patients who are telemonitored [47-48]. Frost \& Sullivan estimated the home telemedicine market will see US\$ 422 million in market earned revenue in 2019. An essential ingredient in the development of a telemedicine system and its eventual acceptance by end-users (e.g. patients and care-professionals) are usability studies. Usability is defined as the extent to which a product can be used by specified users to achieve specified goals with effectiveness (accuracy and completeness), efficiency (resources needed for effectiveness) and satisfaction (comfort and acceptability) in a specified context of use. Measuring usability requires awareness and knowledge of the user, their goals, and environments. It must be driven by clear objectives. The principles of usability engineering, evaluation and telemedicine are well established, which may contribute to the adoption and eventually deployment of telemedicine systems and services [51]. A review study by the American Heart/Stroke association presented evidence-based recommendations for the use of telemedicine to facilitate stroke care at home, including teleconferencing, tele-stroke consultation based systems and systems that facilitate the assessment of occupational, physical, or speech disabilities. It is therefore important that a good usability is reached for final acceptance of such a system by end-users for a successful implementation within the health-care system. [52]

Research shows the advantages of telemonitoring, and that there are financial benefits in monitoring patients on an outpatient, ambulant, basis. If monitoring stroke patients in their home environment is the solution for a reduction in healthcare cost and a more efficient treatment plan, what information do we still miss order to implement such technical solutions in healthcare? 


\section{What happens with stroke patients at home and a possible solution?}

Stroke patients are trained to recover adequate control over their movements with the objective to optimize their daily-life functional performance [53]. In current clinical practice of stroke rehabilitation, the capacity of stroke patients to perform functional tasks is assessed using standardized clinical tests. These tests are done regularly during the entire rehabilitation process to predict functional performance at home [53]. While, the main objective of the rehabilitation program is to maximize the functional performance at home, the actual performance of patients in their home environment is unknown [54]. It is commonly assumed by clinicians that the quality of movement is constant in the chronic stage [55].Therefore, daily-life monitoring of the quality of movement during functional activities of stroke survivors in their physical interaction with the environment is essential for optimal guidance of rehabilitation therapy.

There are several challenges in performing a quantitative analysis of daily-life performance using telemedicine technology, compared to clinically assess motor capacity using standardized clinical tests. First, metrics need to be developed that quantify quality of movement (QoM) during daily-life. Current metrics in-clinic, to describe movements, cannot directly be transferred to the evaluation of movements in a daily-life setting. For instance, in clinical assessment scales participants are instructed to reach as far as possible, while in a daily-life setting it might not be necessary to reach that far. A second challenge is the absence of context when measuring movements without any visual reference, which is available in clinic but not available in a daily-life setting. Finally, during continuous home measurements, large amount of data will be gathered. Metrics and visualizations derived from this 'big data' should be presented in a concise manner, otherwise the evaluation of all data might be very time consuming for care-professionals. Therefore we have to investigate into how can we monitor stroke patients during daily-life and by which technology and what do we want to show to care-professionals after measuring patients at home.

To accomplish this, a new project was started in 2011, called "INTERACTION". The main goal of the project was to develop and evaluate and un-obtrusive ambulatory sensing system that is able to objectively assess the quality of movement of stroke patients in clinic and home environment. This thesis is part of that project and focusses on several aspects, namely: what are the right usability tools we can use to develop and evaluate the INTERACTION sensing system? Are we able to make a 
sensing system than can be used for remote telemonitoring of stroke survivors? Are we able to develop metrics of extremity function that are able to show the quality of movement of stroke patients and compare in-clinic and home usages? Furthermore, as an addition, we would like to investigate if we can use the INTERACTION system, or parts of it, to train stroke patients at home. This might make rehabilitation more efficient handling the constant or reduction of the QoM among stroke survivors.

\section{Thesis objectives}

The objectives of this thesis are outlined below.

- Develop and evaluate a tele-supervision system and intelligent on-body feedback technology for monitoring and coaching stroke patients in a home environment.

- Develop and evaluate new metrics of extremity function in stroke patients.

Sub goals:

1. Identify relevant usability evaluation approaches currently used in tele monitoring devices.

2. Develop a tele-supervision system to be able to monitor stroke patients during daily-life tasks

3. Develop new metrics of extremity function which are able to show differences in the QoM of stroke patients in clinic and home environment

4. Evaluate QoM metrics with care-professionals

5. Develop and evaluate on-body feedback technology able to motivate stroke patients in using their impaired arm in daily-life tasks

In Chapter 2, a literature survey is done to investigate how usability methods are applied in developing telemedicine systems. In this literature survey, scientific databases are searched for all telemedicine studies in which a usability or ease-of-use analysis is applied to. A thorough analysis of the literature is performed, for example, to relate usability methods to patient health conditions, and outcomes are presented and discussed. In Chapter 3, the design of the INTERACTION sensor system and the telemonitoring component is described and implemented. We present a prototype of the sensing system and demonstrate that we are able to send the sensor data of the system via a wireless connection to a back-end server on another location, process and retrieve the data and visualise it in preliminary metrics of extremity function on a 
tablet or pc. In Chapter 4, we present metrics of both upper and lower extremity function. These metrics have been constructed by engineers, researchers and careprofessionals specifically to show differences between in-clinic and at home movement data of stroke patients. These metrics are placed in one software package using an activity monitor, movement visualizer and patient report generator. In Chapter 5 we evaluate those metrics with care-professionals outside the project. The results obtained from Chapter 2 are used to construct a usability evaluation plan and the evaluation was performed in five different stroke rehabilitation centres with over 23 care-professionals. In addition to the system presented in Chapter 3, a reduced sensor set and algorithms have been developed, called the Arm Usage Coach. The goal was to monitor stroke patient's arm movements whilst performing activities of daily living and to coach the patients by giving vibrotactile feedback based on their arm usage. The development and evaluation with healthy subjects is described in Chapter 6. Finally, a pilot study has been done on the usability evaluation of the Arm Usage Coach and on feedback modality preferences among stroke survivors. This is described in Chapter 7. Following the final chapter is a conclusion, discussion and future perspective section, reflecting to the main and sub goals of this thesis and the work that has been done. Each chapter includes an abstract and a discussion. 


\title{
Chapter 2
}

\section{USABILITY IN TELEMEDICINE SYSTEMS - A LITERATURE SURVEY}

\author{
B. Klaassen ${ }^{{ }^{1,2}}$ B.J.F van Beijnum ${ }^{1,2}$ and H.J. Hermens ${ }^{1,2,3}$
}

${ }^{1}$ Biomedical Signals and Systems group, University of Twente, Enschede, the Netherlands.

${ }^{2}$ Centre for Telematics and Information Technology, University of Twente, Netherlands ${ }^{3}$ Roessingh Research and Development, Roessingh Rehabilitation Hospital, The Netherlands.

Published in the International Journal of Medical Informatics, volume 93, Pages 57-69 (June 2016)

\section{ABSTRACT}

Introduction: The rapid development of sensors and communication technologies enable the growth of new innovative services in healthcare, such as Telemedicine. An essential ingredient in the development of a telemedicine system and its final acceptance by end-users are usability studies. The principles of usability engineering, evaluations and telemedicine are well established, and it may contribute to the adoption and eventually deployment of such systems and services. An in-depth usability analysis, including performance and attitude measures, requires knowledge about available usability techniques, and is depending on the amount of resources. Therefore it is worth investigating how usability methods are applied in developing telemedicine systems. Our hypothesis is: with increasing research and development of telemedicine systems, we expect that various usability methods are more equally employed for different end-user groups and applications. 
Method: A literature survey was conducted to find telemedicine systems that have been evaluated for usability or ease of use. The elements of the PICO framework were used as a basis for the selection criteria in the literature search. The search was not limited by year. Two independent reviewers screened all search results first by title, and then by abstract for inclusion. Articles were included up to May 2015.

Results: In total, 127 publications were included in this survey. The number of publications on telemedicine systems significantly increased after 2008. Older adults and end-users with cardiovascular conditions were among largest target end-user groups. Remote monitoring systems were found the most, in 90 publications. Questionnaires are the most common means for evaluating telemedicine systems, and were found in 88 publications. Questionnaires are used frequently in studies focusing on cardiovascular diseases, Parkinson's disease and older adult conditions. Interviews are found the most in publications related to stroke. In total $71 \%$ of the publications were trial-orientated and the remaining process orientated. An increase in telemedicine research, development and applications is found worldwide, with the majority of publications conducted in America.

Discussion and conclusion: Monitoring patients in their homes can lead to better healthcare at lower costs which implies increased demand of new healthcare strategies like telemedicine. We expected that with the increase in telemedicine research and development, a greater range of usability methods would also be employed in the included publications. This is not the case. Researchers employed questionnaires as a preferred usability method for each type of telemedicine system and most end-users. However, in process-orientated studies a greater range of usability evaluations were applied, with fewer differences found in the amount of publications for each evaluation method. Questionnaires enable researchers to evaluate a system quickly on end-users, as it requires less expertise on the evaluation method compared to the other methods. They are easily distributed and are customizable. The use of questionnaires is therefore an evaluation method of choice for a variety of telemedicine systems and end-users. 


\section{INTRODUCTION}

The rapid development of sensors and communication technology enables the proliferation of new innovative services in healthcare, such as Telemedicine. Telemedicine often can be differentiated into three modalities: 1) consultation, 2) remote monitoring and 3) remotely supervised treatment or training. Consultations are remote meetings between a healthcare professional and client (e.g. older adults, focussing on healthy aging) may rely on the use of interactive video, chat, diagnostic images or data sharing. External monitoring of a client's condition can be done either at home (i.e. at a fixed location) or ambulatory (portable). Methods for monitoring include: questionnaires, diaries, medical dispenser counters and physiological sensors. Sensors can be worn on-body or are installed inside the end-user's home. Training (and "medical education") can be given web-based, targeting individual endusers or groups in remote locations to improve their health. The latter also provides insights into the client's own medical data for e.g. self-managing their condition.

An essential ingredient in the development of a telemedicine system and its eventual acceptance by end-users (e.g. patients and care-professionals) are usability studies. Usability is defined as the extent to which a product can be used by specified users to achieve specified goals with effectiveness (accuracy and completeness), efficiency (resources needed for effectiveness) and satisfaction (comfort and acceptability) in a specified context of use [1]. Foundations for usability evaluations were established in the 1990 os by ISO (ETR 095, Human Factors; guideline for usability evaluations of telecommunication systems and services) and research. Effectiveness and efficiency are part of the performance of the system. Both parameters can be measured objectively, by assessing how users achieve certain goals with the developed product by performing specific tasks. Satisfaction, which is captured subjectively in attitude measures, comprises what the user thinks of the system and its components. Performance and attitude measures do not have to be related in any way. Measuring usability requires awareness and knowledge of the user, their goals, and environments. It must be driven by clear objectives. Identifying which user characteristics, tasks and environmental aspects influence usability is called a usability context analysis. The ETR o95 guide for usability evaluations presents guidelines for performing a usability analysis, based on ISO standards, earlier work by the MUSiC project and others. It provides a clear and solid framework, which can also be applied to any telemedicine system. [2-4]. 
The World Health organization has adopted the following description of telemedicine: "The delivery of health care services, where distance is a critical factor, by all health care professionals using information and communication technologies for the exchange of valid information for diagnosis, treatment and prevention of disease and injuries, research and evaluation, and for the continuing education of health care providers, all in the interests of advancing the health of individuals and their communities" [5-6]. However, in this manuscript a compact version of this definition is in use, where we exclude the "education of care providers", as we are only focusing on clients.

The principles of usability engineering, evaluation and telemedicine are well established, which may contribute to the adoption and eventually deployment of telemedicine systems and services. An in-depth usability analysis, including performance and attitude measures, requires knowledge about available usability techniques (e.g. knowledge about the toolbox of methods that can be used), and is depending on the amount of resources (e.g. time and money). For example, questionnaires are a popular usability tool as they provide a "quick fix" (cheap and easy to implement) for research methodology, where observational methods require more extensive amount of resources [7]. Therefore it is worth investigating how usability methods are applied in developing telemedicine systems.

Our hypothesis is: with increasing research and development of telemedicine systems, we expect that various usability methods are more equally employed for different enduser groups and applications.

This literature survey answers the above by searching in databases for all telemedicine systems (with no year restriction) where a usability or ease-of-use analysis is applied to. A thorough analysis of the literature is performed and outcomes are presented and discussed. The process for performing the literature search is presented in Section 2, including the inclusion and exclusion criteria, selection method and data analysis. The results of the literature search are described in Section 3, and discussed in Section 4. Finally, a conclusion is given in section 5 . 


\section{METHODS}

\subsection{Literature search}

A literature survey was conducted by two independent reviewers in using the following databases: IEEE, Pubmed/Ovid Medline, Embase, Scopus, Springerlink and Web of Science. The MeSH, Emtree terms and the combinations that were used are listed in Table 1. The search was not limited by year and only the title and abstract were screened. Publications were included up to May 2015.

Table 1. MeSH/Emtree terms for the literature search

\begin{tabular}{|l|l|}
\hline Term OR & \multirow{2}{*}{ AND } \\
\hline Telemedicine & \\
\cline { 1 - 1 } Teletreatment & \\
\cline { 1 - 1 } Telerehabilitation & \multirow{2}{*}{ (usability OR } \\
\cline { 1 - 1 } Teleconsultation & \\
\cline { 1 - 1 } Telemanage of use)
\end{tabular}

\subsection{Selection criteria}

The elements of the PICO (Population (P), Intervention (I), Control(C), Outcome (O)) framework [8] were used as a basis for the selection criteria in the literature search:P: End-users (adults) of a telemedicine system. It must include end-users (e.g. care-professionals or patients) of the system. I: Using Information Communication 
Technology (ICT) for telemedicine purposes (a complete architecture or parts of it) in a home environment, targeting systems that support independent living. C: A control group is not required for this research. $\mathbf{O}$ : Usability evaluations on the applied telemedicine architecture or parts of it, including trials or tests focusing on the target population.

- Excluded were publications:

- That were non-peer-reviewed conference and journal publications.

- With no inclusion of system usability evaluation methods (or aspects of it).

- Which did not cover a telemedicine system architecture or parts of it (e.g. did not include a Body Area Network (BAN), back-end system, web portal or interface).

- That only included software and/or hardware engineering/development or performance tests.

- Where the system was not tested on an intended target group for the developed system.

- Where solutions were presented which only focused on children.

- Non-English articles.

- Review articles.

- Publications where ICT only focused on the back-office systems (e.g. management of documents or data).

- ICT systems in hospitals and care institutes (e.g. hospital information systems).

- $\quad$ Systems that give specialist support only (for example, in rural areas).

\subsection{Selection method}

Two independent reviewers screened all search results first by title, and then by abstract for inclusion based on the criteria stated above. Each abstract was categorized into either an included, excluded or doubt group. Discrepancies within categories were discussed in detail for each publication. The results from the included and doubt group were compared between reviewers, and publications in the doubt category were thoroughly analyzed. After a thorough analysis of each publication, a final selection was made for the included publication. 


\subsection{Data extraction and presentation}

All included publications where read and analysed. One main extraction table was constructed, which included several categories for extracting relevant information from each publication. The following categories were included: author, year, country, objective of study, type of medical condition, end-users, type of system technology, usability evaluation method, the number of participants in the study and when a usability evaluation method was applied. By using the extraction table, data was extracted and combined as follows: the publications were grouped per year, per type of medical condition (e.g. COPD) and what type of telemedicine technology. For the latter, different clusters were pre-defined as follows:

1) Consultation systems. Systems that focus on patient-medical professional interaction via ICT mediated communication (for example chat, teleconferencing or email).

2) Training and medical education systems. This type of system includes selfmanagement systems, web-based training and exercise-based systems for rehabilitations at home and medical information platforms e.g. online diaries.

3) Remote monitoring system. This cluster includes systems that collect data from the end-user using on-body sensors, such as inertial, oxygen saturation, blood pressure, and heart rate sensors, and sensors installed at home (e.g. optical sensors for movement detection) or diaries and questionnaires. Data is transferred to a back-end system and becomes available for further analysis and for a medical professional to evaluate patients and decision support.

Furthermore, publication were grouped by usability evaluation method. The methods, defined in the ETR 095 Human Factor guide [3], were adopted. These are: logging (by e.g. sensor based data, manual scoring by researchers during observations or system $\log$ files), observation (for example, video based systems, PC screen capture software or supervision by usability experts), questionnaires, interviews, and self-descriptive (in which users perform tasks while thinking aloud and commenting on their expertise and impressions during or slightly after each task is performed). These were related towards the type of telemedicine technology. Publications were also classified in when a usability method was applied by its orientation towards the design lifecycle. A differentiation was made between "trial orientated", where studies mainly focussed on (clinical) trials or "process orientated", where studies described the process of system development. The "trial orientated" classification was further categorized into three phases for medical devices according to Becker, 2006 [9]: Phase 1) pilot studies of 
safety, performance and/or design, Phase 2) pivotal studies of safety and effectiveness and Phase 3) post marketing studies, collecting long term data and adverse effects. Publications in both orientations were related towards the applied usability evaluation method within each study. Finally, to place the included publications in a perspective of telemedicine in general and per world continent, an additional literature search was conducted in the Web of Science database, as it facilitates search by country, using the same Mesh terms as presented in section 2.1, but without usability and ease-ofuse. The in/exclusion criteria were not applied. 


\section{RESULTS}

\subsection{Database search}

The title and abstracts of the publications were retrieved from the different databases (IEEE, Pubmed/Ovid Medline, Embase, Scopus, Springerlink and Web of Science) by using the MeSH/Emtree terms. In total, 596 abstracts were selected after the removal of duplicates. Two independent reviewers screened the title and abstract and applied the exclusion criteria accordingly. Results from both reviewers were combined. Mismatches in "included" publications and publications in the "doubt" group were discussed. In total, 144 abstract remained. In retrieving the full text publications, one publication could not be accessed via digital or physical libraries. After reading each publication, 16 publications were excluded: 12 publications did not present or describe a usability evaluation and four publications did not test the system on a target group. Finally, 127 full text publications were included for this survey.

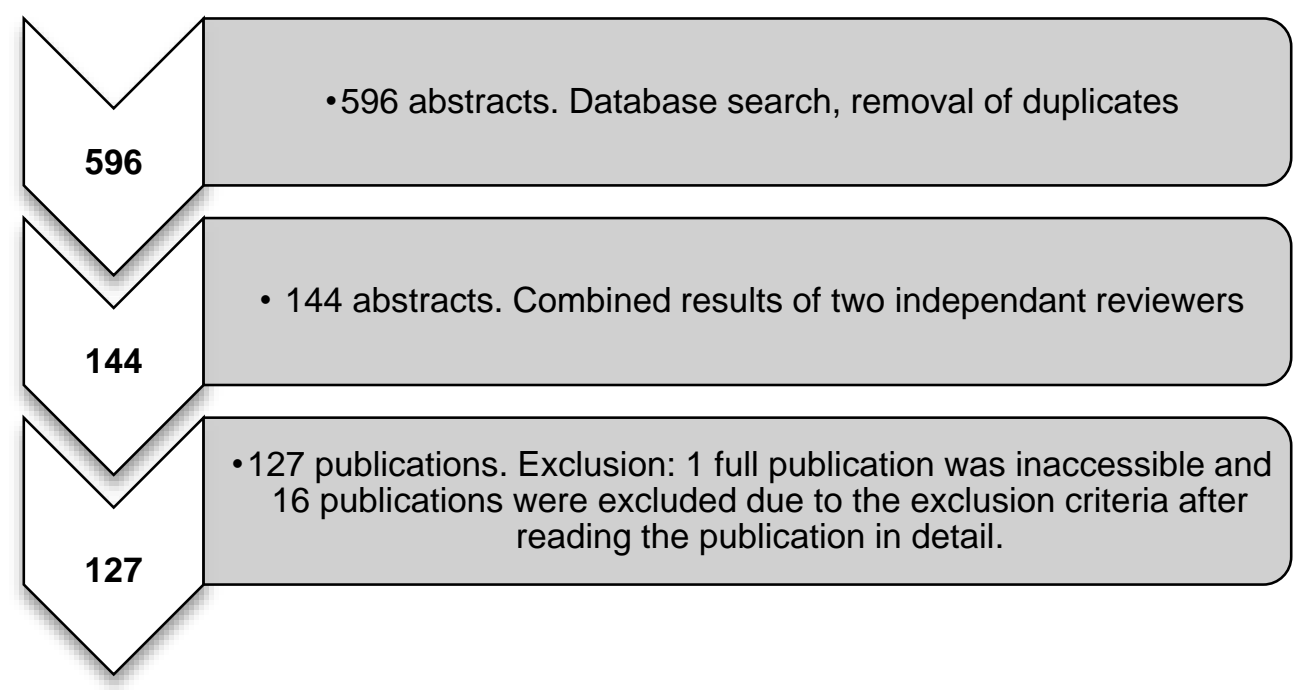

Figure 1. Search results and number of included publications. 


\subsection{Demographic and publication year}

Publications were grouped by demographic region and year of publication (listed in Table 2 and shown in Figure 2 respectively). Most studies were conducted in the US, Europe and Australia. The number of publications increased significantly after 2008. The largest number of publications in any one year is in 2013 with 29 publications and followed by 2014 with 20 publications. In the period 2013 - 2014 a total of 18 publications originated from the US. No publications were found before 1995.

Table 2. Telemedicine systems (with a usability analysis) per country, with the percentage of the total number of publications in brackets

\begin{tabular}{|l|l|l|l|}
\hline Country & \# Publications (\%) & Country & \# Publications (\%) \\
\hline US & $38(29.9 \%)$ & Germany & $3(2.4 \%)$ \\
\hline Spain & $15(11.8 \%)$ & Denmark & $2(1.6 \%)$ \\
\hline The Netherlands & $11(8.7 \%)$ & Portugal & $2(1.6 \%)$ \\
\hline UK & $10(7.9 \%)$ & China & $1(0.8 \%)$ \\
\hline Australia & $8(6.3 \%)$ & France & $1(0.8 \%)$ \\
\hline Italy & $6(4.7 \%)$ & Greece & $1(0.8 \%)$ \\
\hline Norway & $4(3.1 \%)$ & India & $1(0.8 \%)$ \\
\hline Sweden & $4(3.1 \%)$ & Japan & $1(0.8 \%)$ \\
\hline Taiwan & $4(3.1 \%)$ & Saudi Arabia & $1(0.8 \%)$ \\
\hline Finland & $3(2.4 \%)$ & Slovakia & $1(0.8 \%)$ \\
\hline Austria & $3(2.4 \%)$ & South Korea & $1(0.8 \%)$ \\
\hline Canada & $3(2.4 \%)$ & South Africa & $1(0.8 \%)$ \\
\hline
\end{tabular}




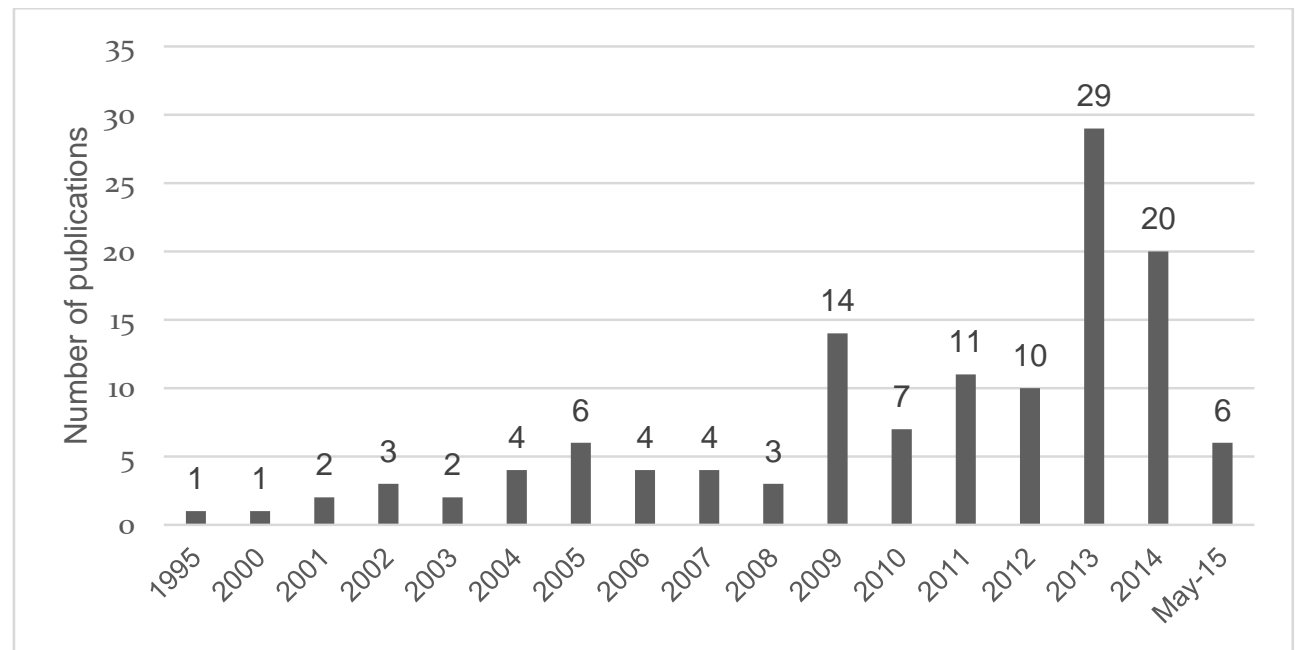

Figure 2. Telemedicine studies with the inclusion of a usability analysis per year.

\subsection{Health conditions}

The health condition addressed by the telemedicine system in each publication is shown in Figure 3. Older adults (where the focus is on healthy aging, and common problems that occur with getting older and how to cope with daily activities) and endusers with cardiovascular (CV) conditions, such as heart failure and chronic heart disease, are among the most addressed target groups (25 (18\%) and 22 (16\%) publications respectively). Publications which included end-users with diabetes follows with $16(11 \%)$ publications. Studies that focused on the usability of a telemedicine system by healthy subjects, e.g. health-care professionals, come next with $14(11 \%)$ publications. 


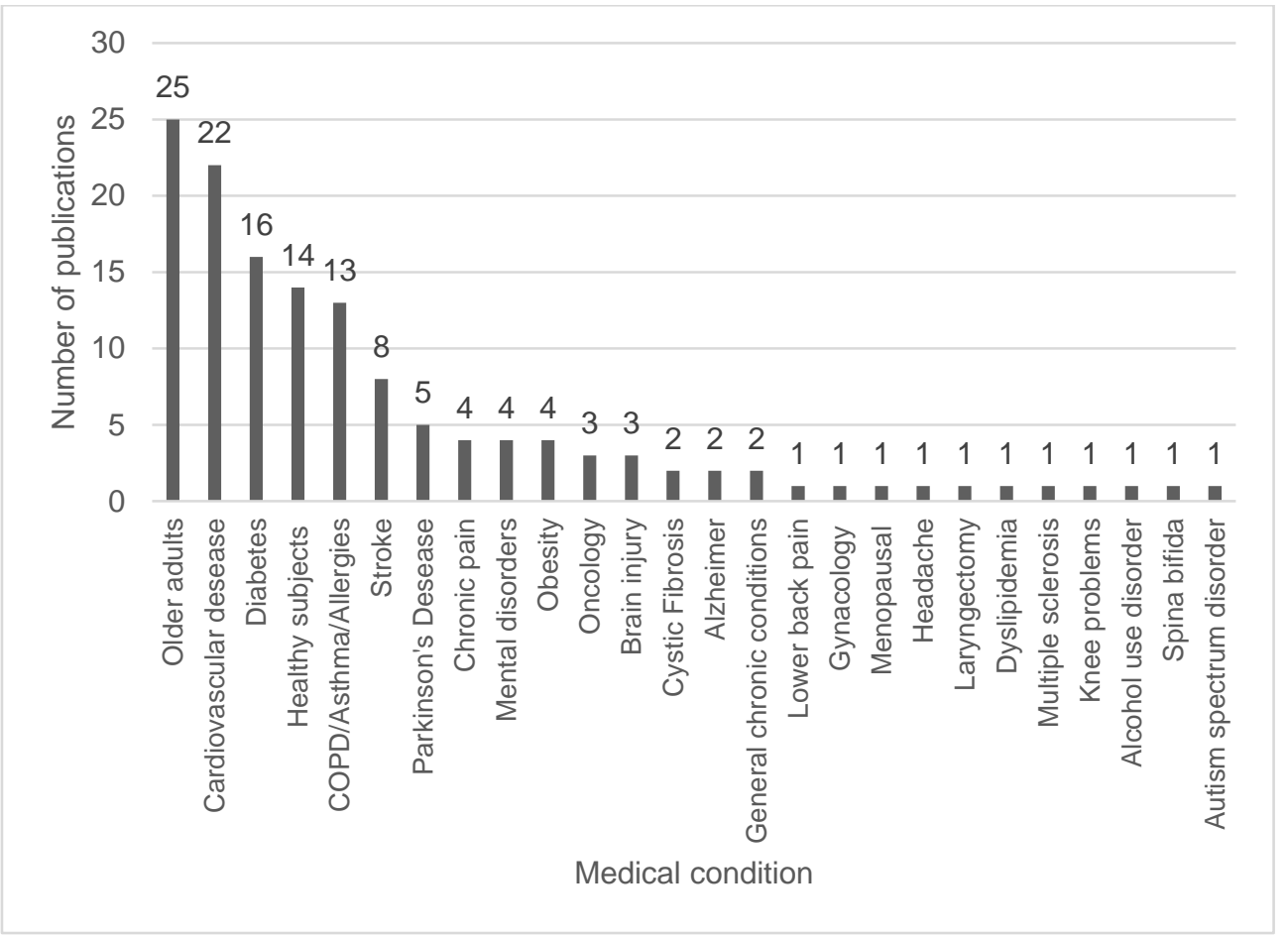

Figure 3. Medical conditions of end-users in telemedicine publications.

\subsection{Type of telemedicine systems}

The number of publications with the inclusion of a certain type of telemedicine system is summed over five years and shown in Figure 4. Consultation systems were found the least (namely 38 publications). This type is followed by systems that focus on training the end-user and providing the opportunity for (self-) education, with 64 publications. Remote monitoring systems were found in 90 publications. Most often, systems described in these studies exhibit a combination of different system types, therefore the total number of publications implied by Figure 4 is greater than the actual number of selected publications in this survey. There is an increase in the number of publications after 2010, where the telemedicine system type remote monitoring and training and medical education outnumber those for type consultation. 


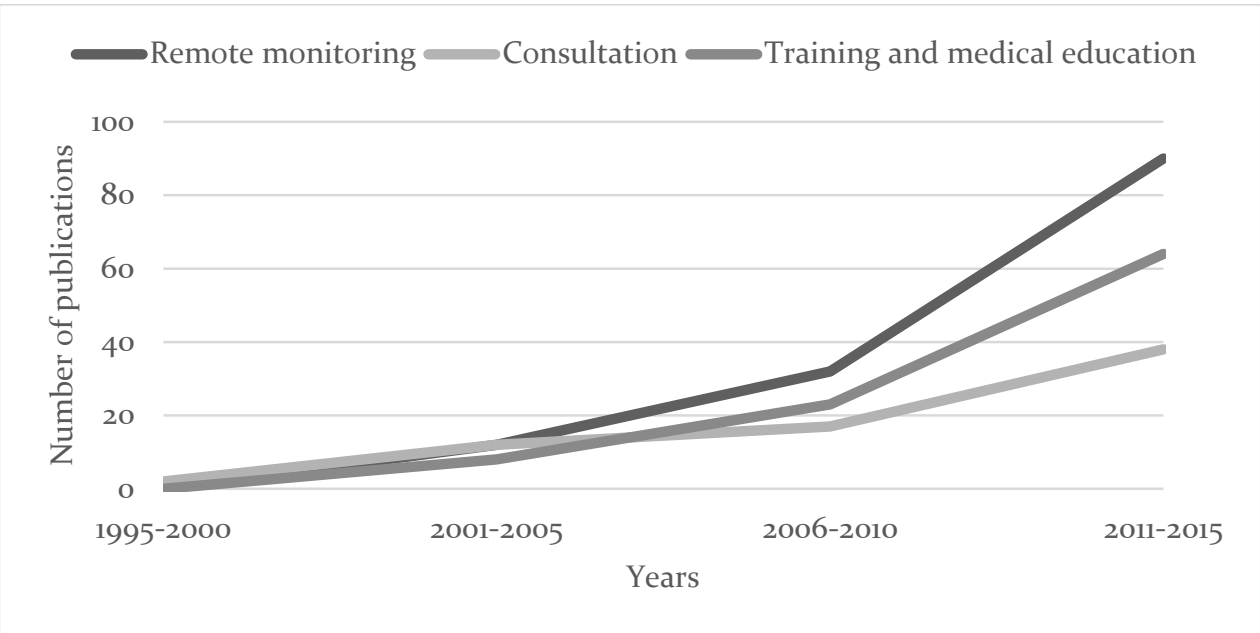

Figure 4. Cumulative number of publications per type of telemedicine system per 5 years.

\subsection{Methods for usability evaluation}

The prevalence of different usability methods for evaluating telemedicine systems is shown in Figure 5, and the number of participants for each method is listed in Table 3. When multiple methods were found in a publications, the number of participants was added to each method. Figure 5 shows that questionnaires are the most common means for evaluating telemedicine systems, being used in 88 (69\%) publications with 4176 participants in total. Standardized questionnaires that were used are: IBM ease of use (in four publications) [10], SUMI (in two publications) [11], NASA TLX (in one publication) [12], SUS (in 8 publications) [13], EUnetHTA based (in two publications) [14], HCIATL (in two publications) [15], the QUIS (in one publication) [16] , the PSSUQ (one publication) [17] and TAM-2 (in four publication) [18-19]. This is followed by observational methods, in 33 publications (26\%). Interviews were included in 35 (28\%) publications. A self-descriptive method was employed in $16(13 \%)$ publications. The logging methods is included in 14 (11\%) publications. Figure 5 shows a large increase in the number of publications using questionnaires and interviews after 2010. Studies that included the observational and self-descriptive methods remained approximately constant throughout the years, but the interview and logging method is found to be increasing in the number of studies after 2010. In Table 3, the median, minimum and maximum number of participants per usability method per 5 year period are listed. The questionnaire method has the highest median number of participants throughout each period, with the highest median of 40 participants in the 
2001-2005 period. The median number of participants for observation, questionnaire and interview methods were the highest in that period. The maximum number of participants per usability method for any one study is increasing per year period for the questionnaire method, peaking at 279 participants in 2011-2015 period.

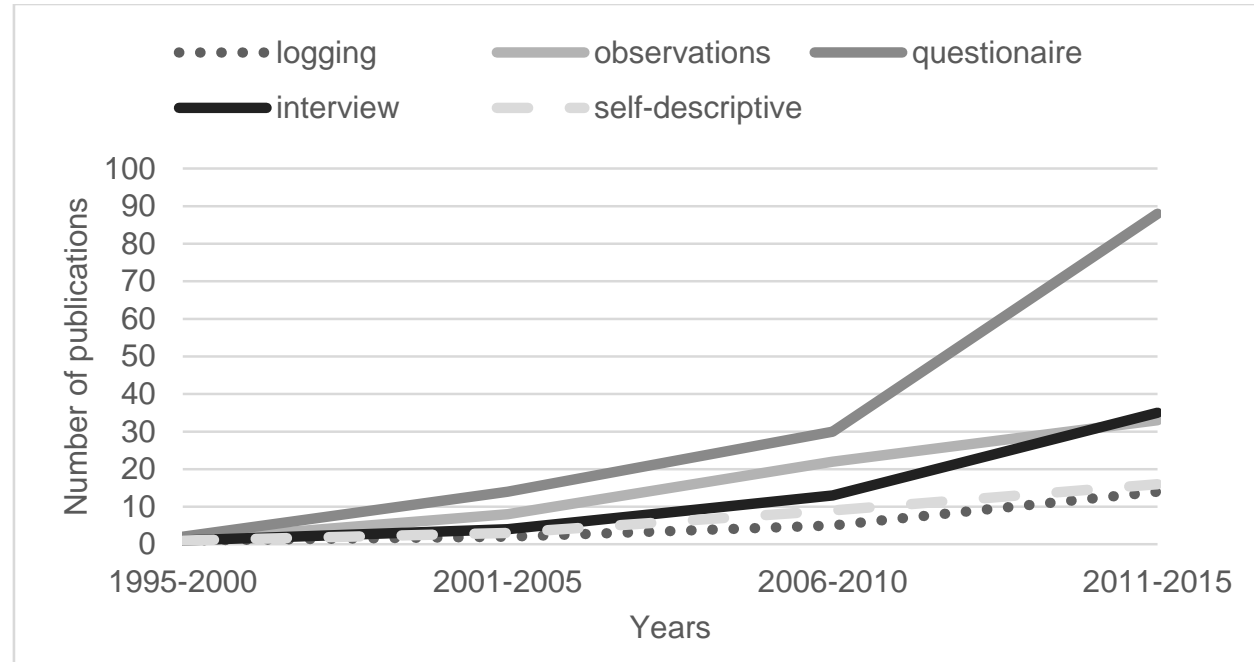

Figure 5. Cumulative number of publications per usability method per 5-year period.

\subsection{End-user medical condition related to usability}

In addition, we related the usability evaluation method with the target end-user population as shown in Figure 6, with the exact number of publications shown within the boxes. Questionnaires are mostly found in studies focusing on end-users with cardiovascular and Parkinson's disease, older adult's conditions and in the remaining conditions. Interviews are commonly applied as a usability method in publications targeting end-users which had a stroke. All evaluation methods are evenly divided among publications targeting diabetes (except for the logging method). The logging method is mainly found in COPD (four publications), older adults (three publications), Healthy subjects and Stroke (two publications each). The selfdescriptive method is missing in publications focusing on end-users with cardiovascular diseases, Parkinson's disease, and Alzheimer's and is only found in a small percentage of the remaining publications. It is mainly included in systems targeting diabetes and mental disorders. 


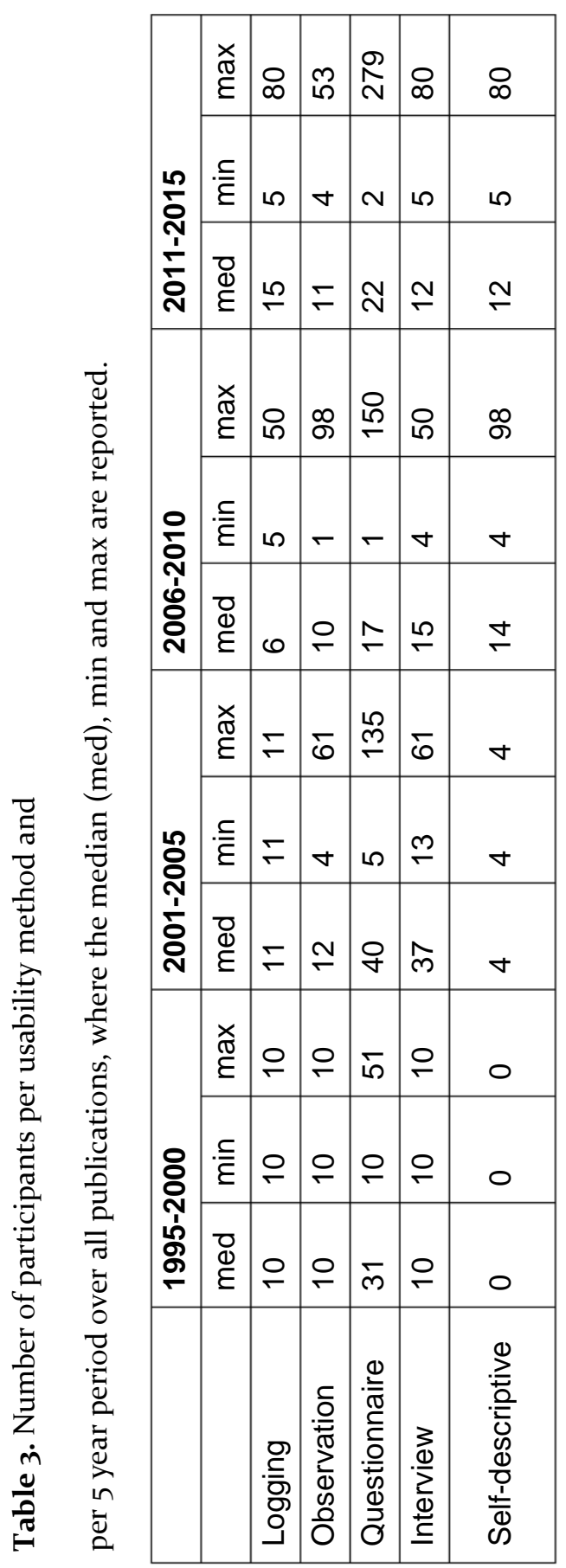


Chapter 2: Usability in telemedicine systems - A literature survey

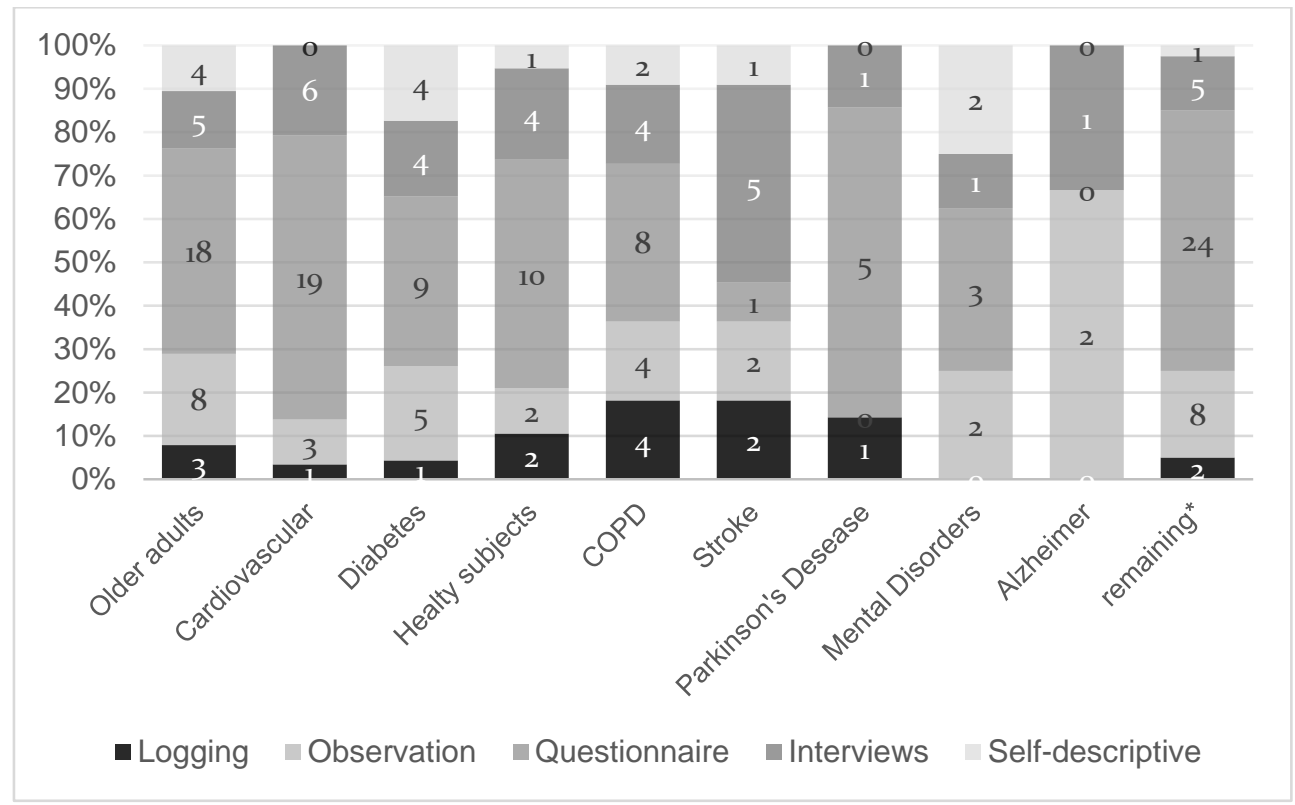

Figure 6. Usability evaluation method related to the end-user medical condition. *remaining conditions with only one publication. Normalized to $100 \%$ and the number of publications is shown in the boxes. 


\subsection{Usability method related to the type of telemedicine system}

The relation between the type of telemedicine system and the applied usability method was investigated and results are shown in Figure 7 . The number of publications which included a questionnaire were the highest in each type of telemedicine system, followed by publications that included observational methods in monitoring and consultation systems. The logging method was applied the least. The interview method was applied the most in publications on training and medical educational based systems besides questionnaires.

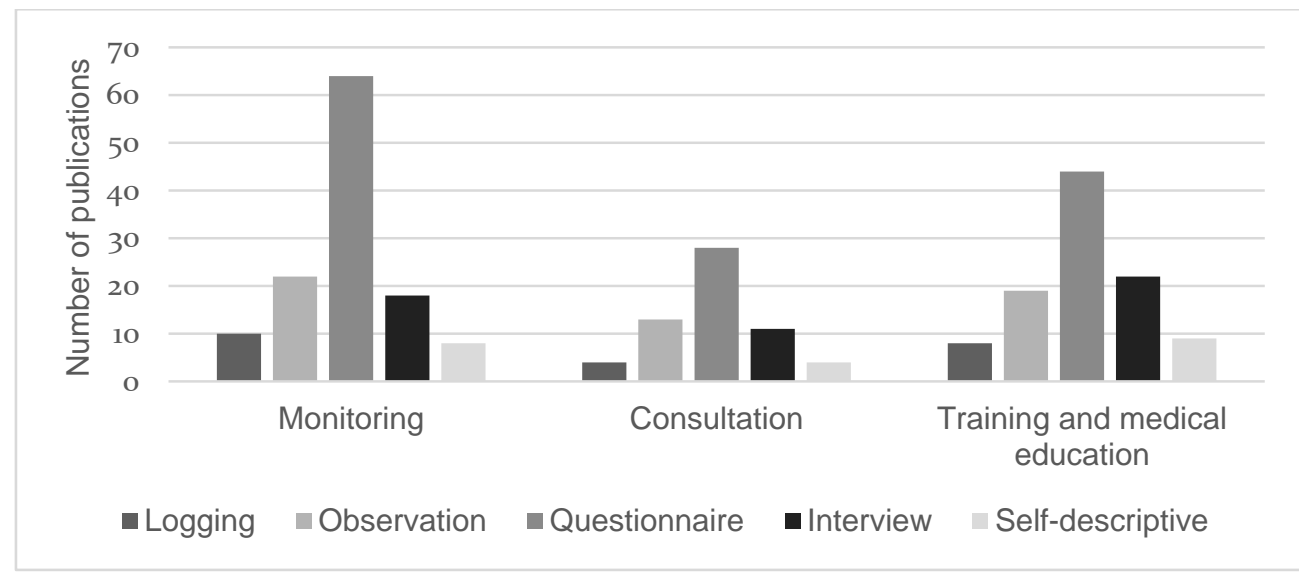

Figure 7. Usability method related to the type of telemedicine system.

\subsection{When was usability applied?}

Each publication was classified in either a trial or process orientated study. In total, 90 out of 127 publications (71\%) are trial orientated, where 80 publications are in the pilot phase (Phase 1), eight are pivotal trial publications (Phase 2) and two publications are post-marketing studies (Phase3). Furthermore, 37 publications were process orientated. Phase 3 trials only consists of two publications, including large randomized controlled trials (number of participants: 1500 and 383 ), both focusing on collecting long term data on cardiovascular diseases. Figure 8 shows the relation between publication orientations, trial phase and usability evaluation method among publications. Questionnaires are the preferred method on both trial and process 
orientated publications. The amount of publications for each evaluation method decreases in Phase 2 and Phase 3 trials.

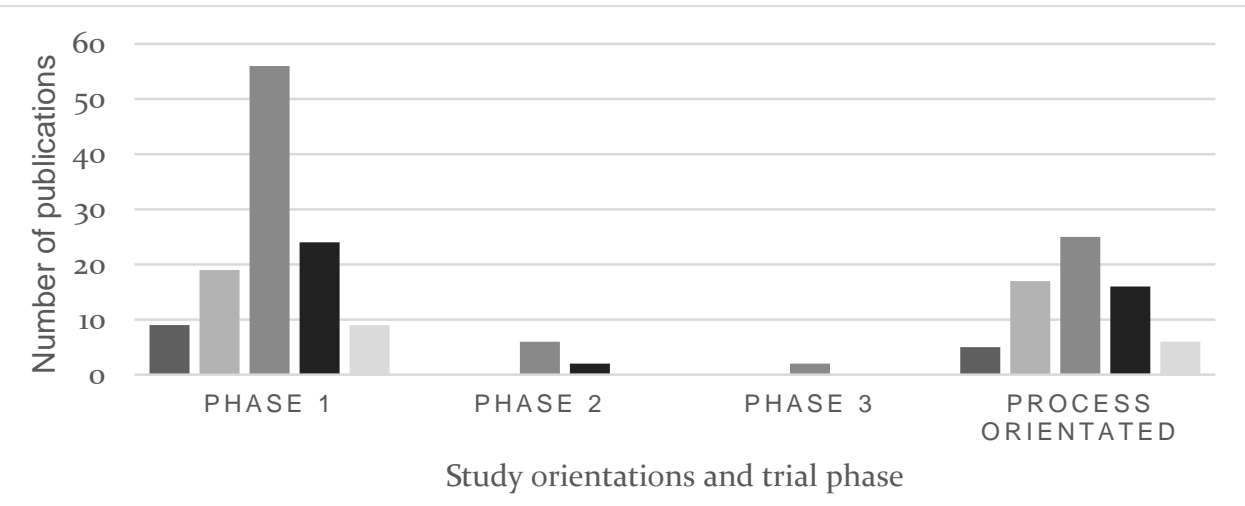

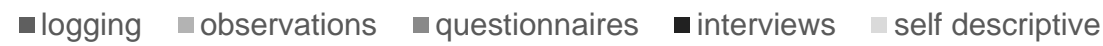

Figure 8. Usability method per study orientation and trial phase.

\subsection{Telemedicine related publications}

To place the included publications in a broader perspective of telemedicine, an additional literature search was conducted on telemedicine, but without usability and ease-of-use only in the Web-of-Science database. The in/exclusion criteria were not applied. The results were categorized per world continent and are shown in Figure 9. In total, 14296 publications were found. For all continents, an increase is seen in telemedicine related publications per five year period. Both Europe and North America (US and Canada) include the largest amount of publications and have a similar increase over the years. 


\section{Telemedicine related publications in Web of Science}

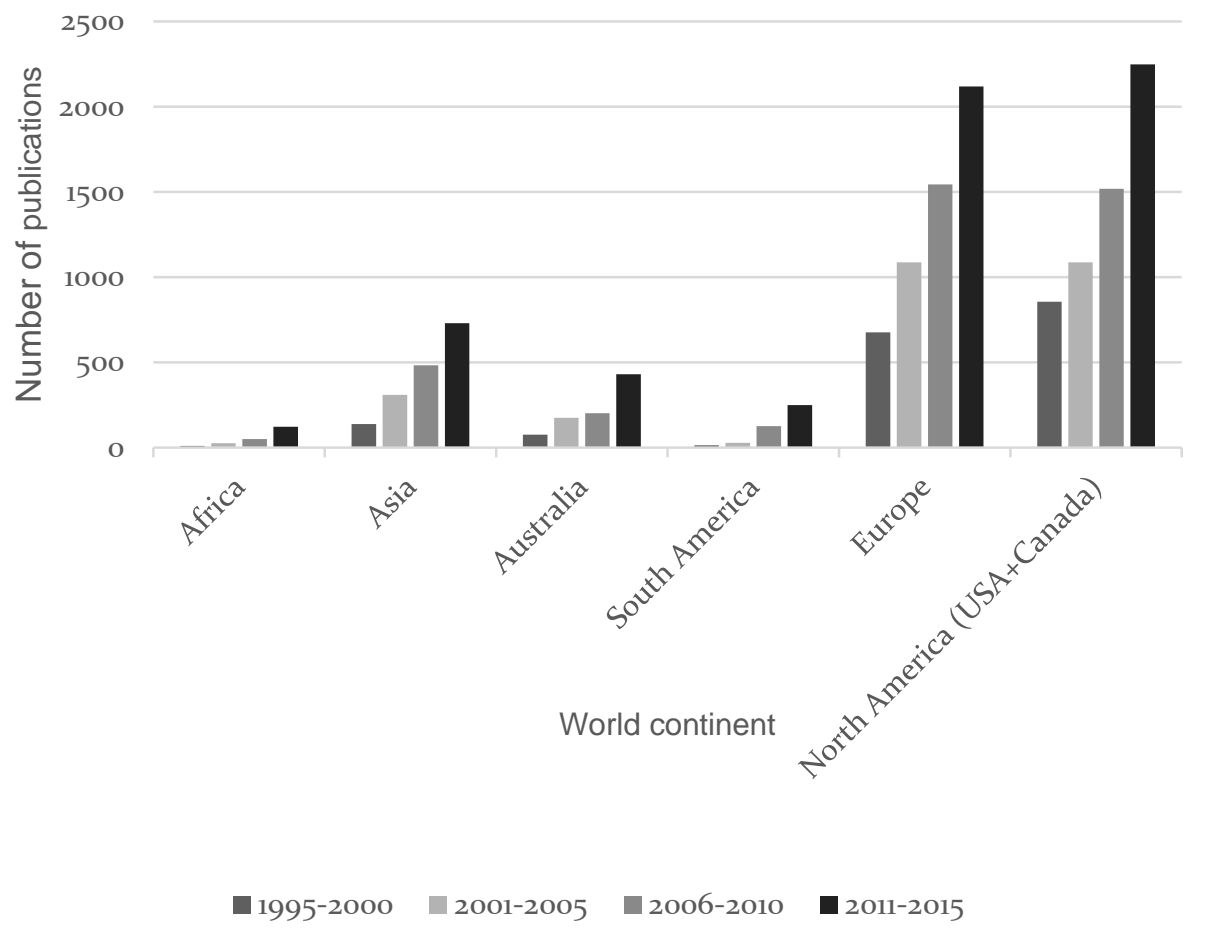

Figure 9. Telemedicine related publications per five year period per world continent. 


\section{DISCUSSION}

By using telemedicine systems, it is possible to monitor, train, consult and inform endusers in their home environment. It enables healthcare professionals to maintain or even improve an end-user's condition and quality of life, and at the same time reduce in-hospital costs [20-24]. But, for a successful implementation, it seems essential that the users experience a good usability of such systems. This literature search resulted in 596 publications of telemedicine systems which include a usability or ease of use evaluation, of which 127 were included by applying the exclusion criteria. There is an increase in the number of publications about telemedicine systems after 2010, especially in remote monitoring. Studies that focus on remote monitoring systems were found the most among all included publications and studies including consultation type systems the least. Consultation type systems are based on older technologies such as telephone or SMS, where remote monitoring systems employ data capturing strategies via e.g. Wi-Fi and internet to stream data towards back-end servers to be analysed. New communication and interaction modes were investigated over the years and applied worldwide such as mobile communication, data services and internet at home, which favours the deployment of such monitoring technologies in telemedicine systems.

\subsection{Medical conditions}

Systems that were designed for older adults were mostly concerned with their impairments and increased risks but not directly with certain types of conditions. These systems focus on healthy aging. Most publications were targeting older adults focusing on healthy aging, and more direct conditions like heart failure, which could be explained by the fact that in the USA alone, $1 / 3$ of the healthcare expenditure was on elderly care (US\$ 414 billion in 2011) [25]. The highest expenditure among the older adults were for care and treatment of heart diseases (US\$ 48.4 billion in 2008). Also, Heidenreich et al, predicted that between 2010 and 2030, real total direct medical costs of cardiovascular diseases will triple, from US\$273 billion to US\$ 818 billion [26-27]. Both types of target patient populations were the most common target population within the selected publications. The costs of diagnosed diabetes in 2012 was US\$ 245 billion, including US $\$ 176$ billion in direct medical costs and US $\$ 69$ billion in reduced productivity. $43 \%$ of these costs were related to hospital inpatient care [28]. High expenditures such as this provide reasons for an increase in research and development. In total, 16 publications targeted diabetic patients for system development and rank third for type of conditions found in telemedicine systems with 
the inclusion of a usability analysis. Having a larger expenditure for a certain type of medical condition does not seem to be related to the usability evaluation method applied in publications targeting patients with that medical condition. Publications targeting cardiovascular conditions (a condition with high expenses) included questionnaires as a main evaluation method, which requires relativity low amount of resources. Observational methods, which require more resources (time, money and equipment), can be found in over $33(26 \%)$ publications. It could be that publications that target high-expenditure conditions focus more on the number of participants, as the median number and maximum amount of participants per publications is the highest for questionnaires throughout each year, thus employing cheaper usability evaluations rather than resource-intensive usability methods with fewer participants.

\subsection{Usability methods}

Choosing the right usability method is not based on one right way to do usability. Usability is a property of a device or application that can be measured by various methods. The right method is the one that lets researchers achieve their goals in their current situation (including, constrains like time and money). However, each method has its advantages and disadvantages. Logging is a technical-orientated usability method. It is mostly applied in monitoring systems (9.3\%), presumably by utilizing the advantages of sensor based systems. Logging is used to objectively measure the interaction with a system, which can be expressed in different measures like for instance the timing between user actions. In this way, large amount of data is captured which needs to be processed. This type focuses on the efficiency and effectiveness parts of usability and provides objective measures (performance measures). This is not always possible with the other methods, although observations can also target both parts. With this technological requirement, most publications will or are not able to include this type of evaluation method. Figure 5 shows that only $11 \%$ of the publications used logging as a usability method and is mainly found in COPD, older adults, healthy subjects and stroke as shown in Figure 6. For COPD, it could be due to the way different low-tech user friendly sensors are used in a home environment. For stroke and Parkinson's disease, patients often have cognitive impairments, which could favour a logging method. Besides logging, self-descriptive and observational methods were found in $16(13 \%)$ and $33(26.1 \%)$ publications respectively as shown in Figure 5. The difference between self-describing methods and observational methods is that the user (considered as expert) comments on the system while performing tasks by a think aloud protocol, slightly after each task or during a video replay. It provides insight into cognitive activity, but that can also be the reason why this self-descriptive 
method was not frequently applied in the included publications. Providing a usable self-description while doing tasks can be difficult for first-time users and requires training. Another reason for not including this method is that it interferes with the task performance and it takes more time to analyse the data. It seems that researchers choose observational methods in combination with interviews or questionnaires above the self-descriptive method. Interviews and questionnaires can be performed from concept to final operation during system development. In combination with their low-cost and high-flexibility features, these methods are widely used in the included articles (in 88 studies). The interview method is included in the highest number of publications focusing on training and medical educational systems. In these systems there is a high end-user to system interaction. It might give end-users more freedom to express their opinion in an interview after interacting with the system, then with for example a self-descriptive method. However, questionnaires are mostly applied in all types of telemedicine systems. Over time, we see a large increase in publications that uses questionnaires as a usability method and most were found in studies related to cardiovascular diseases. Only a few publications applied standardized questionnaires. Standardized questionnaires are not always appropriate for the target population, which gives reason to customize a questionnaire for a particular end-user. It is highly recommended to use a standardized questionnaire like the SUS, PSSUQ or TAM-2, as those are validated. However, the medical condition of the participant has to be taken into account and methods might have to be customized. For example, for evaluations among stroke patients, an observation or logging method is preferred due to cognitive inabilities. With new technological innovations, more participants can be reached via web-based questionnaires, than with traditional tools during an interview, intervention or via post. This is reflected in the increased maximum amount of participants for questionnaires throughout the years and in particularly applies for the two Phase 3 trial orientated studies which were found, included more than 1800 participants together.

\subsection{Usability in the design lifecycle}

In this manuscript, we identified five different usability methods: logging, observation, questionnaires, interviews and self-descriptive. An iterative system development lifecycle consists of multiple steps, including elicitation, system design, testing, implementation and maintenance [29]. Because design changes made late in the design process or even in working systems will bring higher expenditure than if identified during requirements, a user-centred system design (UCSD) process is considered to be more effective [30-31]. In each stage of the development process there 
should be room to interact with end-users and use usability evaluation methods as part of iterative design process to further develop a telemedicine system. We found 90 publications (which are trial orientated, where the remaining publications described a user-centric design process. Publications that included (clinical) trials, were mostly involved in pilot studies (8o publications) and used questionnaires as a preferred method. In process orientated studies, we found that the relative differences in the number of publications for questionnaires, interviews and observations methods was less than in the trial orientated process, where in Phase 2 and 3 only questionnaires were used. Phase 2 mainly focusses on determining the effectivity of the system on end- users and it seems that using observations and interview evaluation methods are not preferred. Observations could influence the outcomes of such effectiveness studies, as an intervention takes place. Both observations and interview evaluation methods do give more knowledge about the system from a usability perspective, but it seems that trial orientated studies set usability goals which can be answered by questionnaires alone. Furthermore, the number of publications diminishes for Phase 2 and Phase 3 trials, and only questionnaires were used. It could be that either it becomes scientifically less interesting to publish studies after the pilot phase or that there is a problem in commercializing systems. In addition, it could also be that those clinical trial studies didn't include usability evaluations, as usability might be evaluated earlier within the design process.

\subsection{Telemedicine related publications}

Publications with a usability method originated mainly from Western countries (94\%). Figure 9 show that although North-America and Europe have the largest amount of telemedicine related publications, other continents in Asia, Africa, Australia and South-America also have a rising number of publications. Furthermore, Africa and South-America are growing exponentially each five-year period and can be seen as uprising continents for telemedicine. Asia, Africa and South-America contain vast amounts of rural areas and may be in desperate need of (cheap and easy-to-use) telemedicine applications As a result of applying the exclusion criteria, we observed that only a small fraction of the publications related to telemedicine included a usability analysis (0.9\%). This result could be due to the fact that publications including usability are more difficult to publish in terms of generalizability and follow up research or development, might not be published in scientific journals. Furthermore, in this survey we also excluded publications up front. It could be that an excluded publication was actually part of a larger design study and that only a followup paper (addressing usability in detail) was included. 


\subsection{Limitations and future research}

Within this literature survey, we only addressed publications that specifically include usability and ease-of-use, as we assumed that within these publications a certain structured evaluation plan was evaluable and researchers were aware of usability, design terms and which methods they could use to evaluate their telemedicine application. We utilized this information specifically to come up with conclusions about methods and applications of usability in telemedicine systems. We did not relate the usability methods of each publication with the acceptability of the telemedicine application among end-users. Assessing the acceptability of each publication and comparing them among each other is quite subjective. It is part of the user's performance, and how users interact with a product. Acceptability affects whether or not a product is or will be used and how it will be used. Acceptability depends on the context of use and the characteristics of the user, and can be influenced by factors such as cost, convenience, availability, pre-requisite training, and dislike of computers or organisational constraints. Each publication employed different usability assessment measures and targets different end-users, thus comparing them is difficult due to the many techniques and usability scores applied. Furthermore, during each stage of system development, different usability methods can be used to tests the system on usability experts, healthy subjects and eventually the target group itself depending on available resources. For this research, we only included publications targeting the end-users of the system. Although we investigated the role of the usability evaluations within the telemedicine design, we excluded articles up-front. Follow-up publications, which might present new developments in telemedicine systems published earlier, might also include usability tests with healthy subjects. Furthermore, the final telemedicine system designs might not published in a scientific journal. Future research might also include these publications to give a conclusion about the application of usability methods among the full length of the system design. 


\section{CONCLUSION}

The rapid development of sensors and communication technology enables the proliferation of new innovative services in healthcare, such as Telemedicine. Monitoring patients in their homes can lead to better health care at lower costs, which stimulates increased demand for new healthcare strategies like telemedicine. An increase in publications related to telemedicine research, development and applications is found worldwide, with most studies conducted in North-America and Europe. Telemedicine systems undergo usability evaluations in system development. Researchers have a variety of methods at their disposal to perform these evaluations. They will likely use a method that helps them answer their evaluation goals. Our literature survey included 127 publications on telemedicine, usability and ease-of-use. We expected that with the increase in telemedicine research and development, various usability methods are more equally employed among the included publications. This is not the case. We found that questionnaires are the most applied usability method across different types of telemedicine systems, end-users and study orientations (trial or process orientation). However, we found that publications focussing on stroke patients preferred interviews and logging techniques above questionnaires. Furthermore, in process-orientated studies, which utilise a usercentred design process, a more equal variety of usability evaluations were applied, with fewer differences found in the number of publications for each evaluation method. It seems that trial-orientated studies involve usability goals which can be answered by questionnaires alone. However, the number of publications diminishes for more complex clinical trial phases, and only questionnaires were applied in those publications. It could be that either it is scientifically less interesting to publish studies after the pilot phase of a system , there is a problem in commercializing telemedicine systems in general or that these studies don't apply a usability analysis. Questionnaires enable researchers to evaluate a system on end-users quickly, as it requires less expertise on the evaluation method then, for instance, a self-descriptive or interview. They are easily distributed by e.g. new advances in web-based technologies and are customizable. The use of questionnaires is the evaluation method of choice for a variety of telemedicine systems and end-users according to our findings. 


\section{Chapter 3}

\section{A FULL BODY SENSING SYSTEM FOR MONITORING STROKE PATIENTS IN A HOME ENVIRONMENT}

B. Klaassen ${ }^{1^{*}}$, B.J.F. van Beijnum ${ }^{1}$, M.H.H. Weusthof ${ }^{1}$, D. Hofs ${ }^{2}$, F.B. van Meulen ${ }^{1}$, A. Droog $^{1}$, H. Luinge ${ }^{3}$, L. Slot ${ }^{3}$, A. Tognetti ${ }^{4}$, F. Lorussi ${ }^{4}$, R. Paradiso ${ }^{5}$, J.P. Held ${ }^{6}$, A.R. Luft ${ }^{6}$, J. Reenalda ${ }^{1,2}$, C. Nikamp ${ }^{1,2}$, J.H. Buurke ${ }^{1,2}$, H.J. Hermens ${ }^{1,2}$ and P.H. Veltink ${ }^{1}$

${ }^{1}$ Biomedical Signals and Systems group, University of Twente, Enschede, The Netherlands.

${ }^{2}$ Roessingh Research and Development B.V., Enschede, The Netherlands,

${ }^{3}$ Xsens Technologies B.V., Enschede, The Netherlands.

${ }^{4}$ Interdepartmental Center E.Piaggio, University of Pisa, Italy,

${ }^{5}$ Smartex SRL, Pisa, Italy.

${ }^{6}$ Division of Vascular Neurology and Neurorehabilitation, Department of Neurology, University Hospital of Zurich, Zurich, Switzerland.

Published as an extended version in Springer International Publishing, Chapter Biomedical Engineering Systems and Technologies, Volume 511 of the series Communications in Computer and Information Science pp 378-393, January $7^{\text {th }} 2016$, of our publication in the International Conference on Health Informatics (HEALTHINF 2014) (Angers), 125-132 (2014) 


\begin{abstract}
Currently, the changes in functional capacity and performance of stroke patients after returning home from a rehabilitation hospital is unknown to a physician, having no objective information about the intensity and quality of a patient's daily-life activities. Therefore, there is a need to develop and validate an unobtrusive and modular system for objectively monitoring the stroke patient's upper and lower extremity motor function in daily-life activities and in home training. This is the main goal of the European $\mathrm{FP}_{7}$ project named "INTERACTION". A full body sensing system is developed, which integrates Inertial Measurement Units (IMU), Knitted Piezo resistive Fabric (KPF) strain sensors, KPF goniometers, EMG electrodes and force sensors into a modular sensor suit designed for stroke patients. In this paper, we describe the complete INTERACTION sensor system. Data from the sensors are captured wirelessly by a software application and stored in a remote secure database for later access and processing via portal technology. Data processing includes a ${ }_{3} \mathrm{D}$ full body reconstruction by means of the Xsens MoCap Engine, providing position and orientation of each body segment (poses). In collaboration with care-professionals and engineers, clinical assessment measures were defined and the question of how to present the data on the web portal was addressed. The complete sensing system is fully implemented and is currently being validated. Patient measurements started in June 2014.
\end{abstract}




\section{INTRODUCTION}

Currently, the changes in functional capacity and performance of stroke patients after returning home from a rehabilitation hospital is unknown to a physician, having no objective information about the intensity and quality of a patient's daily-life activities. As a consequence, the physician is unable to monitor the prescribed training program for sustaining or increasing the patient's motor capacity (what a patient is able to do) and performance (what a patient is doing in actual practice) and cannot give advice to the patient outside the hospital setting. Therefore, there is a need to develop and validate an unobtrusive and modular system for objective monitoring of daily-life activities and training of upper and lower extremity motor function in stroke patients. That is the main goal of the European $\mathrm{FP}_{7}$ project named INTERACTION [1]. A physician will be able to continuously evaluate the patient's performance in a home setting by using the INTERACTION system, allowing the physician to compare the patient's performance at home with the patient's capacity in the rehabilitation hospital. Thereby, the system will support the physician in making decisions on, for example, altering the prescribed training programs.

The INTERACTION sensor system is composed of Inertial Measurement Units (IMUs), Knitted Piezo resistive Fabric (KPF) strain sensors, KPF goniometers, EMG electrodes and force sensors. These sensors are integrated into a custom-made modular suit for stroke patients, which consists of a shirt, a pair of trousers, shoes and gloves (e-textile). The iterative design process for the sensor suit includes several usability tests as well as an extensive user requirements analysis with medical and technical experts. Data are captured wirelessly on a home-gateway, which transmits the data to a secure database. Portal technology can access and process the data. The results can be consulted by a care-professional whenever necessary.

In this paper, we describe the complete sensing system, including the architecture and the requirements for presenting the assessment measures to care-professionals. Specifically, in section 2, the system requirements are given along with an overview of the whole system and a detailed description of each component. The design of the sensing suit is described in section 3. In section 4, the data processing aspects of the system will be explored in further detail. In section 5 , the design process of the data presentation is elaborated upon. In section 6 , the current implementation of the system is presented and finally, in section 7 , the conclusions and future work are described. 


\section{SYSTEM ARCHITECTURE}

\subsection{System requirements}

Five major requirements were set before the initial system development:

1. The system should compute and display motor capacity and performance measures to evaluate stroke patients during daily-life activities in a home setting.

2. The sensing system should be unobtrusive for patients to wear and easy to use.

3. The system should be divided into several modules: upper extremity (shirt), lower extremity (trousers), gloves and shoes. This will allow clinicians to assign different modules to different patients according to the careprofessionals specific interests.

4. Analysis of the sensor data will not be done in real time. The system should be able to store the computed data such that it can be accessed by a careprofessional when needed.

5. The system should present the performance information of the patient to the care-professional, such that it optimally supports monitoring the progress of the patient and decisions about continued therapy. The care-professional should be able to inspect the information in progressive detail from global performance parameters to details concerning the quality of specific movement tasks, according to his or her needs.

\subsection{System architecture overview}

The INTERACTION system's architecture is based upon a generic architectural approach described by Pawar et al. [2]. Figure 10 shows a general overview of the current system's architecture. The Body Area Network (BAN) is composed of several sensors listed in Table 4 and a home gateway. The Xsens wireless Awinda protocol is used to connect and synchronize the sensors to the home gateway, which captures the data and stores it in a European Data Format (EDF) [3]. The EDF file protocol was extended for the INTERACTION project by adding additional signal labels to the header of the file. The home gateway application uploads the EDF file to a secure and remote SQL database if an internet connection is detected. A server, installed at the University of Twente, runs Liferay portal software with Matlab [1, 4-6]. The portal obtains the data from the database and sends the results to Matlab for processing. The 
results are saved and visualized on the web-portal on request. Each component is explained in detail in the following sub-sections.

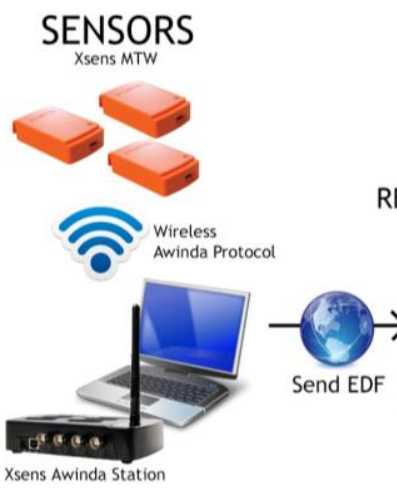

HOME GATEWAY
Data storage RESTful webservices

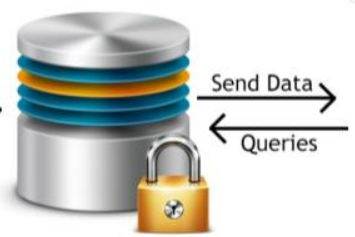

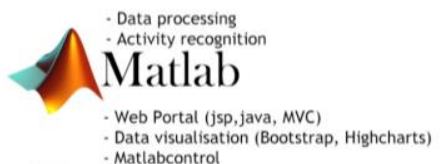
* LIFERAY

Client requests

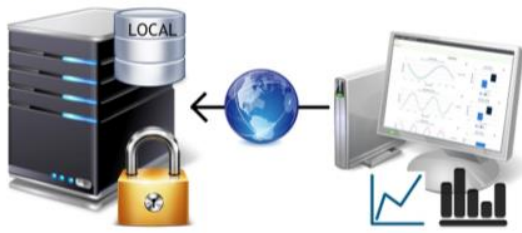

Figure 10. System Architecture. The home gateway captures sensor data and sends it in an EDF to a secure database. Portal technology can access and process the data and visualize the results to care-professionals on a web-portal.

\subsection{Body Area Network}

The Body Area Network (BAN) consists of all body sensor components and a gateway to capture, store and upload sensor data.

\subsubsection{Sensors}

The INTERACTION sensor system is divided into four modules, each of which comprises of a number of sensors as listed in Table 4. Each Xsens MTw sensor box includes 10 primary signals: a $3 \mathrm{D}$ accelerometer, a $3 \mathrm{D}$ goniometer, a $3 \mathrm{D}$ magnetometer and one Pressure channel [5]. Knitted Piezo resistive Fabric (KPF), the properties of which include a short transient time, reduced aging, washability and signal reproducibility has been employed both as strain sensors and, arranged in a double layer structure, as goniometers to monitor joint movement of the shoulder and respectively the thoracic spine, knees and fingers. The KPF sensors are developed by the University of Pisa; the strains are fully integrated in the e-textile suit, but the goniometers for the knees and spine are removable. Two sets of EMG electrodes are integrated into the shirt (on the left and right shoulder) and the signal is pre-processed by an on-body front-end system into a smooth rectified signal. Only the EMG 
electrode set, located on the affected side of the patient, is connected. The choice of realizing an unobtrusive, minimal EMG sensor set led to the use of the electrodes on the deltoid only to detect its activity and discriminate the presence of compensatory movements in the shoulder.

The kinaesthetic and kinetic glove module was designed to identify reaching and grasping activities. KPF goniometers were integrated in the metacarpal-phalangeal area of thumb, index and medium fingers. Moreover, force sensitive resistors were integrated in the palm and lateral side of the glove to measure contact pressures and give an indication of hand loading in stroke patients. An additional force sensor was integrated on the lateral side of the middle phalanx of the forefinger to complete the information derived from the goniometers and to improve the discrimination between hand positions that have similar joint angular values (Figure 14). Force insoles were made for different shoe sizes to be fitted into the patient's shoes. Each insole comprises of two pressure sensors: one under the heel and the other under the forefoot, such that they measure the forces act on the main pressure points under the feet (Figure 15). The Xsens Awinda Auxiliary Data Functionality enables users to combine data coming from a wide range of devices with the inertial data from the MTw sensors and use the wireless link of the MTw as a means of transporting this data. The KPF strain sensors, KPF goniometers, EMG electrode set on the patient's affected side and force sensors on the gloves and shoes are each physically linked to a modified MTw sensor box by passing the data to the MTw's pressure channel. The strain sensors and force sensors on the shoes and the force and goniometers on the gloves are multiplexed to be sent over one channel. As a result, the wireless capabilities of the MTw's for data transmission from the BAN to the gateway are preserved. The integrated sensors are connected via waterproof connectors to insure the washability of the shirt. Figure 11 provides a global overview of the sensing system for the upper and lower extremity. Each MTw sensor unit outputs 10 primary signals, each of which is assigned a unique sensor label within the EDF file. The data collection rate is dependent on the number of sensors. In the INTERACTION project, the collection rate is set to 20 Hertz. This data collection rate has been assessed to be appropriate, since $3 \mathrm{D}$ kinematics is analysed at a higher frequency (18oo Hertz) inside the MTw sensor units before transmission to the Awinda base station. This local analysis provides a more accurate estimation of acceleration and angular velocity values. $20 \mathrm{~Hz}$ is an appropriate rate for transmission of ${ }_{3} \mathrm{D}$ orientation as well as the other quantities measured by the sensors, as specified in Table 4. 
Table 4. Number of sensors

\begin{tabular}{lcccc}
\hline Type of sensor & Shirt & Trousers & $\begin{array}{c}\text { Pair of } \\
\text { shoes }\end{array}$ & $\begin{array}{c}\text { Pair of } \\
\text { gloves }\end{array}$ \\
\hline IMU & 6 & 4 & 2 & 2 \\
\hline $\begin{array}{l}\text { KPF Strain } \\
\text { sensors }\end{array}$ & 2 & & & \\
\hline KPF goniometer & 1 & 2 & & 6 \\
\hline EMG & 2 & & & 12 \\
\hline Force & & & 4 & \\
\hline
\end{tabular}

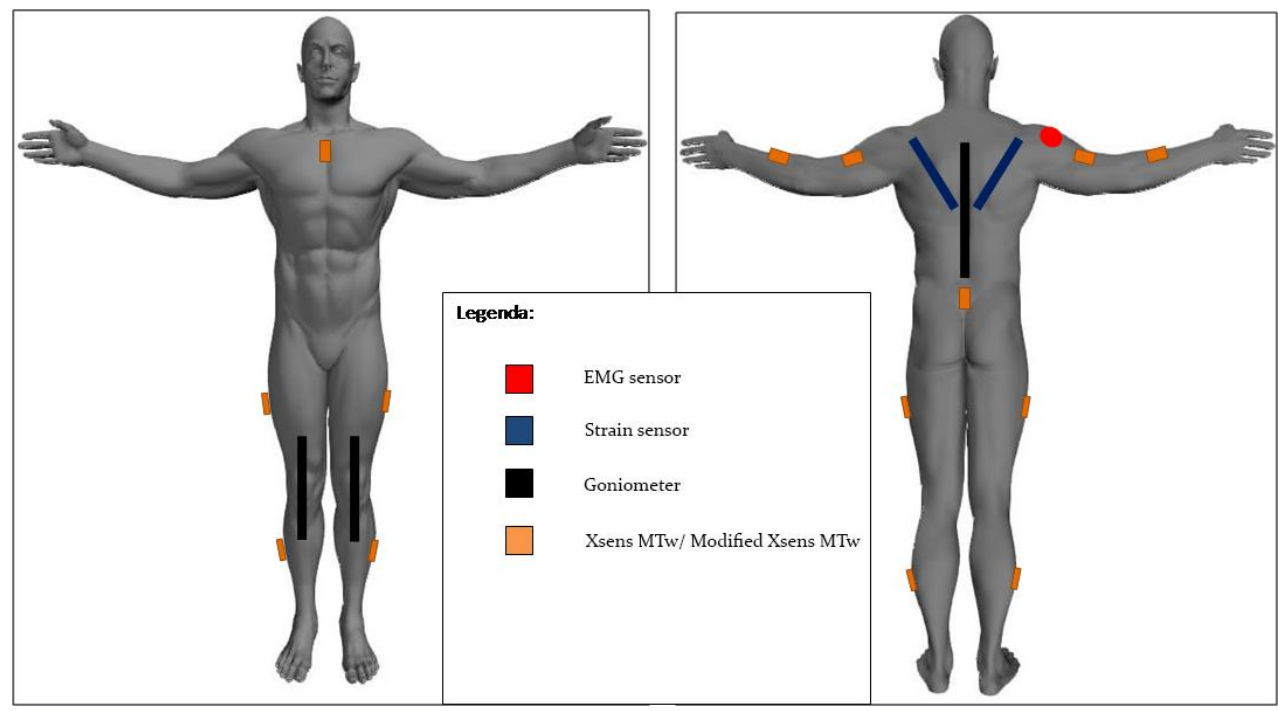

Figure 11. Sensing system overview. The KPF goniometers over the knee and spine are removable and only one EMG sensor set, located on the affected side of the patient, is connected.

\subsubsection{Gateway.}

The home gateway has three main functions: 1) collecting the data from the sensors, 2) storing the sensor data inside an EDF file every five minutes and 3) uploading the EDF file to the database. The sensor data is first logged using an Xsens mtb file structure to handle sensor packet loss and data retransmissions and then converted 
to EDF. The software automatically tries to reconnect with the sensors in case one or multiple sensors are out of range. The data storage interval of five minutes was determined by considering the available network bandwidth as well as the decreasing overhead of the EDF file with measurement time. With five minutes of data, the EDF data record has a size of $1.6 \mathrm{MB}$ in total according to equation 1 (also called the "payload") and a header size of $35.25 \mathrm{kB}$ according to equation 2 . Therefore, the header occupies only $2.15 \%$ of the total EDF file space. The ratio between the payload and the header of a file is called the "overhead".

$$
\begin{aligned}
& \text { Payload size }=\mathrm{M}_{\mathrm{t}}{ }^{*} \mathrm{~F}_{\mathrm{s}}{ }^{*} \mathrm{~N}_{\text {imu }}{ }^{*} \mathrm{~N}_{\text {signals }}{ }^{*} \text { bytes } \\
& \text { Header size }=\left(\mathrm{N}_{\mathrm{imu}}{ }^{*} \mathrm{~N}_{\text {labels }}+1\right){ }^{*} 256 \text { bytes }
\end{aligned}
$$

The inputs for equations 1 and 2 are as follows: Nimu: 14 (Number of IMU's), Nsignals: 10 (Number of sensor signals per IMU), Nlabels: 10 (number of sensor labels), Mt: 300 seconds (Measurement time) and Fs: 20 Hertz (data collection rate). The 256 bytes in equation 2 is the size of the general EDF header. The data is uploaded to the database with SSL secure data encryption over the network using RESTful web services, and the users of the database are authenticated using a username and password combination. Furthermore, within the EDF file, only a device ID is used to identify each sensor suit, so no patient names are exchanged. The home gateway software is used by careprofessionals to setup the INTERACTION system for collecting patient data at home or in the clinic. The user interface was designed in an iterative process throughout the INTERACTION project. Several usability tests were done during software development. Care-professionals were monitored (with video cameras) while performing several measurement scenarios with the hardware and software while thinking out loud. After the scenarios were done, interviews were conducted to get the care-professional's opinion. This cycle was repeated several times while developing the gateway software. Options in the interface include: choose a patient, choose the type of measurement (a calibration measurement, a performance measurement or a capacity measurement), switch a sensor (in case of a malfunction) and view sensor data. The interface provides visual feedback on the duration of the measurement, when sensors get out of range or when data is uploaded to the server.

\subsubsection{Database}

An SQL database was configured at the Roessingh Research and Development center (RRD) by reason of their technical experience in secure databases. Dedicated API's were constructed for communication between the home gateway and portal using 
SSL. For obtaining the data, a correct combination of username and password is required to authenticate the user, and a separate authorization model is in use which determines the access rights of the user, including his or her reading and writing rights. A query engine is developed based on RESTful web services to obtain EDF sensor data from the RRD database on receiving a request from the web portal with a start and end time.

\subsection{Portal}

The web-portal is responsible for controlling and visualizing the data. We selected the Liferay portal framework as it provides a flexible working environment to develop portlets in a Spring Model-View-Controller (MVC) structure using Java, JavaScript, CSS and JSP. This structure is shown in Figure 12. Liferay includes a dedicated Content Management System (CMS), which allows the portal to be personalized for different users by means of a detailed access-control scheme for assigning different rights to different users. The View component is responsible for displaying the processed data to the user and includes two visual libraries: the Highchart library [6] for graphs and the Bootstrap library [7] for a responsive layout and website elements. The front-end Controller component is connected with the View and initiates the Model(s). The Model components obtain the data from the database by use of multiple queries and subsequently send the data to Matlab via a Matlab-Java bridge [8]. Users are able to send requests for different types of measurement data in a specific portlet (by pressing, for instance, a button on the web-portal). These requests are directly forwarded to the Controller component associated with that portlet. This Controller initiates several Models accordingly. With this MVC structure, we are able to process and visualize large amounts of data in an organized way. Multiple portlets can be constructed, each having a different function to show different types of data on the same web-page or on separate web-pages.

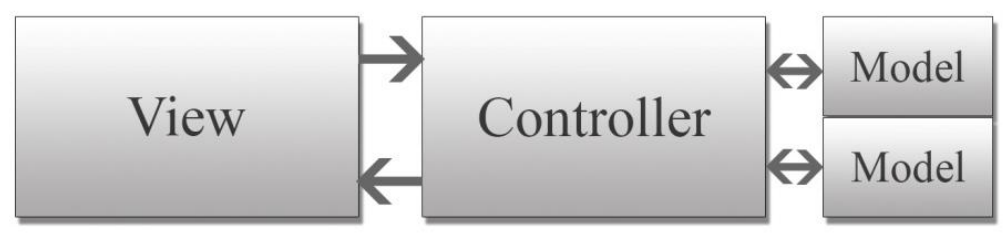

Figure 12. A Spring Model-View-Controller structure of a portlet. 


\section{E-TEXTILE SUIT DESIGN}

The INTERACTION sensor suit combines a shirt, trousers, shoe insoles and gloves. These fabrics are characterized by a different amount of elastic component and different weight. A heavier fabric with higher elasticity was used for the sensing part of the shirt and the trousers to guarantee a good fitting with the body shape, whilst a fabric based on ceramic components was used to realize the rest of the suit. These mineral components, that are introduced at fiber level, affect the thermo-regulation of the body and improve blood micro-circulation when in contact with the skin for more than six hours. The properties of the fibers do not deteriorate after repeated washing cycles. Several prototypes were realized in a joint effort between designers, engineers, clinicians and stroke patients. To evaluate the functionality of the KPF strain and goniometer sensors, a series of testing prototypes have been designed. These prototypes offer the possibility to evaluate different configuration of the system by varying the location, the dimension and the number of textile sensors. The prototypes were accessorized with velcro $^{\circledR}$ strips to facilitate this process. The positions of the strips were varied to test the functionality of the corresponding sensors that can be attached with the velcro ${ }^{\circledR}$ on the garments. Decisions on the materials, dimensions, shapes and locations of the textile EMG electrodes were made after a round of experiments, performed to determine the best solutions that optimized the functionality of the garments in terms of their sensing properties [9]. The sensing glove has to accurately fit the hand in order to provide an adherence similar to a second skin. Furthermore, thermal comfort is another fundamental requirement, solved by the selection of a suitable material in term of breathability and elasticity. A patented fabric has been used for the basic prototype of the glove, which combines two types of fibres: a polyamide microfiber and LYCRA ${ }^{\circledast}$ elastomer. In Figure 14, the glove is shown in detail. The force shoe insoles were designed based on regular shoe insoles. Two layers of fabrics were merged, where the force sensors [10] were placed in between to make a tight fit. The force insoles are shown in Figure 15. The final designs resulted in a system that balances the wearability properties of the prototypes with the requirements in terms of the positions and mechanical constraints of the sensors. Patients tested the final designs, in which solutions were added to increase the easiness of wearing and removing the sweatshirt and the leggings (for example, zippers on the side of the shirt and sleeves). Different designs were made for male and female. In total, four complete sensing systems and one backup system were made, each with several e-textile clothing sizes ranging from S to XL. In Figure 13, the INTERACTION sensor system is shown. 
Chapter 3: A full body sensing system for monitoring stroke patients in a home environment

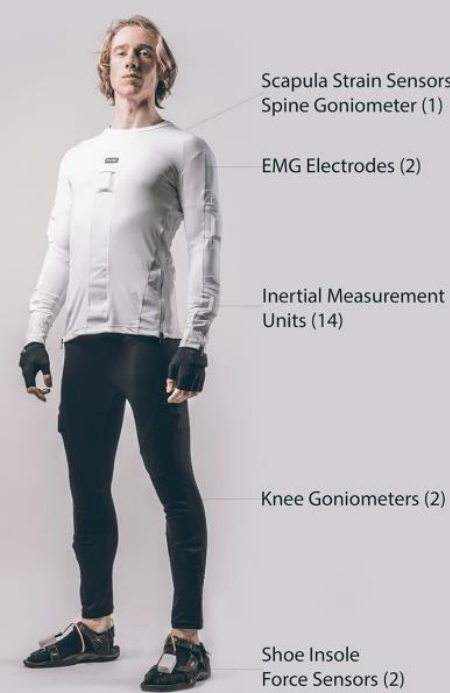

\section{INTERACTION for stroke}

Full Body Sensing System for Daily Life

Performance Monitoring

Force Sensors (2)

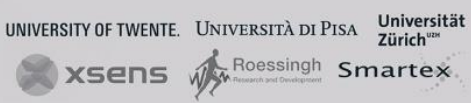

Figure 13. The final design of the INTERACTION suit.



Figure 14. Glove design. KPF goniometers were integrated in the metacarpalphalangeal area of thumb, index and medium fingers. Force sensitive resistors were integrated in the palm, lateral side of the glove and the lateral side of the middle phalanx of the forefinger. 


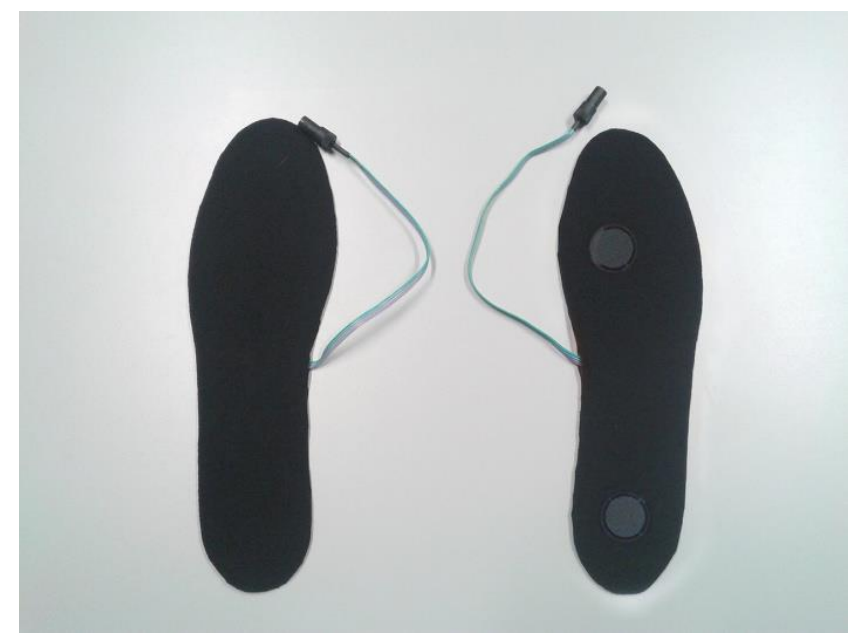

Figure 15. Force shoe insoles. Each insole comprises of two pressure sensors: one under the heel and the other under the forefoot. The right insole shows the sensor locations. 


\section{DATA PROCESSING}

Within INTERACTION, sensor data is captured from up to 14 IMU's. The data is stored in a secure database and will be processed overnight. This ensures a short waiting time during the day for displaying patient reports to care-professionals on a website. Matlab [8] software is used for data processing, which also includes several external libraries from Xsens. The data processing flow is shown in Figure 16. The first step in processing the data is obtaining sensor data in EDF from the database. This step is realized by the use of RESTful web services to access the database and implemented via a custom-made Java portlet in the Liferay web-portal software. The second step is to initiate Matlab and pre-process the EDF sensor data for the later steps. The preprocessing includes matching the correct calibration data with the measurement data, estimating the orientation of the sensors and structuring the data. Furthermore, Additional sensors from the INTERACTION suit, such as the KPF strain sensors on the shoulders, goniometers and force sensors inside the glove and force sensors in the shoe insoles, are demultiplexed. Step three consists of inserting the pre-processed sensor data into the Xsens MoCap Engine (XME). The XME computes poses of all body segments, where a pose is defined as an orientation and position of a body segment [11]. A full body $3 \mathrm{D}$ reconstruction can be made by using the XME. From these poses, joint angles according to the ISB standards and several kinematic distances (like the hand-sternum distance) are calculated as part of step four. In step five, basic activities of the patient are detected based on the results of step three and four. A number of daily-life activities were classified as shown in Figure 17. The activity algorithms were developed with the goal of getting a high specificity in identifying the activities. In the final step, the INTERACTION metrics are computed. These metrics are presented to care-professionals in the form of a report and should provide valuable insight into the patient's capacity and performance during daily-life activities. INTERACTION metrics were constructed in a joint effort among care-professionals and engineers. Several examples are listed in Table 5 .

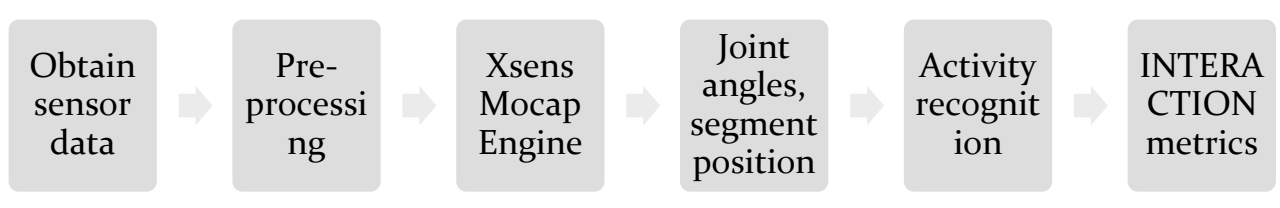

Figure 16. Data processing flow. 

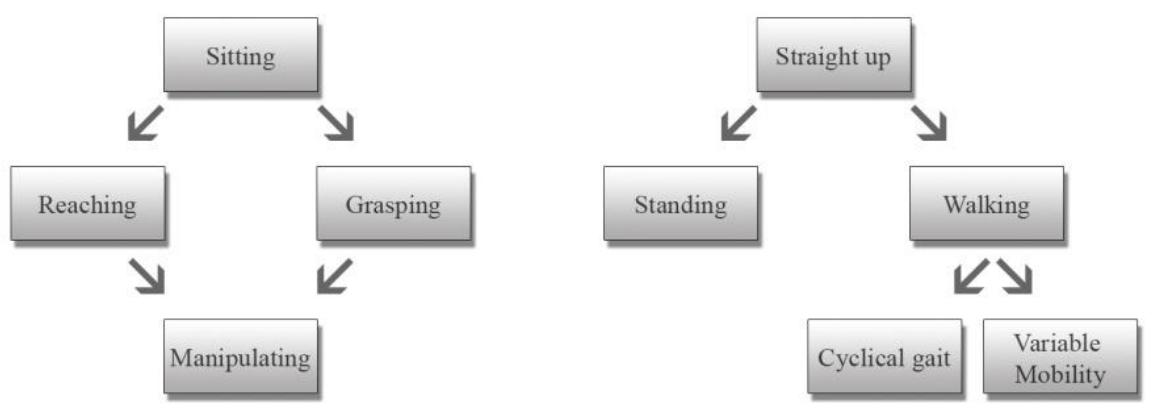

Figure 17. Activity classification.

Table 5. Examples INTERACTION metrics.

\begin{tabular}{ll}
\hline 1 & Arm usage of the affected and non-affected arm \\
\hline 2 & Maximum reach of the affected and non-affected arm \\
\hline 3 & $\begin{array}{l}\text { Range of Motion of the elbow and shoulder of the affected and } \\
\text { non-affected arm }\end{array}$ \\
\hline 4 & Range of Motion of the trunk \\
\hline 5 & Maximum grasping force of the affected and non-affected arm \\
\hline 6 & Number of grasps of the affected and non-affected arm \\
\hline 7 & Number of steps, step length and step time \\
\hline 8 & Weight support by affected and non-affected leg \\
\hline
\end{tabular}




\section{USER INTERFACE}

Designing a graphical user interface for care-professionals to access the web-portal and determining which metrics to present on the web-portal is one of the major challenges in the INTERACTION project. The INTERACTION system will be collecting data that care-professionals are not familiar with in current clinical practice and the data has to be presented in a format that care-professionals understand and able to evaluate within a few minutes. By means of several interview sessions between care-professionals from the Netherlands (Roessingh Research and Development centre, Enschede) and Switzerland (University hospital in Zürich and Cereneo A.G,, Vitznau and engineers involved in the project, metrics were identified able to show the capacity and performance of a patient over time. These metrics will be evaluate in a later stage with care-professionals not related to the project. We concluded the following: Care-professionals can have as many as 40 stroke patients in treatment at a given moment, all of whom have to be evaluated within one hour by the end of the week. This amounts to only a few minutes per week to analyse the performance of each patient. Hence, there is a need for a basic overview of all patients on the webportal with an option to successively drilldown to a particular data set for a particular patient. As soon as the patient data is processed, it will be available in a report format on the website. This report includes the assessment measures of INTERACTION for the upper extremity and lower extremity. A basic overview of all the subjects is available. The care-professional is then able to choose a subject and a measurement day and ask for the report for that day. In this report, the patient's capacity measurements in the clinical setting (consisting of multiple clinical measures such as the Berg Balance Scale [12]) are compared with his or her performance measurements in a home environment and can also be compared with healthy subject measurements. An example of the upper extremity webpage is shown in Figure 18. Different Range of Motion charts for the elbow angle, hand-sternum distance and trunk flexion angle are shown for comparing capacity with performance during reaching activities. Box plots are available as well to show the distribution. Furthermore, the reaching positions of the left and right hand relative to the sternum are shown as a top view $(x, y)$ along with, for example, the reaching areas for comparing the left and right arm. Extracting relevant assessment measures and how to visualize them is, and remains an ongoing process within INTERACTION. 


\section{Upper Extremity}

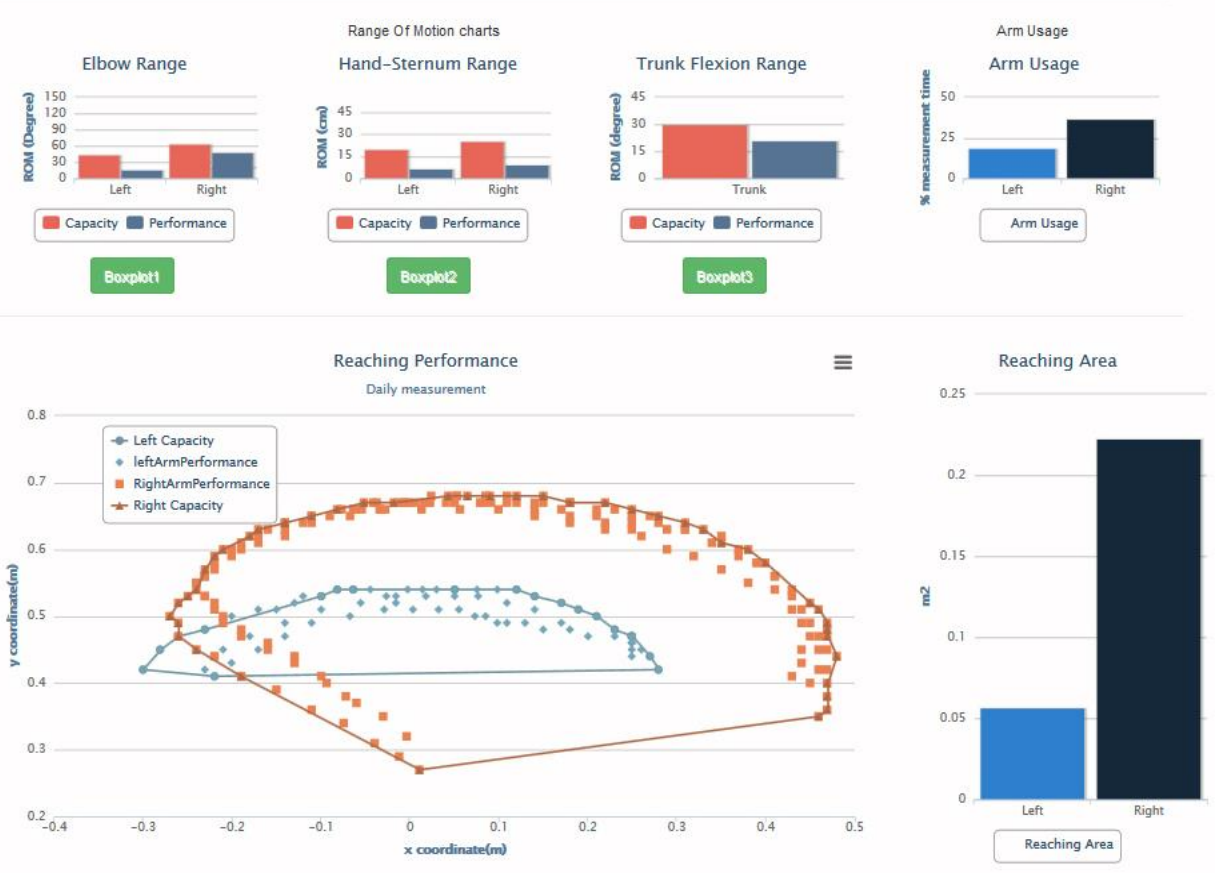

Figure 18. Example of the upper extremity webpage. The patient's capacity is compared with his or her performance during reaching activities for the left and right arm. Several Range of Motion graphs are shown on top. A plot of the hand-sternum distance in the transversal plane $(\mathrm{x}, \mathrm{y})$ is shown on the bottom. The outline is visualized and the area in this outline is computed. 
Chapter 3: A full body sensing system for monitoring stroke patients in a home environment

\section{IMPLEMENTATION}

We finished and tested the complete system architecture, from sensors to web portal, with a full body configuration. This includes all system components with 14 Xsens MTw sensors. Prior to this, the systems architecture was constructed by first using one sensor, then extending it to three sensors with a combination of a basic upper body biomechanical model and finally to a total of 14 sensors with a full body biomechanical model. The gateway software, web-portal software and biomechanical model were developed in parallel and merged together in May 2014.

To measure with the INTERACTION system, the Xsens Awinda base station is connected to a laptop which runs the gateway software. A pre-determined sensor configuration (for example, full body with gloves and shoes), subject ID and the type of measurement have to be set using the gateway software options menu. The mode to initialize the system then becomes available. Initializing the system includes waking up the sensors (they are in sleep mode when not used and can be woken up by a slow turning motion), and waiting until all sensors are synchronized with the Awinda base station. We use an anatomical print with sensor locations where sensors can be placed during the initialization phase. The care-professional then knows which sensor is assigned to which body segment and can later place the sensor boxes in the correct textile suit pockets. After all sensors are synchronized, the software automatically goes into calibration mode and waits for the user input to measure. In this phase all MTw sensor boxes are placed in the e-textile suit pockets and additional sensors like strain, goniometers and force sensors are connected. The subject is now instructed to stand in an $\mathrm{N}$-pose (standing up straight with arms alongside the body) for 20 seconds for a calibration measurement. When a calibration is successfully performed, the software continues to the specified measurement mode and when the user and subject are ready, the measurement can be started by the care-professional by pressing "start measurement".

In April and May 2014 a number of tests were performed on healthy subjects wearing the complete sensor system, both in lab and home environment. An example of a healthy subject performing a 10-meter walking test is shown in figure 19 . A $3 \mathrm{D}$ visual reconstruction is shown on top and the left knee joint angle is plotted for the different axes according to the ISB standards. The walking test started by sitting in a chair, then standing up, walking 10 meters in a normal pace, turning around, waiting, walking back and finally sitting down again. During sitting, the knee joint angle is arround 90 degrees flexion, and when walking it oscillates from 5 to 75 degrees for this particular 
subject. The activity recognition schemes were implemented and measurement data was successfully processed. Finally, upper extremity metrics were shown on a webportal. In Figure 20, care-professionals are measuring with the complete sensing system. The sensing suit is worn under regular clothing.

Several training days were organized in Enschede and Zurich to train careprofessionals in using the INTERACTION sensor system. The training included how to use the hardware and software of the complete sensing system in several measurement scenarios and practicalities such as how to wash the specialized e-textile suits. Support protocols were developed so that technical experts were available during patient measurements and one complete set of sensors was built as a back-up in case of sensor failure. Protocols were made for patient measurements in clinic and at home. Furthermore, a number of lab and in-home tests were done by wearing an on-body tablet pc with an Xsens Awinda USB dongle to solve connection issues with the Xsens Awinda base station when walking out of range. These tests were successful and further options are explored like how patients can safely wear a small tablet onbody (in for example a pouch attached to a belt) and optimizing the wireless connection by the placement of the USB dongle.

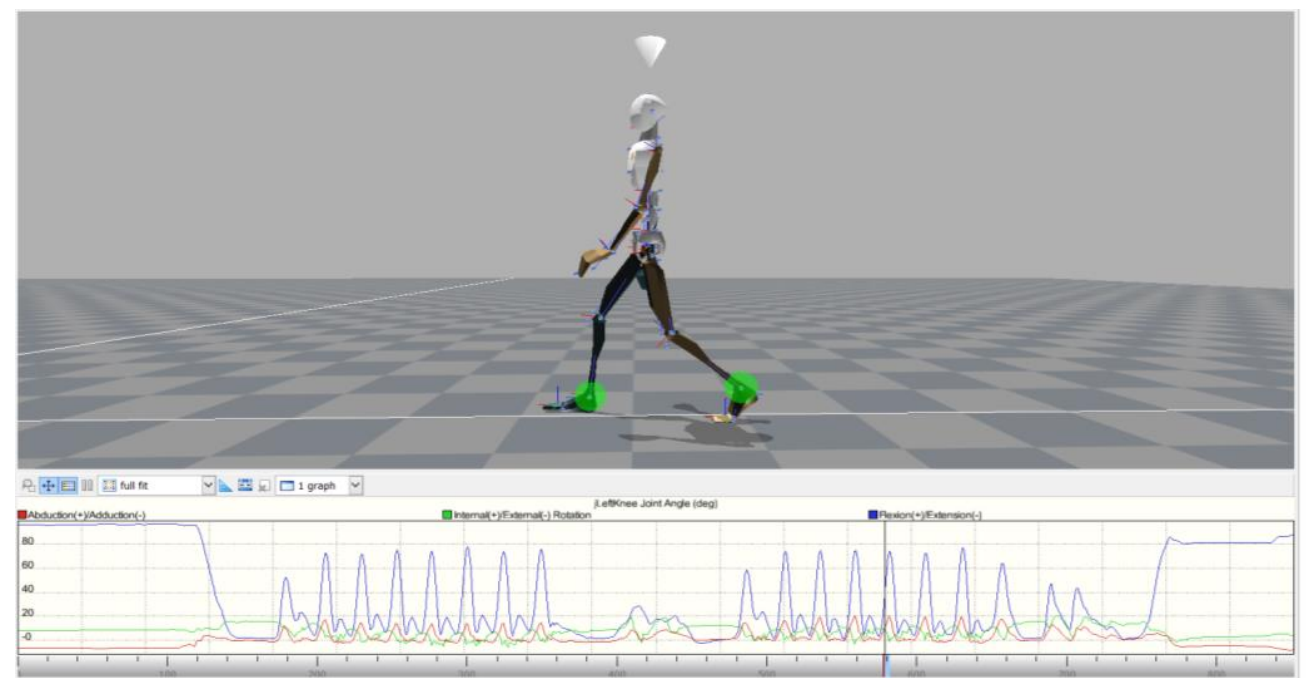

Figure 19. INTERACTION $3{ }_{3}$ full body reconstruction during a walking test. The left knee joint is plotted over time for abb/adduction, internal/external rotation and flexion/extension. 
Chapter 3: A full body sensing system for monitoring stroke patients in a home environment

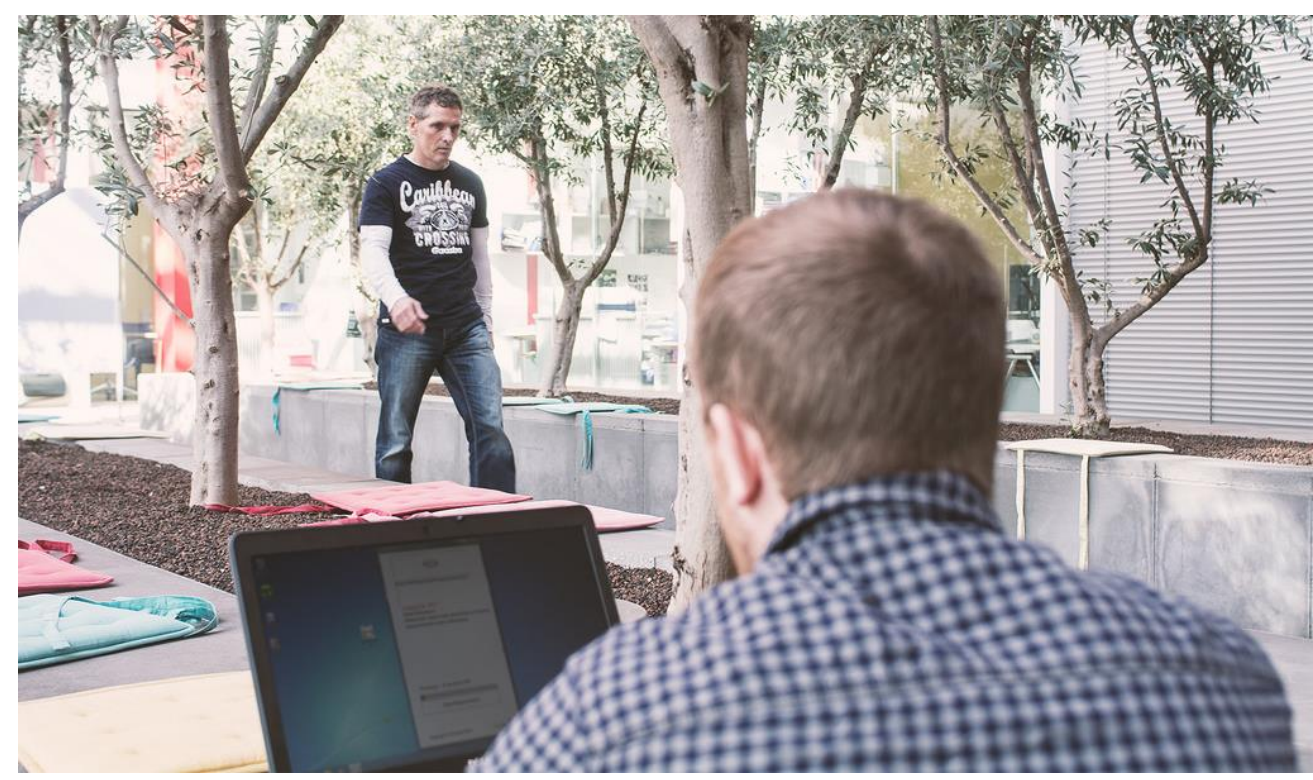

Figure 2o. Care-professionals measuring with the INTERACTION system. The sensing suit is worn under regular clothing. 


\section{CONCLUSION AND FUTURE WORK}

The INTERACTION project aims to develop and validate an unobtrusive and modular system for objectively monitoring of upper and lower extremity motor function in stroke patients during daily-life activities. The system's complete architecture was developed according to the requirements identified at the beginning of the project. The architecture, including all its components, have been tested for up to 14 MTw sensors for a full body configuration. The biomechanical model, including the Xsens MoCap Engine (XME), was optimized for the INTERACTION sensor configuration and provides a full body $3 \mathrm{D}$ reconstruction. Position and orientation of body segments, joint angles and anatomical distances were computed successfully from several test measurements with healthy subjects in the lab and at home. The gateway software was extended with an auto-reconnect feature when sensors went out of range and return within range. This will ensure that more measurement data are collected when measuring subjects at home, which is prone to out of range issues. Furthermore, the portal's MVC structure has been designed to be extensible and provides a flexible coding environment for engineers by the inclusion of a Matlab-Java bridge for backend data processing algorithms. The XME, and the algorithms for activity recognition and for computing clinical assessment measures are included within the back-end data processors. An additional option was investigated for the out of range issues, namely by measuring with an on-body tablet. This option was successfully tested in the lab and at home with a full body configuration and is currently being optimized for use. The next step is to validate the sensor suit by comparing it with Vicon motion capture system [13] as an optical reference measurement system. Finally, the activity recognition algorithms for upper and lower extremity metrics have to be validated. Patient measurement are starting in June 2014 at both the Roessingh Research and Development clinic in the Netherlands and the neurorehabilitation clinic Cereneo A.G. in Switzerland as well as at the patient's home. Home measurements will present additional challenges as external factors such as unpredictable magnetic distortions and movement of clothing will have more influence on the quality of the ${ }_{3} \mathrm{D}$ reconstruction, than in a controlled environment. In this project, we have identified an extensive list of potential metrics. The list presented in this paper is an example of what the INTERACTION system will deliver. We are now in the process, together with care-professionals and engineers, to make a final selection of these metrics to be implemented by the system. 


\section{Chapter 4}

\section{OBJECTIVE EVALUATION OF THE QUALITY OF MOVEMENT IN DAILY-LIFE AFTER STROKE}

B.Klaassen $^{* 1,2}$, F.B. van Meulen ${ }^{* 1}$, J.P. Held ${ }^{1,3}$, J.Reenalda4, 5, J.H. Buurke ${ }^{1,4}$, B.J. F. van Beijnum $^{1,2}$, A.R. Luft ${ }^{3}$ and P.H. Veltink ${ }^{1}$

${ }^{1}$ Biomedical Signals and Systems, MIRA - Institute for Biomedical Technology and Technical Medicine, University of Twente, Enschede, Netherlands.

${ }^{2}$ Centre for Telematics and Information Technology, University of Twente, Enschede, Netherlands.

3Division of Vascular Neurology and Neurorehabilitation, Department of Neurology, University Hospital of Zurich, Zurich, Switzerland.

${ }^{4}$ Roessingh Research and Development, Roessingh Rehabilitation Hospital, Enschede, Netherlands.

${ }_{5}^{5}$ Biomechanical Engineering, MIRA - Institute for Biomedical Technology and Technical Medicine, University of Twente, Enschede, Netherlands.

${ }^{*}$ Bart Klaassen and Fokke B. van Meulen have contributed equally to this work.

Published in: Frontiers in Bioengineering and Biotechnology. 2015; volume 3, on Jan $13^{\text {th }}, 2016$.

\section{AbStract}

Background: Stroke survivors are commonly left with disabilities that impair activities of daily living. The main objective of their rehabilitation program is to maximize the functional performance at home. However, the actual performance of patients in their home environment is unknown. Therefore, objective evaluation of daily life activities of stroke survivorsintheirphysicalinteraction withtheenvironmentisessentialforoptimal guidance of rehabilitation therapy. Monitoring daily life movements could be very challenging, as it may result in large amounts of data, without any context. Therefore, suitable metrics are necessary to quantify relevant aspects of movement performance during daily life. The objective of this study is to develop data processing methods, 
which can be used to process movement data into relevant metrics for the evaluation of intra-patientdifferences in quality of movements in a daily life setting.

Methods: Based on an iterative requirement process, functional and technical requirements were formulated. These were prioritized resulting in a coherent set of metrics. An activity monitor was developed to give context to captured movement data at home. Finally, the metrics will be demonstrated in two stroke participants during and after their rehabilitation phases.

Results: By using the final set of metrics, quality of movement can be evaluated in a daily life setting. As example to demonstrate potential of presented methods, data of two stroke patients were successfully analysed. Differences between in-clinic measurements and measurements during daily life are observed by applying the presented metrics and visualization methods. Heel height profiles show intra-patient differences in height, distance, stride profile, and variability between strides during a 10-m walk test in the clinic and walking at home. Differences in distance and stride profile between both feet were larger at home, than in clinic. For the upper extremities, the participant was able to reach further away from the pelvis and cover a larger area.

Discussion: Presented methods can be used for the objective evaluation of intra-patient differences in movement quality between in-clinic and daily life measurements. Any observed progression or deterioration of movement quality could be used to decide on continuing, stopping, or adjusting rehabilitation programs. 


\section{INTRODUCTION}

Patients who have suffered a stroke are commonly left with dis- abilities that impair activities of daily living. They are trained to recover adequate control over their movements with the objective to optimize their daily life functional performance [1]. In current clinical practice of stroke rehabilitation, the capacity of stroke patients to perform functional tasks is assessed using standardized clinical tests. These tests are done regularly during the entire rehabilitation process to predict functional performance at home [1]. While the main objective of the rehabilitation program is to maximize the functional performance at home, the actual performance of patients in their home environment is unknown [2]. Therefore, daily life monitoring of the quality of movement during functional activities of stroke survivors in their physical interaction with the environment is essential for optimal guidance of rehabilitation therapy, which goes beyond established activity monitors.

A system for daily life monitoring and assessment of the quality of movements should be a small wearable system, not be directly visible, not stigmatizing, and contain small and embedded sensors [3]. Wearable sensing systems using inertial sensors are already frequently used for the assessment of daily life activity [2, 4, 6, 8] .These types of systems are small and not restricted to a lab environment. We previously developed, via an iterative process, a modular sensor system for quantitative analysis of daily life activities of upper and lower extremity motor function [7, 9-10]. This system can be used to obtain knowledge about quality of movement of stroke patients during inclinic measurements and performing in a daily life setting.

It should be noted that several challenges remain in performing a quantitative analysis of daily life performance using wearable sensing, compared to clinically assess motor capacity using standardized clinical tests. First, metrics need to be developed that quantify relevant aspects of quality of movement during daily life. Metrics that are used in clinic to describe movements cannot directly be transferred to the evaluation of movements in a daily life setting. For instance, in clinical assessment scales, participants are instructed to reach as far as possible; while in a daily life setting, it might not be necessary to reach that far. A second challenge is the absence of context when measuring movements without any visual reference. During the evaluation of movements in a clinical or lab setting, it is known where and what kind of activities a participant is performing. This information is not available in a daily life setting. Therefore, a method is needed to classify the performed activities from the sensed 
signals. Finally, during continuous home measurements, a full body inertial sensor system will produce large amounts of movement data. Metrics and visualizations derived from these large amounts of data should be presented in a concise manner; otherwise, the evaluation of all data might be very time consuming for care-professionals.

The objective of this study is to develop data processing methods, which can be used to process movement data into relevant metrics for the evaluation of intra-patient differences in the quality of movements in clinic and in a daily life setting.

In a collaborative effort of care-professionals, researchers, and engineers, a requirements analysis on methods to assess daily-life quality of movements was performed. Subsequently, methods were developed that also should overcome mentioned challenges in the daily life assessment of movements. These methods include the estimation of metrics that show intra-patient differences in the quality of movements between in-clinic measurements and out- clinic measurements. These metrics will be demonstrated in two stroke participants during and after their rehabilitation phases. 


\section{MATERIALS AND METHODS}

This section is divided into six parts: (1) a requirement analysis, resulting in a coherent set of "must-haves"; (2) a description of the metric development process and the underlying theory, resulting in a coherent set of metrics; (3) a description of the sensor system for the assessment of daily life movements in stroke patients; (4) the development of an activity monitor to provide context to the captured movement data of stroke patients performing activities of daily living; (5) the presentation of vast amounts of movement data to care-professional, and (6) an analysis of intra- patient differences, for two cases, in quality of movements between structured in-clinic and unstructured daily life measurements, determined using the developed metrics.

\subsection{RequirementAnalysis}

As part of the European project called INTERACTION [7, 9-10], a requirement analysis was performed as a basis for the metric development. A questionnaire was sent out to selected care-professionals with a background in stroke rehabilitation in the Netherlands (response: $n=12$ ) and Switzerland (response: $n=4$ ). In addition, an interview in a round table setting was held with selected stroke patients $(n=3)$ in the Netherlands. Furthermore, a consensus meeting with project team members and advisory board (consisting of stroke patients, care-professionals, health insurance companies, and researchers) was organized. Based on the results from the questionnaire, the interviews, and the consensus meeting, and using the PACT (People, Activities, Contexts, and Technologies) [11] and FICS (Functionalities, Interaction, Context, and Service) [12] frameworks, user requirements and technical state of the art developments were translated into functional requirements and technical specifications. These requirements and specifications were divided into two groups, namely for lower extremity and upper extremity. The requirements and specifications were prioritized using the MoSCoW technique ("Must-have," "Should-have," "Couldhave," and "Won't have") [13]. These "must-have"-requirements were the basis for the methods development and are listed and labeled in Table 6. 
Table 6. "Must-haves" as a result of the requirement analysis ${ }^{\mathrm{a}}$

\begin{tabular}{|c|c|c|c|c|c|}
\hline & Lower extremity & Inc. $^{\mathrm{b}}$ & & Upper extremity & Inc. ${ }^{\mathrm{b}}$ \\
\hline & $\begin{array}{l}\text { Which activities are } \\
\text { performed? }\end{array}$ & & & $\begin{array}{l}\text { Which activities } \\
\text { are performed? }\end{array}$ & \\
\hline LE1 & Standing & Yes & UE1 & Reaching & Yes \\
\hline LE2 & Sitting & Yes & UE2 & $\begin{array}{l}\text { Grasping (with } \\
\text { gloves) }\end{array}$ & Yes \\
\hline \multirow[t]{2}{*}{ LE3 } & Walking & Yes & & & \\
\hline & Intensity of walking & & & $\begin{array}{l}\text { Intensity of } \\
\text { reaching }\end{array}$ & \\
\hline LE4 & Frequency of activities & Yes & UE3 & $\begin{array}{l}\text { Frequency of } \\
\text { activities }\end{array}$ & Yes \\
\hline LE5 & Duration of activities & Yes & UE4 & Duration of activities & Yes \\
\hline LE6 & Speed & Yes & UE5 & $\begin{array}{l}\text { Unilateral versus } \\
\text { bilateral activities }\end{array}$ & Yes \\
\hline \multirow[t]{2}{*}{ LE7 } & Covered walking distance & Yes & & & \\
\hline & Quantification of balance & & & $\begin{array}{l}\text { Quality of } \\
\text { movement }\end{array}$ & \\
\hline LE8 & Step length & No & UE6 & $\begin{array}{l}\text { Hand position } \\
\text { relative to pelvis }\end{array}$ & Yes \\
\hline LE9 & Relative feet position & No & UE7 & $\begin{array}{l}\text { Flexion and } \\
\text { extension in the } \\
\text { elbow }\end{array}$ & Yes \\
\hline LE10 & Stability during stance & No & UE8 & Shoulder abduction & Yes \\
\hline LE11 & $\begin{array}{l}\text { Stability during single } \\
\text { support }\end{array}$ & Yes & & & \\
\hline LE12 & Orientation of the feet & No & & & \\
\hline LE13 & $\begin{array}{l}\text { Center of mass movement, } \\
\text { relative to base of support }\end{array}$ & No & & & \\
\hline LE14 & Knee flexion and extension & No & & & \\
\hline LE15 & $\begin{array}{l}\text { Dorsal/plantar flexion of the } \\
\text { ankle }\end{array}$ & No & & & \\
\hline LE16 & Circumduction & No & & & \\
\hline
\end{tabular}

a When applicable, metrics will be evaluated for the affected and non-affected side.

b"Must-haves" that are included in the final set of data processing methods. 


\subsection{Design of Metrics}

An iterative design process was adopted to translate the "must- have"-requirements that are technically feasible into metrics the system must contain. These requirements were continually assessed and revised during the design phase of the project to ensure alignment between technical developments and users' needs. The design process included focus group sessions and teleconferences between engineers, careprofessionals, and researchers.

In total, 25 focus group sessions and 15 teleconferences were organized between 2014 and 2015, which included discussions and demonstrations of the metrics. Finally, a metrics-overview was created, which includes realizable "must-have" metrics for lower and upper extremities, as shown in Figures 21 and 22, which are further explained in the following sections.

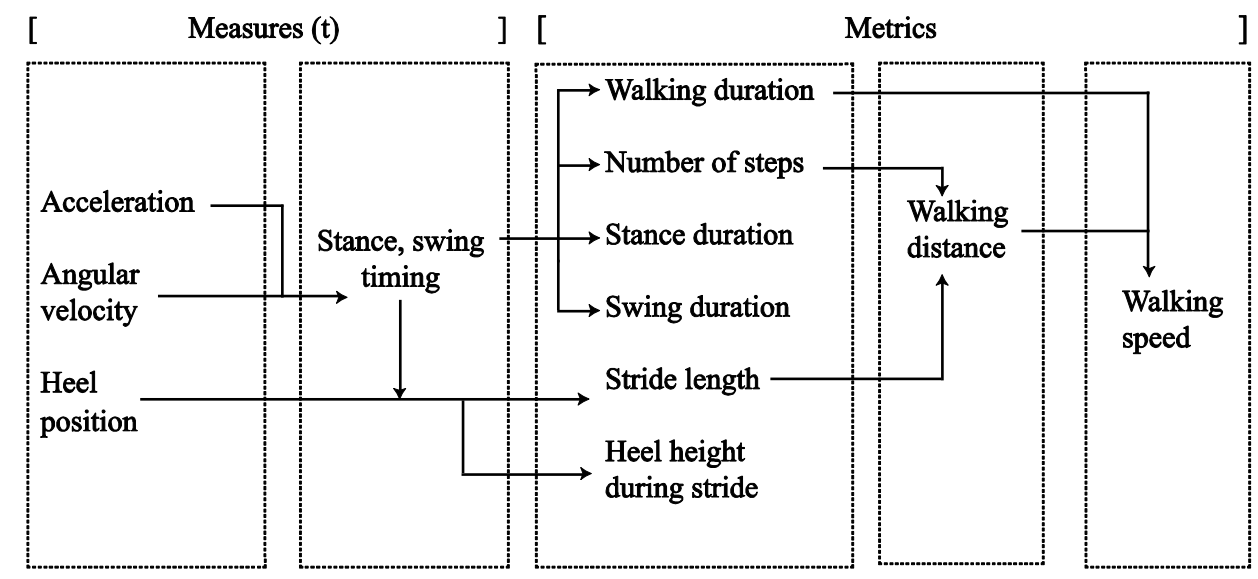

Figure 21. Lower extremity measures and metric relations. 


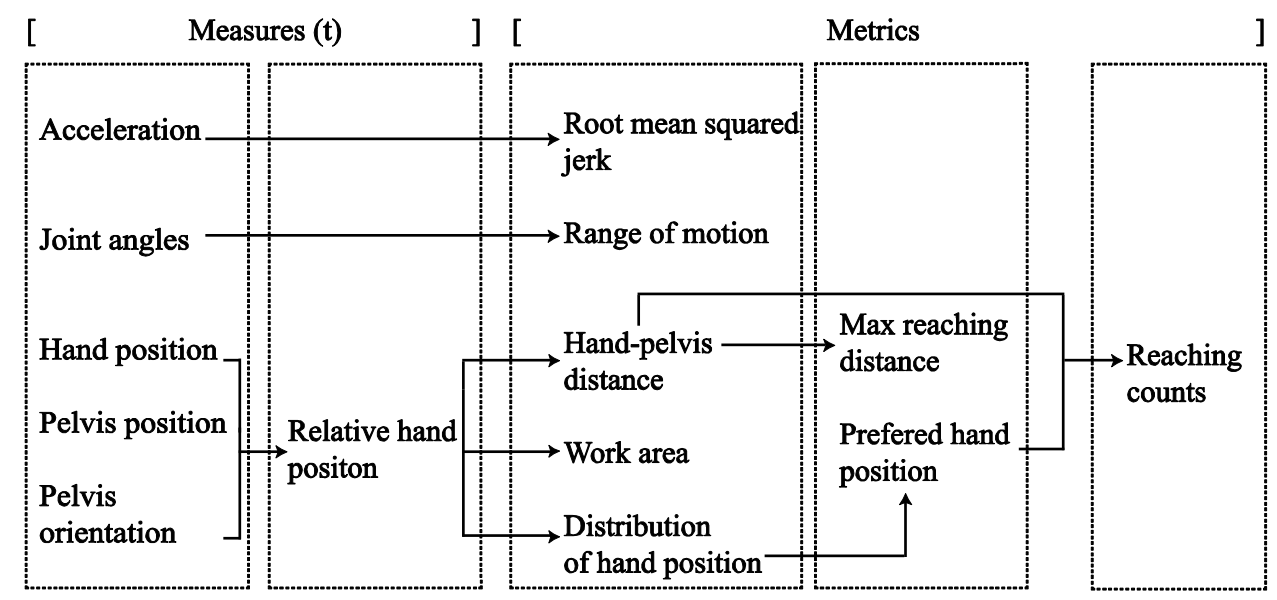

Figure 22. Upper extremity measures and metric relations.

\subsubsection{Lower Extremity Metrics}

The lower extremity metrics and their relation with system measures [14] are shown in Figure 21. All metrics, shown in Figure 21, were realized by evaluating the heel positions and by calculating the timing values of stance and swing during gait, utilizing a step detection algorithm [15]. Each metric is determined within a selected time window. The covered requirement walking distance (LE7) was directly rendered to the walking distance metric, by combining the number of steps and stride length as shown in Figure 21. Walking distance was included, as it is an important predictor for com- munity walking abilities in stroke patients [16-17]. The walking speed (LE6) requirement was included, which is regarded as a significant, sensitive, and reliable marker of deficit severity and functional community walking ability and results from the walking distance and walking duration metrics [18]. The frequency of activities (LE4) requirement was translated into the number of steps that a patient takes within a certain time. Furthermore, the duration of activities $\left(\mathrm{LE}_{5}\right)$ requirement was rendered to the walking duration metric. For quantifying balance during gait, focus was set on stability during single support (LE11) requirement, which includes stance and swing times. These classical gait parameters were implemented earlier by, e.g., Kuo and Donelan (2010), who explained the dynamic principles of gait and their clinical implications but also in other studies related to stroke [20-27].Variability in stance and swing time parameters predicts motor disability and, therefore, seems to be related to walking impairments and can be used as a quantifiable biomechanical marker to evaluate motor performance $([\mathbf{2 5 - 2 6 ]})$. Due to the limited accuracy of the sensor system [9] in estimating the relative feet position (LE9), step length (LE8) requirement 
was changed into stride length. Studies focusing on fall risks revealed that the stride length, the corresponding variability, and the swing time variability are key parameters for gait characteristics in elderly adults [28-29]. Stride length is based on the heel position of the foot, an output measure of the applied kinematic model, and the stance and swing timing values. The center of mass movement (LE13) and stability during stance (LE10) requirements were left- out of the final metric selection, due to the absence of any type of force sensing in the system. Finally, the heel-height profiles were added to the final metric selection, which resulted from discussions in the design process with care-professionals. These profiles are important to estimate the risk of falling and show imbalances and impairments during walking [29-30].

\subsubsection{Upper Extremity Metrics}

The upper extremity metrics target trunk, shoulder, and arm movements. Each of the measures and metrics associated with the upper extremity are shown in Figure 22. The quality of movement requirement hand position relative to pelvis (UE6) was rendered to the metrics: hand-pelvis distance, covered work area, and maxi- mum reaching distance for both hands. The hand positions were expressed in a coordinate frame relative to the pelvis orientation and position as described by van Meulen et al. (2015). The relative hand position measure was used to calculate the three- dimensional hand-pelvis distance and work area that patients are able to cover with their hands. In addition, the hand trajectory during a reaching movement was included. Finally, a newly developed metric named "hand distribution" was added as an extra quality of movement requirement, which visualizes the distribution of the patient's hand position in the transversal plane. The maximum reached distance and the size of the work area, the hand is able to cover, was investigated by van Meulen et al. (2015). They compared these metrics to the upper part of the Fugl-Meyer assessment scale and found a positive correlation. The reaching distance was also mentioned in an earlier study by Zariffa et al. (2012) and was also investigated by Balasubramanian et al. (2012), who provided a definition of reachable work space.

Another requirement is the flexion and extension in the elbow (UE7) and the abduction of the shoulder (UE8), which was quantified as the joint range of motion metric for the elbow and shoulder. Joint range of motion during functional movements was investigated in several studies [32-34] and the joint range of motion in complete simulated activities of daily living has also been described extensively in de los ReyesGuzmán et al. (2014). A final quality of movement metric was added, related to the smoothness of motion. For each reaching movement of the hand, a smoothness 
parameter, which is referred in this paper as the root mean squared jerk (RMSJ), is calculated based on the change in acceleration of the hand. The RMSJ, which normalizes the jerk over time, has been applied in several studies, including stroke patients [36-38]. The frequency of activities $\left(\mathrm{UE}_{3}\right)$ requirement was translated to a metric showing the number of reaching motions a patient has performed during a selected time period. The number of reaches provides an indication of the overall arm activity level during daily life. Although it is not mentioned in previous research on arm activity of stroke patients [39-40], reaching counts could provide insight in arm activity and, therefore, this is a new metric as well. A reaching activity was derived from the relative hand-pelvis distance and the preferred hand position within a certain measurement time frame during either sitting, standing, or walking.

\subsection{Sensor System Overview}

Figure 23 shows a flowchart of the main data processing steps. The modular sensor system that was previously developed for the assessment of movements in a daily life setting [7,9-10] consists of twelve Inertial Measurement Units (IMUs), each consisting of a three- dimensional accelerometer, gyroscope, and magnetometer. These IMUs are embedded in a garment consisting of a shirt, a pair of shoes, and a pair of trousers [10]. The IMUs are placed on the upper and lower arms, upper and lower legs, both feet, head, pelvis, and sternum. The data are collected at a sampling rate of $20 \mathrm{~Hz}$, which converted from a higher internal sensor sampling rate of $1800 \mathrm{~Hz}$ [9]. As part of the Xsens MVN studio software package (Xsens Technologies B.V., Enschede, the Netherlands, [14]), a full body kinematic model is used to process the captured sensor data and to estimate the three-dimensional body movements over time, including the position and orientation of each body segment as well as the joint angles. From there, selected metrics are computed, which are in turn fed into two filters. The first filter is a temporal selection filter, with which the time period of interest can be selected to analyze the data. The second filter is the activity monitor, which allows the evaluation of certain metrics for specific activities. All data processing steps are performed in an offline environment, using MATLAB ${ }^{\circledast}$ (MathWorks Inc., Natick, MA, USA). 


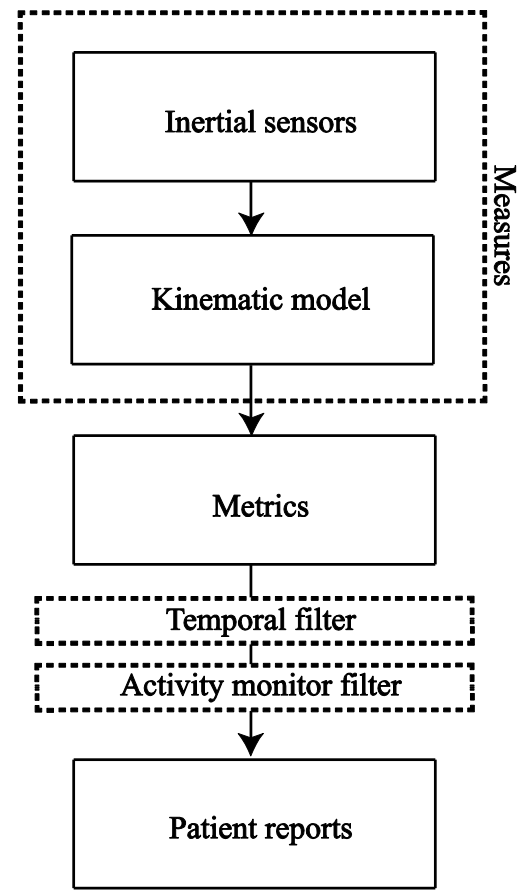

Figure 23. Data processing steps. From captured inertial sensor data to patient reports.

\subsection{Development of an Activity Monitor}

While performing activities of daily living, stroke patients are monitored unobtrusively while wearing a full sensor system. Since visual observation is not employed to monitor the patient, there is a lack of information about the context in which the different activities are performed by the patients. Several metrics are context dependent, such as walking speed or reaching distance. For example, estimating walking speed is only relevant when patients are walking. Another example is the evaluation of reaching distance that should be evaluated without including the arm swing during walking. In order to provide this context to the data, an activity monitor is required. The activity monitor acts as a filter and can be considered a separate step within our data processing methods.

The activity monitor was developed to apply metrics for a select type of movements, by detecting these movements based on the kinematic data. The activity monitor has two detection algorithms as shown in Figure 24. The first algorithm contains a posture 
detection (sitting or standing) and walking detection (cyclical or variable walking). The second algorithm contains an arm movement and reaching detection. Using a moving time window of 1 second, the type of posture is estimated. First, the classifier estimates if the patient is seated by evaluating both knee angles. If the flexion of both knees is more than 40 degrees for the entire second, it is concluded that the patient is seated. If the participant is not seated, the feet movement will be evaluated. Foot movement can be detected by applying a step detection algorithm and using accelerometer and gyroscope signals from the sensor on both feet [15]. If detected, it is inferred that the patient is walking, and if not, the patient is standing still. If walking is detected, a distinction is made between variable walking and cyclical walking (with exclusion of start and stop moments). Cyclical walking consists of at least three consecutive, alternating steps of the left and the right foot, while other types of feet movements are classified as variable walking.

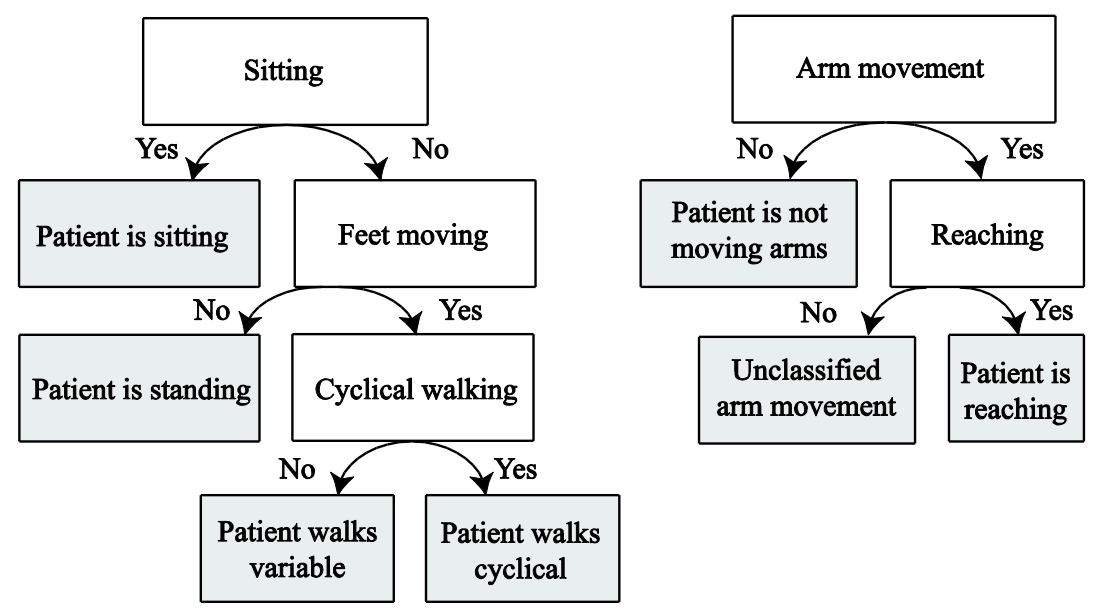

Figure 24. Decision tree of the activity classifier. The grey areas indicate classified activities.

Arm movement is detected by evaluating the three-dimensional hand movements relative to the pelvis. When the participant is seated and the three-dimensional hand displacement is more than $15 \mathrm{~cm}$ within a second (i.e., the average hand speed of at least $0.15 \mathrm{~m} / \mathrm{s}$ ), then that particular one second window will be annotated as one with hand movements of the specific arm. If the patient is walking (variable or cyclical), the three-dimensional hand displacement must be more than $25 \mathrm{~cm}$ within a second (i.e., the average speed of at least $0.25 \mathrm{~m} / \mathrm{s}$ ) for it to be considered a deliberate hand 
movement. A hand movement is classified as a reaching movement, when a hand displacement of more than $10 \mathrm{~cm}$ is away from the preferred hand position (the average hand position relative to the pelvis). To evaluate the performance of the activity monitor, two independent reviewers manually classified four example data sets. Each data set, of a duration of $5 \mathrm{~min}$, includes activities of daily living. By reviewing the kinematic reconstruction of the data, as with the activity monitor, the reviewers determined for each second the posture (sitting, standing, variable walking, or cyclical walking) of the patient and if the affected and/or non-affected arm is moving. The overall agreement between the reviewers was $85.5 \%$ of the time. Of these cases where there is an agreement between both reviewers, $86.3 \%$ was also in agreement with the activity monitor.

\subsection{Presenting Large Amounts of Data}

A large amount of movement data can be collected. At the same time, our methods must present clinically relevant, usable, and interpretable data to the health professional in order to assist clinical decision making and improve the rehabilitation program. Therefore, large amounts of data have to be presented in a concise way by, for example, using descriptive statistics and data distribution methods. The resulting set of metrics contains different types of data, each presented differently to the careprofessional. We can summarize the data by using overall statistics (mean and SDs), show distributions in box plots, present relative differences for the affected and nonaffected side in a ratio, or visualize body movement in graphs. These methods make it possible to aggregate potentially large amounts of data. For the lower extremities, the mean and SD of stance and swing times, and stride lengths per foot are estimated (including all strides). The ratio of the metric values between the affected and nonaffected side are also presented for the number of steps, stance and swing duration, and stride length. Box plots are created for the stance and swing durations for multiple steps of each foot. A single statistic is shown for the walking distance, duration, and walking speed. Visualizations are presented for the heel height during walking. These stride profiles show the heel height and distance of each stride during cyclical walking. They are derived from the heel position measures and the stance and swing times as described in Figure 21. The three-dimensional trajectories of each stride are projected onto a two-dimensional plane for visualization by rotating the stride trajectory in such way that all strides are oriented in the samedirection. For the upper extremities, the mean and SD are calculated for all metrics during a reaching movement. The ratios between affected and non-affected arm are calculated for the elbow and shoulder range of motions, work area, maximum reaching distance, and reaching counts. 
Hand-pelvis trajectories during reaching, which show the norm of the threedimensional relative hand displacement over time during reaching, and the distribution of the hand position within the transversal plane are visualized. The hand distribution plots combine spatial and temporal information of arm movements, which is useful as not only is the area a patient can cover with his hand (with respect to the pelvis) of interest but also how frequent and for how long the hand is at a certain position. By utilizing a two-dimensional histogram plot that makes it possible to visualize the distribution of patients' hand positions during a whole measurement. The frequency the hand is at a certain position is indicated by colour, where light is less frequent and dark is the most frequent position.

\subsection{Patient Evaluation}

To evaluate the metrics and to show its ability to distinguish between a stroke patient's quality of movement while performing structured movements in clinic and performing unstructured activities of daily living, three metrics were selected for which large differences were expected. The metrics are as follows: heel height profiles, hand distribution plots, and the total work area. The data of two participants ( $\mathrm{P}_{1}$ and $\mathrm{P}_{2}$ ) were selected, as an example to demonstrate the potential functionality of the metrics. $\mathrm{P}_{1}$ is a 35 -year-old male and $\mathrm{P}_{2}$ is a 50 -year-old woman. Both patients are left-side affected and have a dominant right side. The main focus for P1 was on the evaluation of lower extremity functions. The main focus for $\mathrm{P}_{2}$ was on the evaluation of upper extremity function. The study protocol is a subset of a larger protocol that was approved by the local cantonal medical and ethical committee (registered in ClinicalTrials.gov identifier: NCTo2118363). The participants were recruited from Cereneo A.G., Centre for Neurology and Rehabilitation (Vitznau, Switzerland) and gave written informed consent in accordance with the declaration of Helsinki. Two measurement sessions were selected within the rehabilitation program of both patients for which large differences were observed as the rehabilitation progressed. The first session includes a clinical assessment measurement that was captured in clinic at discharge and consisted of a 10-meter walk test [44] for $\mathrm{P}_{1}$ and a predefined arm task for P2. This predefined arm task consisted of several arm movements, where the patient had to reach as far as possible and to make a circle as wide as possible over a table. The second session includes a measurement session of three hours of movement data, which was captured at the patient's home four weeks after discharge. Finally, these measurement sessions were compared with each other for each patient individually. 


\section{RESULTS}

\subsection{Activity Monitor}

In Figure 25, an example of the activity monitor and a summary report of activities are shown of $\mathrm{P}_{2}$ while performing activities of daily living at home. Each activity classification is plotted as function of time. In total, 201 min of data are analyzed, where the patient was seated for $96 \mathrm{~min}$, standing for $29 \mathrm{~min}$, and walking for $26 \mathrm{~min}$. Data show a difference in arm usage, the non-affected arm was moving in $21 \%$ of the total time, while the affected arm was only moving $7 \%$ of the total time. 

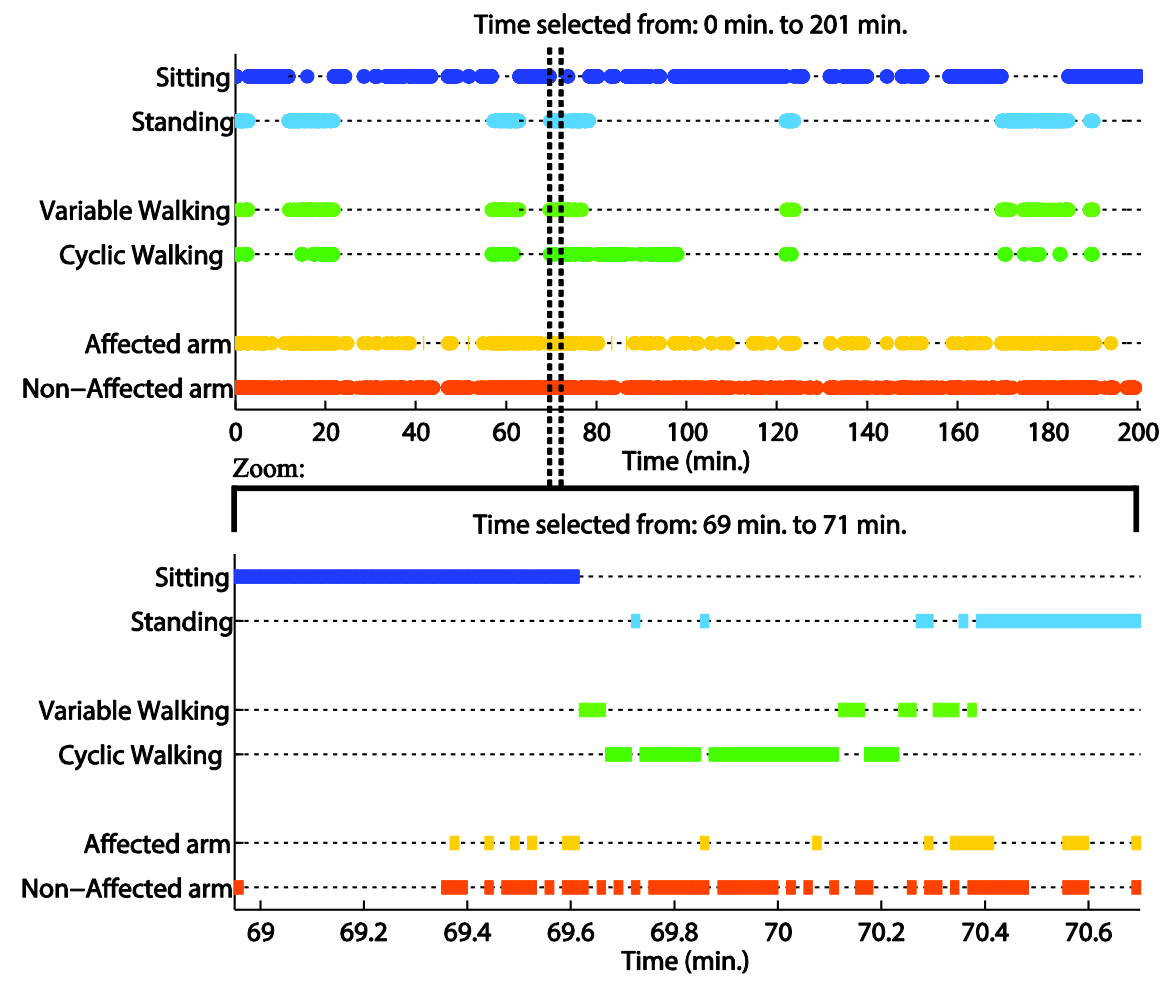

\begin{tabular}{|lllll|}
\hline Total time selected: 201 min. & Time $(\min )$. & \multicolumn{3}{l|}{$\%$ - of Total time } \\
Posture & Sitting: & 95.6 & 47.6 & $\%$ \\
& Standing: & 28.7 & 14.3 & $\%$ \\
& & & & \\
\multirow{4}{*}{ Walking } & Total: & 26 & 13 & $\%$ \\
& Variable: & 7.42 & 3.7 & $\%$ \\
& Cyclical: & 18.6 & 9.26 & $\%$ \\
& Arm & 14.4 & 7.2 & $\%$ \\
& Affected: & 41.9 & 20.9 & $\%$ \\
& Non-Affected: & & & \\
\hline
\end{tabular}

Figure 25. Example report of the activity monitor of a measurement session of $\mathrm{P}_{2}$, performing activities of daily living. First a summary report of all activities during the whole measurement is shown in the table, where the activity times are mentioned in minutes and as percentage of the total duration of the measurement session. The first graph shows the activity classification as a function of time for the whole measurement. A zoom of a selected time period is given in the lower graph. In this selection, the patient is first seated, next raises up from a chair, walks in a cyclical pattern (at least three consecutive alternating steps of both feet), and finally stands still. During this period, the non-affected arm is used more frequently than the affected arm. 


\subsection{Lower Extremity Results of P1}

The lower extremities analysis of the heel height profile are presented for a 10 meter walk test in clinic as shown in Figure 26A and are compared with a selection where the patient is walking cyclical at home shown in Figure 26B. For each step, the heel height as function of distance (stride length) is shown for the left (affected side) and right foot. The length of all strides for both feet of the participant are longer during the 1o MWT than during the measurement at home and the walking speed is lower 0.85 and $0.42 \mathrm{~m} / \mathrm{s}$ respectively. The stride profile during the 10 MWT seems more equal for both feet as compared with the in-home measurement. In-home measurements show a stride profile that differs between the left and the right heel (non-affected side), showing a larger heel height and a steeper curve for the right heel.
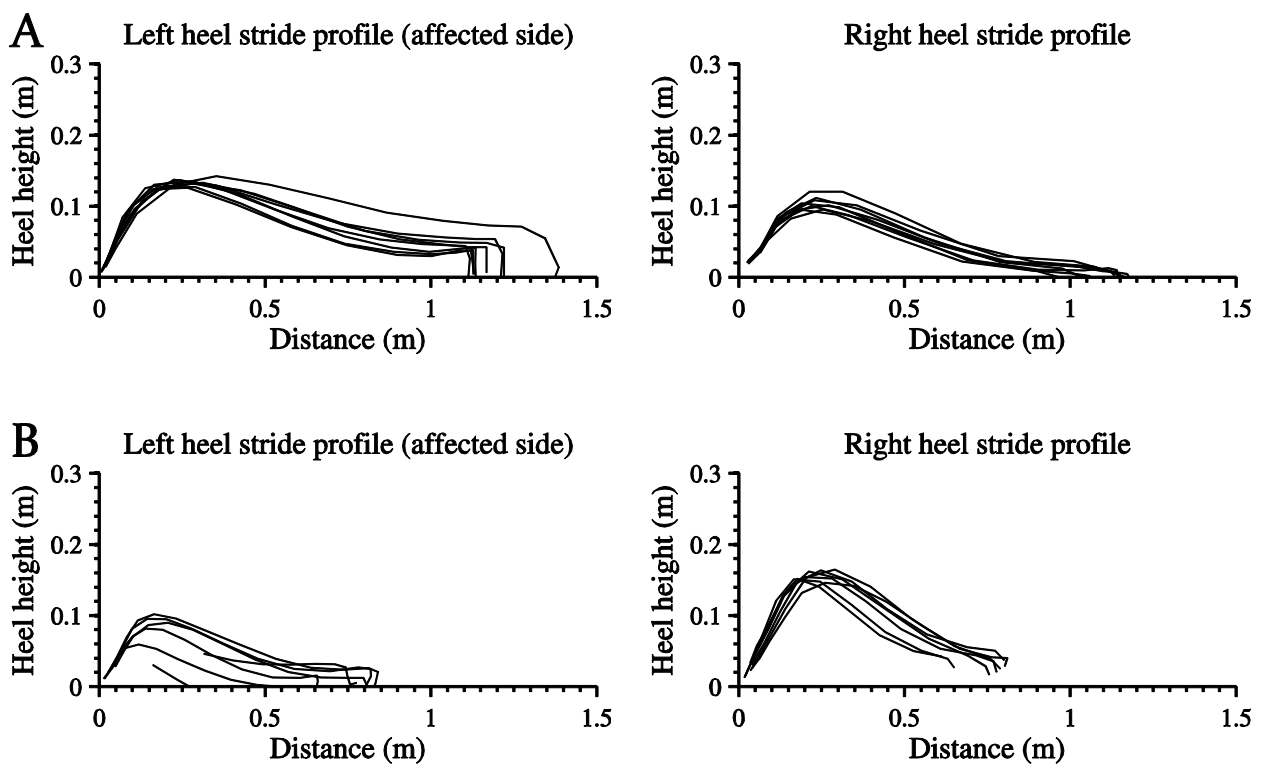

Figure 26. Heel stride profiles during a structured and unstructured measurements of the left (affected side) and right foot. Each line indicates a three-dimensional stride profile, rotated and projected onto a two-dimensional plane, starting at the origin of the graph. (A) Shows a 10-m walk test, a structured in-clinic measurement. (B) Shows an unstructured in-home measurement, where the patient walked in a straight line. 


\subsection{Upper Extremity Results of $\mathrm{P}_{2}$}

The distribution of hand positions relative to the pelvis is visualized for $\mathrm{P}_{2}$ in Figure 27, where each graph is divided into quadrants. The colours indicate the total time during the selected time slot at which the hand is in a certain position, where a darker colour is a longer time. Figure $27 \mathrm{~A}$ shows the predefined arm task for the affected and non-affected arm captured at discharge. Figure $27 \mathrm{~B}$ shows a measurement session at home, while the patients perform different activities of daily living for $201 \mathrm{~min}$ (of which the activity report is presented in Figure 25). For both figures, the total area the patient was able to cover is shown in the lower right corner of the graph. During the predefined arm task, the patient is able to cover a larger area with the non-affected right $\operatorname{arm}\left(0.57 \mathrm{~m}^{2}\right)$ than the left arm $\left(0.46 \mathrm{~m}^{2}\right)$. The patient was able to reach further and cover more area to the contralateral side using the non-affected right hand than with the left hand. Furthermore, $\mathrm{P}_{2}$ is able to reach more behind the pelvis with the right hand. In the home measurement, the right hand is able to cover a larger area (0.91 $\left.\mathrm{m}^{2}\right)$ than the left hand $\left(0.55 \mathrm{~m}^{2}\right)$. In these home measurements, a large difference is found in reaching movements of the right behind her pelvis compared to the left hand. The resting position of the right hand (indicated by a dark area) is more in front of the pelvis, where the left hand is closer and more along the patient's body. 

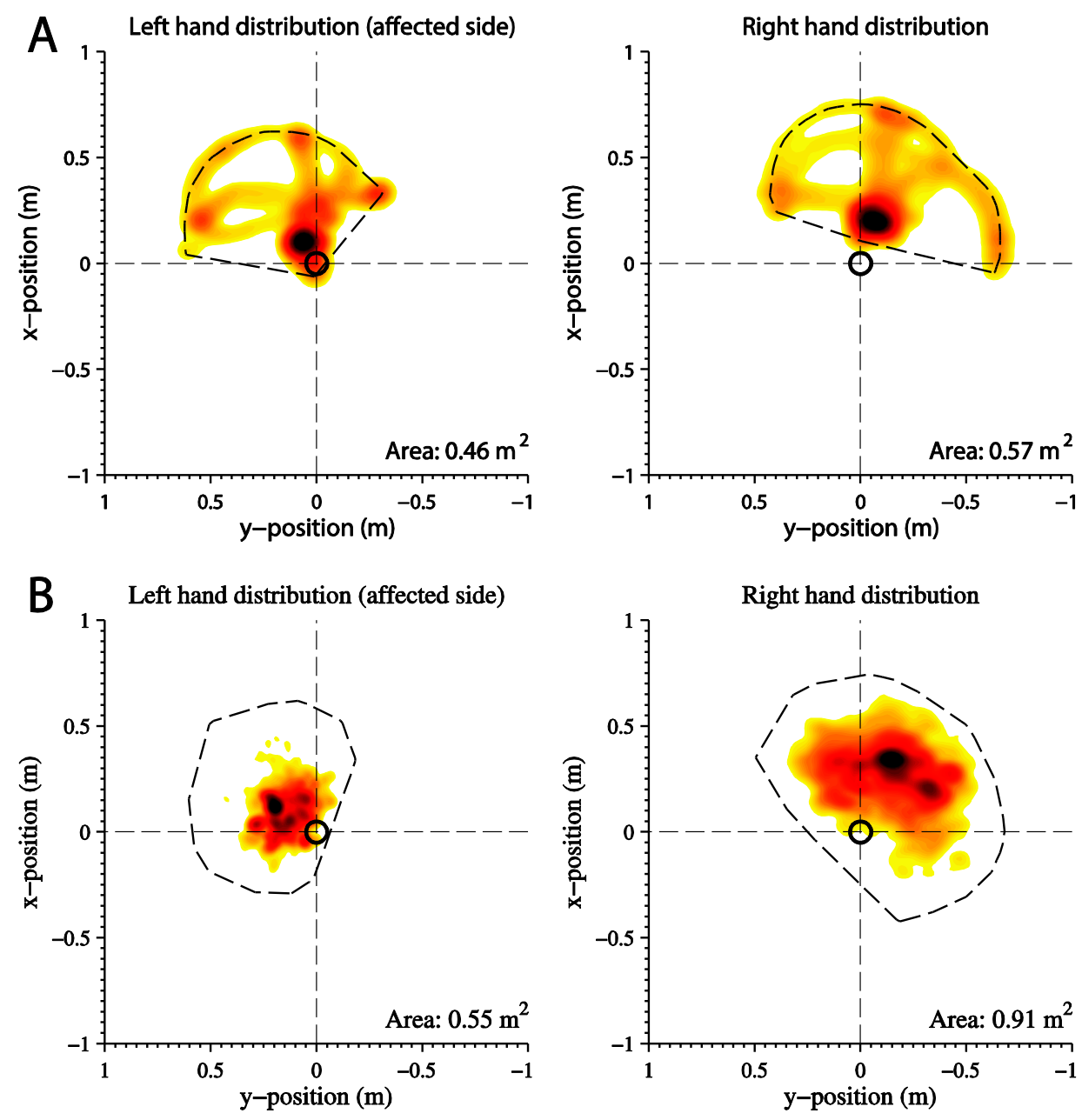

Figure 27. Distribution of the hand positions relative to the pelvis (origin of the graph, indicated with a black circle) in the transversal plane, of the left (affected side) and right hand. (A) Structured in-clinic measurement; (B) Unstructured in-home measurement. A darker color indicates a higher frequency of a specific hand position during the measurement session. A lighter color indicates a less frequent hand position at a particular location. The total work area is contoured with a dotted line and the area size is shown in the bottom right corner of each graph. The activity report of the unstructured in-home measurement is shown in Figure 25. 


\section{DISCUSSION}

Objective evaluation of the quality of daily life movements and intra-patient differences, using a body-worn sensing system, could be very challenging. While measuring in a daily life setting, no context on performed activities is available. Furthermore, suitable metrics are necessary to quantify relevant aspects of movement performance during daily life. Within this paper, we presented data processing methods to evaluate quality of movement. Presented methods can be used for the objective evaluation of intra- patient differences in movement quality between inclinic measurements (more structured measurements in a controlled environment) and measurements in a daily life setting (unstructured measurements in an uncontrolled environment). The selection of metrics is based on discussions with care professionals, engineers, and researchers. To be able to make a distinction between metric values during different activities, an activity classifier was developed, which classifies different types of posture and arm activity. Finally, methods were developed to present large amounts of data in a concise manner. As example to demonstrate potential of presented methods, data of two stroke patients were analyzed. Differences between in-clinic measurements (at the moment of discharge) and measurements during daily life (4 weeks after discharge) can be observed by applying the presented metrics and visualization methods. In the near future, any observed intra-patient progression or deterioration of movement quality could be used to decide on continuing, stopping, or adjusting rehabilitation programs. Future research should demonstrate the usability of suggested methods in more patients and how the objective information $\mathrm{n}$ on quality of movement can be used in clinical practice. Several limitations in the presented work should be acknowledged. First, differences between assessed movements during in- clinic measurements and measurements during daily-life might be the result of the different circumstances in which the data are captured. In clinic, patients were instructed to perform a specific task that might force them to, for instance, use their affected side or walk at a specific speed. While during daily life measurements, when no specific instructions were given, it can be expected that patients will execute tasks in a most comfortable way. This may result in, e.g., a reduced usage of their affected arm, a reduced walking speed, or smaller steps. Therefore, intra-patient difference might be expected on the affected and non-affected side, however, the proposed methods can still be used to describe relative difference between their affected and non-affected side for different measurements. Second, the applied activity classifier determines only a limited number of activities (posture: sitting, standing, walking, and arm movements). This selection of activities was the 
result of the requirement analysis that focused on assessing quality of movements, but detection of other activities is possible as well. Previous research showed many options for identification of activities, using inertial sensors [41-42]. Within the presented data processing method, it is possible to replace the activity monitor filter (as in Figure 23) with a different activity classifier to identify and evaluate other activities of interest. Third, due to technical limitations, the inertial-based sensor system could only be used for measuring daily life movements up to threehours. Within this limited period of time, no significant change in movement performance was expected. When measuring for longer periods of time, physical activity may change during one measurement session.

In addition to the presented work, future research should focus on the unobtrusiveness by reducing the number of sensors, which makes the system more applicable for the assessment of daily life movements. Data of twelve inertial sensors and a full body kinematic model are used to estimate movements of all body segments. Generally, more sensors may increase the validity of activity detection and accuracy in motion analysis. Depending on the metrics of interest, sensor reduction is possible while remaining almost the same validity and accuracy [2]. The currently used sensor system is modular, which allows the reduction of the number of sensors by using only the lower or upper part of the sensor set depending on the metrics of interest. Besides the number of sensors within this, modular part may be decreased. For instance, the number of sensors in the lower extremity module of the sensor system can be reduced to only one inertial and an additional ultrasound sensor on each foot. Using this reduced sensors system, it is already possible to estimate the same metrics that are presented in the current study [43]. Furthermore, in addition to the evaluation of movements of stroke patients, the presented data analysis methods might be useful for other group of patients, for instance, elderly people, Parkinson's disease, multiple sclerosis, and other neurological diseases. Daily-life assessment of their quality of movement might give more insight on the influence of the patient's condition at performing activities of daily living.

\section{Author contributions}

FM and BK developed and tested the algorithms and drafted the manuscript. BK, JH, and AL provided the data of the stroke participants. JH, JR, JB, AL, B-JB, and PV assisted with data interpretation, helped to develop the algorithm, and helped to draft the manuscript. AL and PV supervised the research. All authors read and approved the final manuscript. 


\section{Acknowledgements}

The authors would like to thank all study participants from Cereneo A.G., Centre for Neurology and Rehabilitation (Vitznau, Switzerland) and all care-professionals, researchers, and scientists, who participated in the requirement process. The authors also would like to thank Albert Eenhoorn and Irene Christen for their assistance during the measurements.

\section{Funding}

This study was part of the INTERACTION project, which was partially funded by the European Commission under the 7th Framework Programme (FP7-ICT-2011-7-287351)

\section{Conflict of Interest Statement}

The authors declare that the research was con- ducted in the absence of any commercial or financial relationships that could be construed as a potential conflict of interest. 
Chapter 5: Usability evaluations of a wearable sensing system and resulting metrics for stroke survivors by care-professionals

\title{
Chapter 5
}

\section{USABILITY EVALUATIONS OF A WEARABLE SENSING SYSTEM AND RESULTING METRICS FOR STROKE SURVIVORS BY CARE-PROFESSIONALS}

\author{
B.Klaassen ${ }^{1,2}$, B.J.F. van Beijnum ${ }^{1,2}$, J.P. Held ${ }^{1,3,6}$, J.Reenalda ${ }^{4,5}$, \\ F.B. van Meulen', P.H. Veltink, ${ }^{1}$ H. J. Hermens ${ }^{1,2,4}$
}

${ }^{1}$ Biomedical Signals and Systems, MIRA - Institute for Biomedical Technology and Technical Medicine, University of Twente, Enschede, the Netherlands.

${ }^{2}$ Centre for Telematics and Information Technology, University of Twente, Enschede, The Netherlands.

${ }^{3}$ Division of Vascular Neurology and Neurorehabilitation, Department of Neurology, University Hospital of Zurich, Zurich, Switzerland.

${ }^{4}$ Roessingh Research and Development, Roessingh Rehabilitation Hospital, Enschede, The Netherlands.

${ }^{5}$ Biomechanical engineering, MIRA - Institute for Biomedical Technology and Technical Medicine, University of Twente, Enschede, The Netherlands.

${ }^{6}$ Cereneo A.G., Center for Neurology and Rehabilitation, Vitznau, Switzerland. 
Chapter 5: Usability evaluations of a wearable sensing system and resulting metrics for stroke survivors by care-professionals

\section{AbSTRACT}

Background Inertial motion capture systems are used in many applications such as measuring the movement quality in stroke survivors. The absence of clinical effectiveness and usability evidence in these assistive technologies into rehabilitation has delayed the transition of research into clinical practice. Recently, a new inertial motion capture system was developed in a project, called INTERACTION, to objectively measure the Quality of Movement (QoM) in stroke survivors during dailylife activity. Resulting QoM metrics, where a metric is defined as a measure of some property, are subsequently presented to care-professionals. Metrics include for example: reaching distance, walking speed and hand distribution plots. The latter shows density plot of the hand position in the transversal plane. The objective of this study is to investigate the opinions of care-professionals in using these metrics obtained from INTERACTION and its usability.

Methods By means of a semi-structured interview, two patient reports, which include several QoM metric (like reaching distance, hand position density plots, shoulder abduction) results obtained during daily-life measurements in clinic, and were evaluated by care-professionals not related to the project. The results were compared with care-professionals involved within the INTERACTION project. Furthermore, two questionnaires ( 5 point Likert and open questionnaire) were handed over to rate the usability of the metrics and to investigate if they would like such a system in their clinic.

Results Eleven interviews were conducted, where each interview included either 2 or 3 care-professionals as a group, in Switzerland and the Netherlands. Evaluation of the case-reports by participants and INTERACTION members showed a high correlation for both lower and upper extremity metrics. Participants were most in favour of hand distribution plots during daily-life activities. All participants mentioned that visualising QoM of stroke survivors over time during daily-life activities, has more possibilities compared to current clinical assessments. They also mentioned that these metrics could be important for self-evaluation of stroke survivors. 
Chapter 5: Usability evaluations of a wearable sensing system and resulting metrics for stroke survivors by care-professionals

Discussion The results showed that most participants were able understand the metrics presented in the case-reports. For a few metrics, it remained difficult to assess the underlying cause of the QoM. Hence, a combination of metrics is needed to get a better insight of the patient. Furthermore, it remains important to report the state (e.g. how the patient feels), its surroundings (outside, inside the house, on a slippery surface) and detail of specific activities (does the patient grasps a piece of paper or a heavy cooking pan but also dual tasks). Altogether, it remains a questions how to determine what the patient is doing and where the patient is doing his or her activities. 
Chapter 5: Usability evaluations of a wearable sensing system and resulting metrics for stroke survivors by care-professionals

\section{INTRODUCTION}

Inertial motion capture systems are used in many applications such as measuring the quality of movement (QoM) in patients with neurological conditions, seen as assistive technologies in healthcare, and capturing body movements for e.g. film animation and games. Recently, a new ambulant full body inertial motion capture system was developed in a project, called INTERACTION, to objectively measure the QoM in stroke survivors during daily-life activities [1-3]. Daily-life monitoring of the QoM during functional activities of stroke survivors in their home environment is important, as it is essential for optimal guidance of rehabilitation therapy [4]. The resulting metrics of extremity function, as presented by Klaassen and van Meulen et al., 2016 and listed in Table 9, were clinically evaluated by care-professionals with expertise in stroke rehabilitation related to the project.

The INTERACTION system is composed of a full body sensor suit with 14 inertial sensors specifically designed for stroke survivors to be measured at home during dailylife activities [1]. It consists of a shirt, trousers, and a pair of shoes and is wireless connected to a tablet with the functionality to upload the data to a remote server for data processing. Although the INTERACTION system consist of different type of sensing modules, only the inertial sensors are used to compute the resulting metrics included in this study, as presented in van Meulen and Klaassen et al, 2016. A software package was developed to analyse the data, which includes an activity monitor, movement visualizer and several metrics for the QoM. The algorithms within the software currently only utilizes the inertial sensors. The package generates casereports for each patient measurement as described in van Meulen and Klaassen et al, $2016[2]$.

Although (full body) motion capture systems are used in some specialised clinics for a better understanding of patients, such as Qualisys mocap systems [5], the absence of clinical effectiveness and usability evidence in assistive technologies, e.g. motion capture and telemonitoring systems, into rehabilitation has delayed the transition of research into general clinical practice [6-7]. The potential for these technologies in clinical practice is determined by a complex interaction between clinical and cost-effectiveness; commercial availability of devices; funding and user acceptance including patients, their careers, healthcare professionals, funders and manufacturers [6-7]. Furthermore, key barriers that were found to translate assistive technologies into clinical practice are lack of knowledge, education, awareness and access. Improvements in assistive technology design, clinical evaluation, knowledge, 
Chapter 5: Usability evaluations of a wearable sensing system and resulting metrics for stroke survivors by care-professionals

awareness and in provision of services will contribute to a better and cost-effective stroke rehabilitation [8].

Therefore, it is useful to perform a field study to investigate if care-professionals from other rehabilitation centres, not involved in the project, are able to use the outcome measures from an inertial motion capture system, like the INTERACTION system, in their clinical practice.

The objective of this study is to investigate the opinions of care-professionals in using metrics obtained from INTERACTION system and their usability. In particular, the focus of this study is on the interpretation of the QoM metrics for lower and upper extremity, compared to existing clinical methods and if a system like INTERACTION, including a full body suit with many sensors, can be used in a variety of clinical practices. By means of a semi-structured interview, the evaluation of two case reports by care-professionals involved in INTERACTION was compared with the evaluation of care-professionals outside the project. Furthermore, two questionnaires were handed over to rate the metrics of extremity function in terms of their liking and an open questionnaire to investigate if they would like to use a full body motion capture system in their clinic. 
Chapter 5: Usability evaluations of a wearable sensing system and resulting metrics for stroke survivors by care-professionals

\section{MATERIAl \& MethodS}

Within the INTERACTION project, patient Case-Reports (CR) were constructed. Each report consists of results of a stroke survivor measured with the INTERACTION system in the form of metrics [1-2]. Within each set of INTERACTION measurements, the patient's QoM was estimated at home, performing daily activities, and in clinic during frequently used clinical tasks: Timed-Up-and-Go (TUG) [9] and the upper Extremity part of the Fugl-Meyer Assessment (FMA-UE) [10]. The measurements were part of a larger study from INTERACTION [2]. The results of these measurements were summarized in a case-report for each patient. Care-professionals involved in the INTERACTION project evaluated these case-reports.

During a semi-structured interview, two of these case-reports, one for the lower extremities and one for the upper extremities, were presented to care-professionals from outside the project. Furthermore, a ranking questionnaire and an open questionnaire were given to gain more insight in the use of inertial motion capture systems, such as the INTERACTION system, in clinic and the resulting metrics for therapy.

\subsection{Case reports}

Two CR were generated, where measurement sessions were selected within the rehabilitation program of two patients to construct the CR. One for the lower extremity (CR1) and one for the upper extremities (CR2). The study protocol of obtaining patient data is a subset of a larger protocol that was approved by the local cantonal medical and ethical committee (registered in ClinicalTrials.gov identifier: NCTo2118363). Each report includes the results, in the form of metrics, of a stroke survivor measured with the INTERACTION system in clinic during several days, and at home over a time period of three months. In addition, traditional clinical assessment scores of the patient were obtained from the clinic.

The upper and lower extremity metrics were presented in van Meulen and Klaassen et al, 2016. In short, the following metrics were included for the lower extremities: heel stride profiles, which shows the heel height and stride length plotted for each stride, and walking speed. For the upper extremity metrics the following metrics were selected: reaching distance (hand-sternum distance), reaching area (area in which the patient moves their hand in transversal plane), range of motion of the shoulder and 
Chapter 5: Usability evaluations of a wearable sensing system and resulting metrics for stroke survivors by care-professionals

hand distribution plots. Hand distribution plots are a new type of metric designed for INTERACTION that shows spatial and temporal information of the hand position relative to the pelvis in the transversal plane. . The color shown in these distribution plots are mapped to the duration the hand was positioned in a specific location. No activity monitor results, as described in van Meulen en Klaassen et al, 2016, were shown to reduce the amount of data to be presented to the participants. An example of a case-report is shown in Appendix 1, Figure 30 and 31. Care-professionals were recruited from five different treatment centres: Roessingh Rehabilitation Center (Enschede, The Netherlands), Cereneo A.G., Centre for Neurology and Rehabilitation (Vitznau, Switzerland), University Hospital Zurich (Zurich, Switzerland), Physiotherapy Praxis Meilen (Herrliberg, Switzerland) and Fysio-Holland (Enschede, The Netherlands). These centres were selected because of the expertise they provide in rehabilitation of stroke survivors. In this study, care-professionals had no past involvement with the INTERACTION project, but needed to have experience with stroke survivors and are actively involved in rehabilitation. The decision was made to perform the semi-structured interview with care-professionals in pairs, to encourage discussions which could lead to potentially more insight in the data. Written Informed consent was given, but no ethical approval was needed as no medical intervention took place.

\subsection{Evaluation protocol}

Each interview was done by the same person, following the four steps mentioned below. The interview was captured on a digital field recorder for later analysis. First, information about the INTERACTION project, including a flyer about the system (with pictures and features), and a description of this study was handed over as shown in Figure 28 and 29. Second, an inform consent form was presented and explained to the care-professionals. After informed consent was given, the evaluation started and the digital field recorder was turned on. Third, a semi-structured interview was held, guided by a presentation on a laptop, aimed to last one hour. Finally, a 5 points Likert questionnaire [11] and an open questionnaire were filled in. 
Chapter 5: Usability evaluations of a wearable sensing system and resulting metrics for stroke survivors by care-professionals

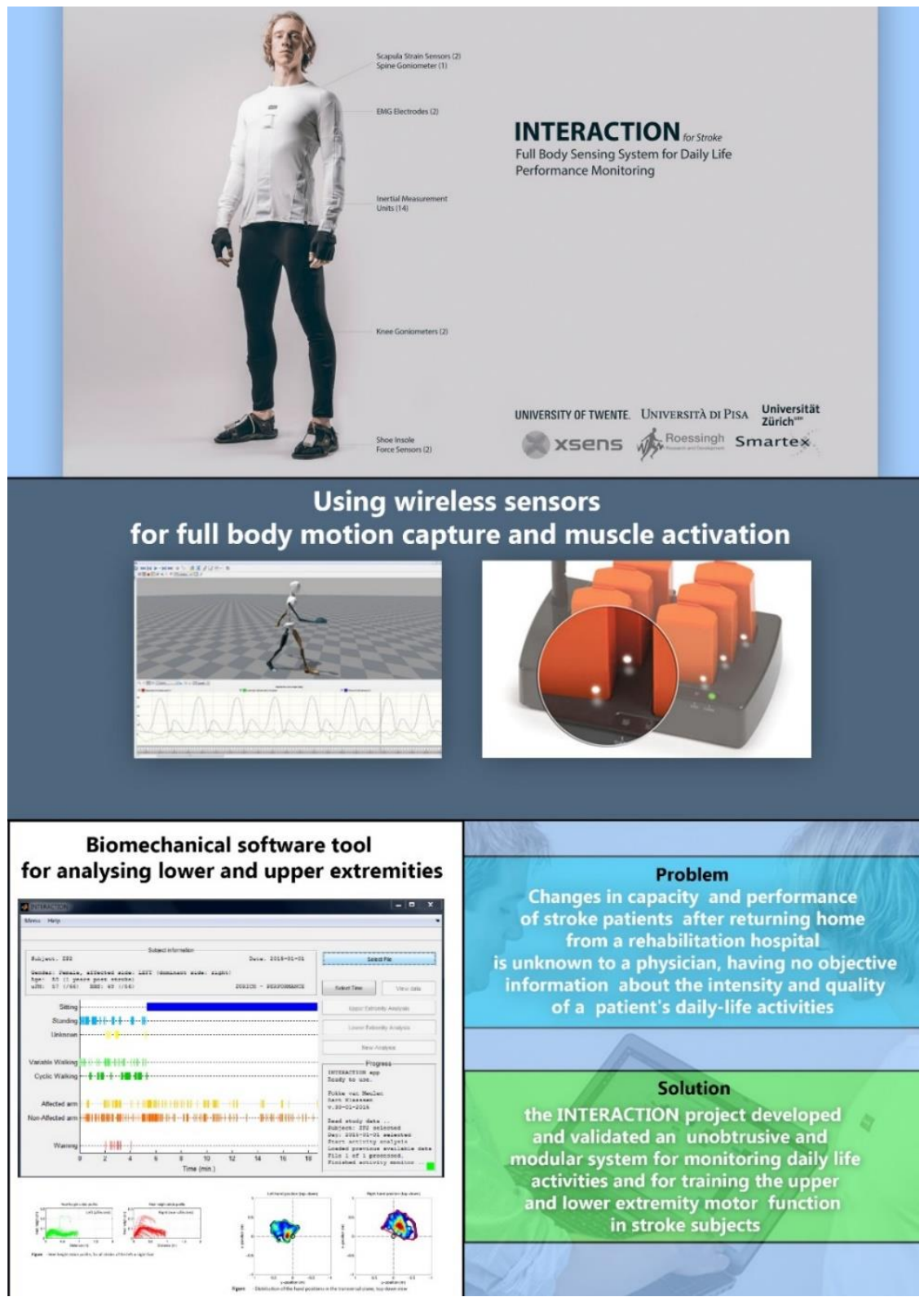

Figure 28. Flyer of the INTERACTION project showing the sensor suit, sensors, software (with activity monitor and case report generator) and the main objectives of the INTERACTION project and solutions. 
Chapter 5: Usability evaluations of a wearable sensing system and resulting metrics for stroke survivors by care-professionals

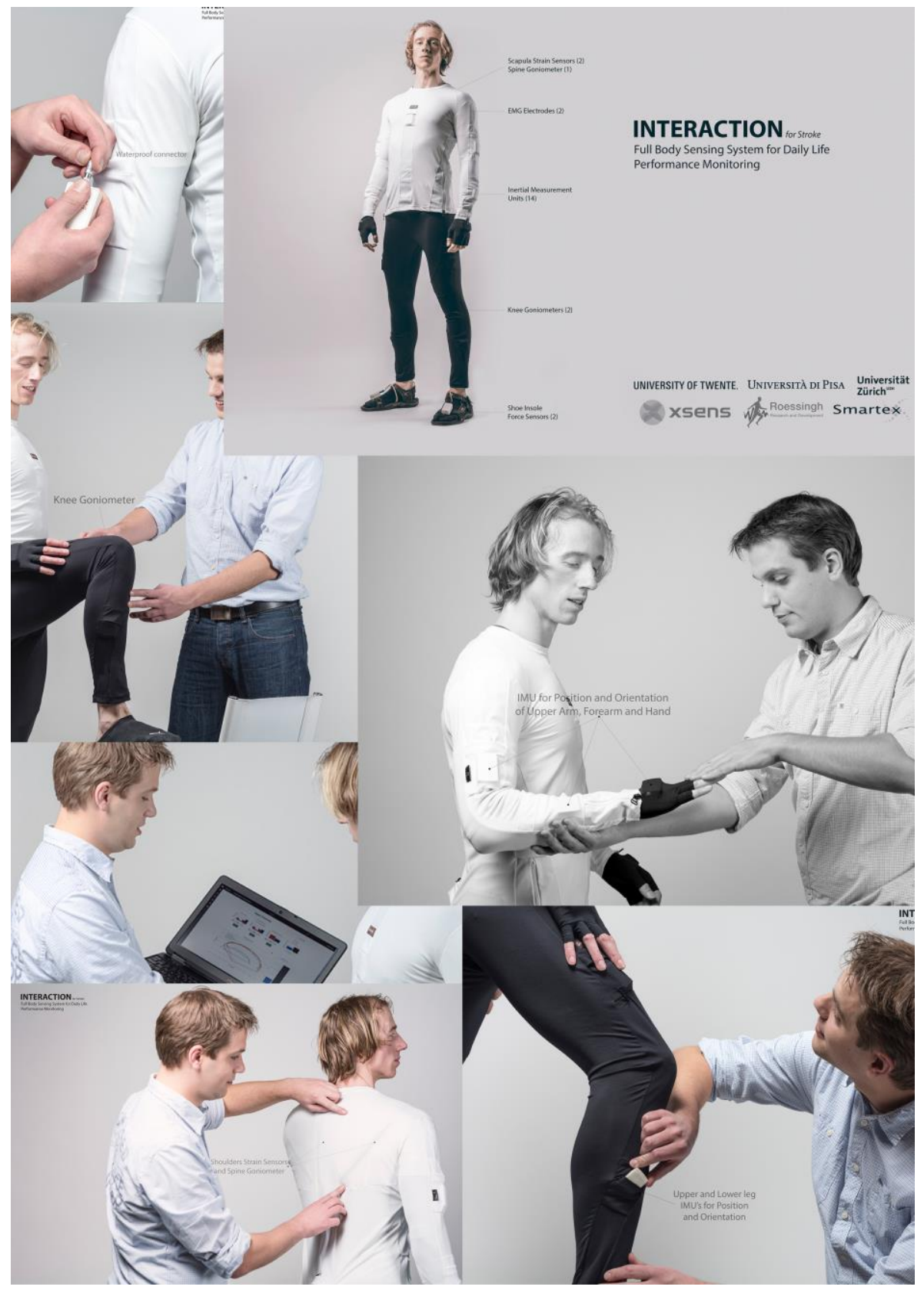

Figure 29. Flyer of the INTERACTION project showing several pictures of the sensor suit and the web-portal for displaying quality of movement metrics 
Chapter 5: Usability evaluations of a wearable sensing system and resulting metrics for stroke survivors by care-professionals

\subsection{Semi-structured interview and presented metrics}

The semi-structured interview was supported by a Powerpoint presentation. The slides were organised as follows: first, the results of the clinical assessment measures, such as the TUG and FMA-UE, were shown, then a INTERACTION metric from a measurement in clinic was shown and finally, the same metric but then captured during daily-activities at home was shown. This process was repeated for all the metrics mentioned in section 2.1. An example of each metric was shown and explained to the participant before the metric with patient data (in clinic or at home) were revealed. In detail, the origin of the data, the type of data and the graphs axis were explained. Subsequently, three questions were asked for each metric:

- What do you see?

- What does it add for you compared to structured clinical measures?

- Is there any downside to this new metric?

\subsubsection{Likert questionnaire and open questionnaire}

After the semi-structured interview, a standard five points Likert questionnaire [1] was handed over to rate the presented metrics with a score of zero (do not want to have) to five points (want to have). Finally, a non-standardized open questionnaire was presented about using the system and metrics in clinic, with the following questions:

- Do you want to have an inertial motion capture system, like INTERACTION, in your clinic?

- Do you have enough resources (e.g. time and money) in your clinic to utilize this system?

- Do you have any additions in what can be measured?

\subsection{Reference analysis}

For comparing the evaluations of care-professionals (in and outside the project), a feature list was constructed, where a feature $(\mathrm{F})$ is a conclusion given by the careprofessional on resulting metrics in the CR (Table 7). A score, with a maximum of five points $(\mathrm{P})$ per feature, were assigned to part of each feature by researchers from INTERACTION. This score provides a weight to each feature, based on their complexity. In total, 10 features were defined based on the patient $\mathrm{CR}$, four (Fl_1-Fl_4) for the lower extremity $\mathrm{CR}$, where $\mathrm{Fl} \_2$ is based on measurement data captured by INTERACTION in clinic and Fl_3 and Fl_4 during daily-life. Six features (Fu_1-Fu_6) are included for the upper extremity $\mathrm{CR}$ as listed in Table 7 , where Fu_2 and Fu_3 are 
Chapter 5: Usability evaluations of a wearable sensing system and resulting metrics for stroke survivors by care-professionals

captured in clinic and $\mathrm{Fu}_{-} 4-\mathrm{Fu}_{-} 6$ during daily-life. Each feature, except for Fl_1 and $\mathrm{Fu} \_1$ are obtained using the INTERACTION system.

The evaluation of both case-reports by care-professionals during the interview was captured and points were given if a feature was mentioned. As a maximum, 50 points could be assigned.

Table 7. Feature reference list. Points $(\mathrm{P})$ are assigned to each feature for the lower extremities (Fl_1, FL_4) and upper extremity $\left(F u \_1-F u \_6\right)$.

\section{CR 1: Lower extremities}

\section{Feature Points Details}

FI_1* 5 Based on TUG assessment scores, see an improvement in function of gait

\begin{tabular}{lll}
\hline \multicolumn{3}{l}{ Based on in-clinic measurements (C) } \\
\hline FI_2 & 2 & $\begin{array}{l}\text { Observed difference in stride profile metric between left/right side } \\
\text { over time for clinical task (TUG) }\end{array}$ \\
\hline 2 & $\begin{array}{l}\text { Indicated that difference disappeared over time for clinical task } \\
\text { (TUG) }\end{array}$ \\
\hline 1 & $\begin{array}{l}\text { Showing an improvement of foot clearance during clinical task } \\
\text { (TUG) }\end{array}$ \\
\hline & Based on daily-life measurements (D) \\
\hline FI_3 & 2 & Observed a difference in heel height between Left/Right in ADL \\
\hline & 3 & Observed no change over time during ADL walking tasks \\
\hline FI_4 & 3 & Noted improvement of walking speed in clinical task (TUG) \\
\hline & 2 & Observed no change in walking speed during ADL walking task \\
\hline
\end{tabular}

\section{CR 2: Upper extremities}

Fu_1*5 Based on the FMA-UE assessment scores, show no distinct improvement over time

Based on in-clinic measurements $(C)$

Fu_2 2 Observed an increase in reaching distance of affected-side between baseline and discharge, but then a decrease back to baseline for clinical task (FMA UE)

Observed an increase in total area/hand distribution plots of

3 between baseline and discharge, but then a decrease back to for clinical task (FMA UE )

Showing that abduction of shoulder increased between 
Chapter 5: Usability evaluations of a wearable sensing system and resulting metrics for stroke survivors by care-professionals

Fu_3 5 baseline and discharge, but then decreased back to baseline of affected and non-affected arm for clinical tasks (FMA UE)

Based on daily-life measurements (D)

Fu_4 3 Noted that shoulder abduction ROM was higher for the nonaffected arm than for the affected-arm during ADL

2 Indicated no clear improvement of shoulder abduction over time during ADL

Fu_5 2 Show little change in max reaching distance over time during ADL

3 Show little change in total area over time during ADL

Fu_6 5 Total reaching area was lower for the affected-side then for the non-affected side during ADL

${ }^{*}$ Obtained via clinical assessments scores, all other features are obtained with the INTERACTION system. TUG = Timed-Up-and-Go assessment task [9], FMA-UE $=$ Upper extremity part of the Fugl-Meyer assessment [10], *ADL = activities of daily living.

\subsection{Data processing}

The captured semi-structured interviews were transcoded in Atlas TI 2.0 [12]. The transcoded interviews were analysed for the reference analysis and both questionnaires. Means and standard deviations of the Likert questionnaire scores were calculated per INTERACTION metric. 
Chapter 5: Usability evaluations of a wearable sensing system and resulting metrics for stroke survivors by care-professionals

\section{RESULTS}

\subsection{Participants}

In total, 11 interviews were conducted with 11 groups consisting of 23 participants. Seven interviews were held in Switzerland divided over three institutes. Six interviews consisted of two care-professionals and one interview was conducted with three careprofessionals. Four interviews were held in The Netherlands divided over two institutes. Each interview group consisted of two care-professionals. The interviews were held between July 2015 and October 2015. The interviews, on average, lasted 51 \pm 11 minutes and were all successfully completed. All participants filled in the questionnaires at the end of the interview.

\subsection{Reference analysis results}

The results of the reference analysis are listed in Table 8 . The participants scored, on average, $47.3 \pm 3.5$ points. For $C_{1}$, they were able to extract each feature. For $C_{2}$, participants scored lower for descriptive statistics of reaching distance over time for both in clinic and at home. 
Chapter 5: Usability evaluations of a wearable sensing system and resulting metrics for stroke survivors by care-professionals

Table 8. Reference analysis results

\begin{tabular}{|c|c|c|c|c|c|c|c|c|c|c|c|}
\hline \multicolumn{5}{|c|}{ CR1 $^{1}$} & \multicolumn{7}{|c|}{$\mathrm{CR}^{2}$} \\
\hline Location ${ }^{2}$ & C & C & $\mathrm{D}$ & $\mathrm{D}$ & C & C & C & $\mathrm{D}$ & $\mathrm{D}$ & $\mathrm{D}$ & \\
\hline Features & FI_1 & Fl_2 & FI_3 & FI_4 & Fu_1 & Fu_2 & Fu_3 & Fu_4 & Fu_5 & Fu_6 & Total \\
\hline \multicolumn{12}{|c|}{ \#interviews $^{3}$} \\
\hline INT S1 & 5 & 5 & 5 & 5 & 5 & 5 & 5 & 5 & 5 & 5 & 50 \\
\hline INT S2 & 5 & 5 & 5 & 5 & 5 & 5 & 5 & 5 & 5 & 5 & 50 \\
\hline INT S3 & 5 & 5 & 3 & 5 & 5 & 5 & 5 & 2 & 5 & 5 & 45 \\
\hline INT S4 & 5 & 5 & 5 & 5 & 5 & 5 & 5 & 5 & 5 & 5 & 50 \\
\hline INT S5 & 5 & 5 & 5 & 5 & 5 & 2 & 5 & 5 & 2 & 5 & 44 \\
\hline INT S6 & 5 & 5 & 5 & 5 & 5 & 5 & 5 & 5 & 5 & 5 & 50 \\
\hline INT S7 & 5 & 5 & 5 & 5 & 5 & 5 & 5 & 5 & 5 & 5 & 50 \\
\hline$\overline{\text { INT NL1 }}$ & 5 & 5 & 5 & 5 & 5 & 5 & 5 & 5 & 5 & 5 & 50 \\
\hline INT NL2 & 5 & 5 & 5 & 5 & 5 & 2 & 5 & 2 & 5 & 2 & 41 \\
\hline INT NL3 & 5 & 5 & 5 & 5 & 5 & 1 & 5 & 5 & 0 & 5 & 41 \\
\hline INT NL4 & 5 & 5 & 5 & 5 & 5 & 5 & 5 & 5 & 5 & 5 & 50 \\
\hline
\end{tabular}

\begin{tabular}{llllllllllll}
\hline Average & 5 & 5 & 4.8 & 5 & 5 & 4.1 & 5 & 4.5 & 4.3 & 4.7 & 47.4 \\
\hline Std & 0 & 0 & 0.6 & 0 & 0 & 1.6 & 0 & 1.2 & 1.7 & 0.9 & 3.8 \\
\hline
\end{tabular}

${ }^{1}$ Case Report (CR) 1: lower extremity, 2: upper extremity

${ }^{2}$ based on in-clinic (C) or during daily life (D) measurements

Interview (INT) held in Switzerland (SX) and The Netherlands (NLX)

\subsection{Interview results}

\section{What do you see?}

Participants were asked to interpret the metrics shown for each case report. Of 11 groups, seven $(64 \%)$ were able to relate data shown in each metric with movement disorder or issues of the patient for the upper extremities, where all groups could do it for the lower extremities. The four groups who had difficulties relating the metric 
Chapter 5: Usability evaluations of a wearable sensing system and resulting metrics for stroke survivors by care-professionals

results to movement disorders for the upper extremities found it difficult to describe what the metric actually showed them in relation to functional movement of the patient. This applied in particular to the metrics: reaching distance and shoulder abduction range of motion. The participants explained that with these metric results, they did not know exactly how the patient managed to get to that result. Therefore, they could not describe the underlying cause of particular movements or give suggestions for future therapy. In total, six groups were able to give a detailed description of the hand distribution plots during daily-life activities, including compensation strategies, certain movements the patient performed and insight in what these patients should train. For example, give therapy to enhance the patient's ability to reach more sideways. The other five groups were able to understand the density plots, but only mentioned differences in density plot surface areas.

\section{What does it add for you?}

In total, nine out of 11 groups mentioned that they prefer objective measures for the quality of movement as presented in the INTERACTION metrics compared to current clinical scores measured with a stopwatch or subjectively scored by a careprofessional. They expect that it will give them specific information about the patient's movements and that it is more accurate than current clinical scores. All groups mentioned that visualising quality of movement by using these metrics, especially during daily-life activities, has more possibilities compared to clinical assessments. Especially when compared over time, which makes it possible to intervene earlier before patients come back to the care-professional with complains. Two groups mentioned that the INTERACTION system and resulting metrics could be a solution in the case you cannot physically see the patient in clinic. According to eight groups, they do not have to be an expert to understand the metrics, in particular the density plots of the hand. In these graphs they see what patients are doing and what areas they have to work on. Two groups mentioned it would also help to show the progress of rehabilitation to insurance companies as proof that the patient is progressing, in order to reimburse their medical costs.

All groups mentioned in detail that feedback towards the patient is important and that these metrics, with particular focus on the density plots and reaching areas, are an important part of self-evaluation. One group also mentioned that patients often loose feeling of progress, particularly at home. Therefore, presenting those patients

with weekly updated metrics about the quality of movement at home (most in favour: density plots) could help them regaining that feeling. These metrics, captured in clinic 
Chapter 5: Usability evaluations of a wearable sensing system and resulting metrics for stroke survivors by care-professionals

and at home are of interest especially for reward-addicted patients according to two groups. Two groups stated that by just wearing such a system at home could be motivating to patients. Three groups mentioned that the shoulder range of movement is a compact and objective measure which can easily be compared over time. In total, 10 out of 11 groups agreed that the density plots are the most interesting metrics to summarize daily life function at home and to visualize differences between the left and right arm. They mentioned that it would be a great metric to be used for clinical assessments, especially in rehabilitation clinics, but not in acute hospitals as these patients are not monitored for longer periods of time.

\section{Are there any downsides to these new metrics?}

According to all groups, the density plots constructed based upon the clinical measurements were more difficult to read compared to density plots constructed from the daily activities at home, especially when trying to compare the left and right reaching area of the patient. In total, 9 out of 11 groups stated that the context of the home measurements is of importance in understanding the movement data. Distractions at home, dual tasks the patients performs or cognitive challenges during the movement capture has influence on the performance of the patient. Furthermore, the environment, e.g. the surface of the ground, is of great influence to for example the movement speed or stride profile metrics. A clinical environment is controlled and safer than at home and therefore difficult to compare. Three groups mentioned that the coaching or motivational aspect of a care-professional being present during clinical assessments has a large influence on the capabilities of the patient during the measurement. Therefore, it might be challenging to compare these clinical results with a home situation. Five groups mentioned that it is not possible to assess how the patients manages to do the movement by only using the reaching distance or shoulder range of motion metric. Including information like: carrying an object, grasping or muscle activation would help in understanding how patients are able to perform a certain movement. Concerning the lower extremity stride profiles, two groups stated that it is not possible to properly assess how the patient is making his foot movement (if he drags the foot or swings it outside) which affects the patient's therapy. One group stated they would like to have the metric values for movements made by healthy subjects as a reference. One group mentioned they want to see the selected metrics only for a very specific activity. 
Chapter 5: Usability evaluations of a wearable sensing system and resulting metrics for stroke survivors by care-professionals

\subsection{Likert questionnaire results}

The metrics, as described earlier, were scored by each group of care-professionals from o (not to have) to 5 (really want to have). The results are listed in Table 9. Hand distribution plots, constructed from activities of daily living (ADL) at home and for the FMA-UE, were the most favourite metric to have, with a mean of $4.2 \pm 1.2$ out of 5 . Next is the reaching area descriptive statistics metric, shown for both ADL and FMAUE task, with a $3.4 \pm 1.1$ and stride profile metric, shown for ADL walking task and TUG task with an average of, $3.2 \pm 1.7$.

Table 9. Likert score results obtained during interviews (INT) in Switzerland (S) and The Netherlands (NL).

\begin{tabular}{|l|l|l|l|l|l|l|}
\hline Interview & $\begin{array}{l}\text { Stride } \\
\text { profile }\end{array}$ & $\begin{array}{l}\text { Walking } \\
\text { speed }\end{array}$ & $\begin{array}{l}\text { Reaching } \\
\text { distance }\end{array}$ & $\begin{array}{l}\text { Shoulder } \\
\text { ROM }\end{array}$ & $\begin{array}{l}\text { Reaching } \\
\text { Area }\end{array}$ & $\begin{array}{l}\text { Hand } \\
\text { distributi } \\
\text { on plots }\end{array}$ \\
\hline INT S1 & 4 & 2 & 3 & 1 & 3 & 5 \\
\hline INT S2 & 3 & 4 & 3 & 3 & 3 & 5 \\
\hline INT S3 & 1 & 3 & 2 & 4 & 5 & 5 \\
\hline INT S4 & 2 & 4 & 3 & 0 & 3 & 4 \\
\hline INT S5 & 5 & 2 & 0 & 2 & 4 & 2 \\
\hline INT S6 & 5 & 3 & 2 & 4 & 3 & 5 \\
\hline INT S7 & 5 & 4 & 3 & 5 & 3 & 5 \\
\hline INT NL1 & 5 & 3 & 3 & 4 & 5 & 5 \\
\hline INT NL2 & 1 & 3 & 1 & 1 & 1 & 1 \\
\hline INT NL3 & 3 & 1 & 2 & 2 & 3 & 4 \\
\hline INT NL4 & 1 & 3 & 2 & 2 & 4 & 5 \\
\hline Average & 3.2 & 2.9 & 2.2 & 2.5 & 3.4 & 4.2 \\
\hline Std & 1.7 & 0.9 & 1 & 1.6 & 1.1 & 1.2 \\
\hline
\end{tabular}

The open questionnaire was given at the end of the interview and focusses more on the INTERACTION system in general. Eight groups mentioned that using the system would probably take too much time, especially in donning and duffing the suit and set-up time. The set-up time of the system replaces regular therapy time for the patient so it needs to be beneficially for therapy. If the data capture and analyses processes can be fully automated and generate reports instantly it would be a big improvement. One group mentioned that within their private clinic, there are no resources (e.g. time and money) available to support such a system. According to three 
Chapter 5: Usability evaluations of a wearable sensing system and resulting metrics for stroke survivors by care-professionals

groups, originating from the Netherlands, roughly 20 percent of available time, in a hospital environment, can be spend on new technology or therapy (including e.g. filling in reports and data processing).

In total, nine groups mentioned that it will be difficult to organise weekly get together with care-professionals to discuss the case reports. They also mentioned that, in order to save time, specialists should be involved that perform the patient measurements, process the resulting data and finally hand over reports. Three groups mentioned that in an acute hospital environment there is no advantage of such a system. The interesting part of this system is for performance measurements at home. However, in an acute care hospital environment, care-professionals rarely work with patients in home situations. In ambulatory care or a rehabilitation hospital this could be interesting technology. There are also more resources available in rehabilitation centres to do performance measurements and discuss the data with care-professionals on a monthly base. One group mentioned they rather use straps with sensors then a full body suit as it is easier for most patients to wear. One other group mentioned that they would like to see standardized activity of daily living tasks for training and connect patient's deficits to these tasks. They would also like to see how many activities are performed and where those took place. Furthermore, a big data approach by incorporating different types of data (heart-rate, ECG) could be interesting. 
Chapter 5: Usability evaluations of a wearable sensing system and resulting metrics for stroke survivors by care-professionals

\section{DISCUSSION}

A full body inertial motion capture system, called INTERACTION, was developed by engineers and care-professionals for the evaluation of the quality of movement of stroke patients in clinic and at home. In this usability study, we combined multiple evaluation methods, including a semi-structured interview, and questionnaires to evaluate the developed metrics among 23 care-professionals from five different treatment centres. In this way, quantitative results on the interpretation of the metrics and the opinion of a full body inertial motion capture system in clinic was obtained. The reference analysis results showed that most groups were able understand, interpret and explain the quality of movement metrics for two case reports by obtaining close to maximum scores. The upper extremities metrics consist mostly of new metrics, whereas for the lower extremities, presented metrics, or similar, were already known by care-professionals and applied in therapy (for instance: foot clearance, which resembles heel-height stride profiles). Two metrics: reaching distance and shoulder range of motion, were more difficult to apply than others related to functional movements of patients. The quality of movement (QoM) shown within these metrics could be realized by patients in multiple ways, therefore it remained difficult to assess the underlying cause of the quality of movement by the participants (35\%). Hence, a combination of metrics is needed, in which the careprofessional can combine multiple results to come to a conclusion on the QoM of the patient

Both the Likert questionnaire and the results from the semi-structured interviews revealed that the hand distribution plots, when applied during daily-life activities, were favoured by most groups. Density plots have proven to be successful to assess upper limb activity outside of the clinic in an earlier study by Bailey et al, 2015, stating that upper limb activity in a patient's real-world environment must be assessed to improve daily function [13].

Hand distribution plots visualize not only the area wherein the patient moves their hands, but also the amount of time the hand is in a certain position. Differences between left and right can be seen instantly and in an intuitive way. Compared to current clinical methods, it gave care-professionals from 6 out of 11 groups more insight into the QoM of the patient and objective results which can easily be documented for the assessment of these patients over time, either numerical on in a graph/picture compared to current clinical assessments. It opens more possibilities to 
Chapter 5: Usability evaluations of a wearable sensing system and resulting metrics for stroke survivors by care-professionals

show progress of patients, which might not be reflected in clinical scores or the feeling of progress by the patient. According to the participants, it could give the opportunity to present visual feedback to the patient, which is important especially at home, as patients tend to lose track of progress.

The largest drawbacks in using such a full body monitoring system are the set-up time, processing and report generation time and the context in which data is captured at home. The first two are merely technological drawbacks. New full body motion capture systems are currently realised, with faster setup times and utilizing straps for attaching sensors [14-15]. The processing and report generating algorithms developed in INTERACTION [2] can potentially be automated for clinical use and need to be more explored in the future. The last drawback is more challenging and involves the patient's state (e.g. feels tired), intentions (e.g. does the patient wants to grab a piece of paper or a heavy cooking pan, or dual tasks) or surroundings (e.g. is he walking indoors or outdoors, on what type of surface, etc.). For example, participants mentioned that dual tasks clearly influence walking speed. Therefore, the patient needs to wear an additional sensor, e.g. gloves which can detect grasping an object. These were also developed in INTERACTION [16], but were found to be to invasive to use at home as it makes daily-life activities like washing hands or go to the bathroom more difficult. Furthermore, the consistency of the surface people walk on (e.g. grass, slippery floor or sand) makes a difference for many of the lower extremity metrics like walking speed and stride profiles. These surface consistencies are difficult to detect, although promising research has been done [17-18]. Within the INTERACTION project, an activity monitor was developed acting like a filter on the acquired data. It consists of basic activities like walking, sitting, standing and arm movement [2]. More complex activities like "brushing your teeth" or "vacuum the floor" would be a nice addition to that filter for a detailed report of activities. More so, quality of movement metric for specific activities can then be inspected by a care-professional, assisting into a more personalized training approach for the patient.

Finally, the results suggest that a full body inertial measurement system is most likely to be used in rehabilitation centres, rather than in (acute) hospitals as patients in rehabilitation centres are like to benefit more from such an extensive system and it remains scientifically more interesting to monitor these patients. Ambulant monitoring is not a common practice in an acute hospital division focusing on stroke survivors. This mixed method usability evaluation study has only been carried out in two countries with five different centres (hospital, rehabilitation) and included 23 
Chapter 5: Usability evaluations of a wearable sensing system and resulting metrics for stroke survivors by care-professionals

care-professionals. A larger analysis in more countries would be beneficial, which might reveal new insights into how stroke therapy is applied in practice, as this might differ from country to country. Certain countries could have therapeutic strategies focussing on functionality of the patient (e.g. can you pick up the cup of tea), where the others try to maximize the full capacity of the patient (e.g. can you pick it up with your arm fully stretched and body upwards).

Altogether, it remains a question how to determine what the patient is doing and where the patient is doing his or her actions. As suggested above, more body sensors can be added, but that makes a system more invasive towards the patient hence a reduced sensor system is more in favour [7]. Another way is to instrument the environment (e.g. smart home concepts and instrument objects [19-20]. Those systems have more issues related to privacy. It seems that in order to address the drawbacks, mentioned by the care-professionals, of the current system, a combination of body sensors and an instrumented environment is needed. Only then, it might be successfully implemented in a variety of clinics.

For future research, the current system can be reduced to a limited number of body sensors and might be combined with vibrotactile actuators for giving feedback [21] and with environmental sensing which makes it possible to determine the impact of the environment on the actual quality of movement shown in the INTERACTION metrics.

\section{Disclosure/Conflict-of-Interest Statement}

The authors declare that the research was conducted in the absence of any commercial or financial relationships that could be construed as a potential conflict of interest.

\section{Acknowledgments}

The authors would like to thank all study participants from the University Hospital Zurich, Cereneo A.G., Centre for Neurology \& Rehabilitation, Roessingh Centre for rehabilitation, Praxis Meilen and Fysio-Holland.

This study was part of the INTERACTION project, which was partially funded by the European Commission under the 7th Framework Programme (FP7-ICT-2011-7287351). 


\section{APPENDIX 1: CASE REPORT EXAMPLE}

\section{Patient example information}

Participant one is a 7o-year-old right-handed woman, who lives with her husband in a flat on the third floor. Before her stroke she was working in administration and case management of a hospital. She suffered an ischemic stroke in October 2011, 12 months before participating in the study. The stroke left her with a left-sided hemiparesis. No cognitive or language impairments were detected. She is partly living independent, as she needs assistance during shopping and heavier tasks.

\section{Clinical assessment score}

Table 10. Clinical assessment scores for the upper and lower extremity

\begin{tabular}{lllll}
\hline Time point & Enrolment & Discharge & Discharge +4w & Enrolment +3m \\
\hline Fugl Meyer total & 56 & 63 & 57 & 58 \\
\hline Fugl Meyer proximal & 31 & 37 & 30 & 32 \\
\hline Fugl Meyer distal & 28 & 27 & 29 & 27 \\
\hline Action Research Arm Test & 57 & 56 & 57 & 57 \\
\hline Timed Up and Go (sec) & 12 & 11 & 8 & 8 \\
\hline 10m walk test (m/s) & 0.7 & 0.8 & 1 & 1.2 \\
\hline
\end{tabular}


Chapter 5: Usability evaluations of a wearable sensing system and resulting metrics for stroke survivors by care-professionals

Time selected from: $0 \mathrm{~min}$. to $201 \mathrm{~min}$.
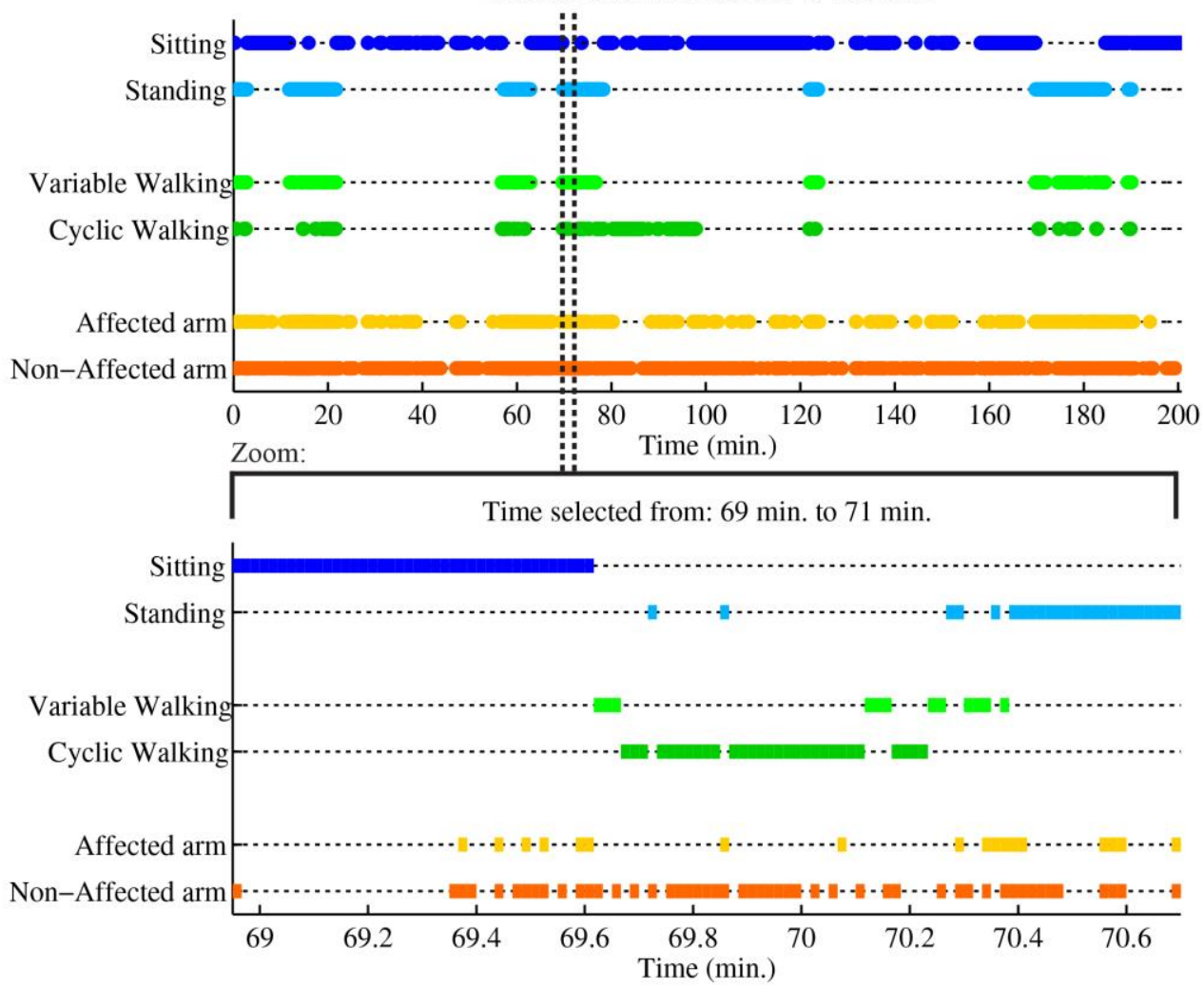

\begin{tabular}{|c|c|c|c|c|}
\hline \multicolumn{2}{|c|}{ Total time selected: $201 \mathrm{~min}$. } & \multirow[b]{2}{*}{$\begin{array}{l}\text { Time (min.) } \\
95.6 \\
28.7\end{array}$} & \multicolumn{2}{|c|}{$\%$ - of Total time } \\
\hline Posture & $\begin{array}{l}\text { Sitting: } \\
\text { Standing: }\end{array}$ & & $\begin{array}{l}\%-\text { of } \\
47.6 \\
14.3\end{array}$ & $\begin{array}{l}\text { Total time } \\
\% \\
\%\end{array}$ \\
\hline Walking & $\begin{array}{l}\text { Total: } \\
\text { Variable: } \\
\text { Cyclical: }\end{array}$ & $\begin{array}{l}26 \\
7.42 \\
18.6\end{array}$ & $\begin{array}{l}13 \\
3.7 \\
9.26\end{array}$ & $\begin{array}{l}\% \\
\% \\
\%\end{array}$ \\
\hline Arm & $\begin{array}{l}\text { Affected: } \\
\text { Non-Affected: }\end{array}$ & $\begin{array}{l}14.4 \\
41.9\end{array}$ & $\begin{array}{l}7.2 \\
20.9\end{array}$ & $\begin{array}{l}\% \\
\%\end{array}$ \\
\hline
\end{tabular}

Figure 30. Case report example page 1: activity monitor, as reported in van Meulen and Klaassen et al, 2016 [2]. 
Chapter 5: Usability evaluations of a wearable sensing system and resulting metrics for stroke survivors by care-professionals
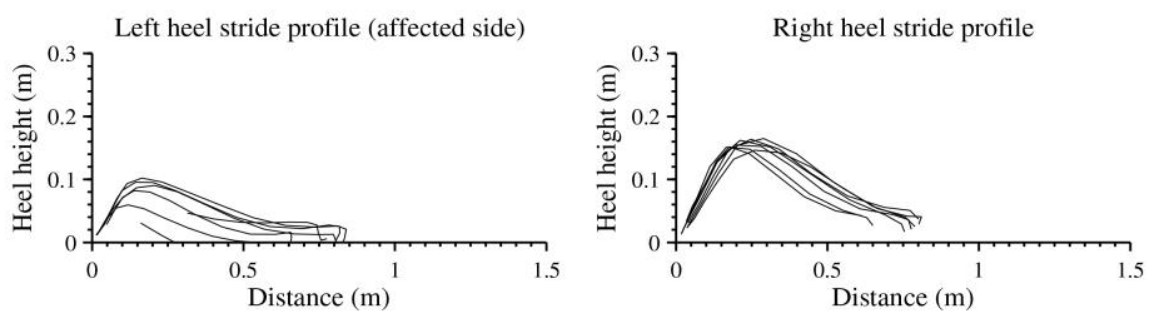

Figure: Heel stride profile of the left (affected) and right foot. Each line indicates a stride.

Table: General parameters lower extremity

Table: General parameters lower extremity
\begin{tabular}{|l|l|l|l|l|l|r|}
\hline & & Left (A) & & \multicolumn{2}{l|}{ Right (NA) } & Overal \\
\hline Metric & Unit & Mean & SD & Mean & SD & \\
\hline Stride Length & $(\mathrm{m})$ & 0.78 & 0.18 & 0.75 & 0.15 & \\
\hline Number of steps & $(\#)$ & 18 & & 18 & & \\
\hline Speed & $(\mathrm{m} / \mathrm{s})$ & & & & & 0.31 \\
\hline
\end{tabular}
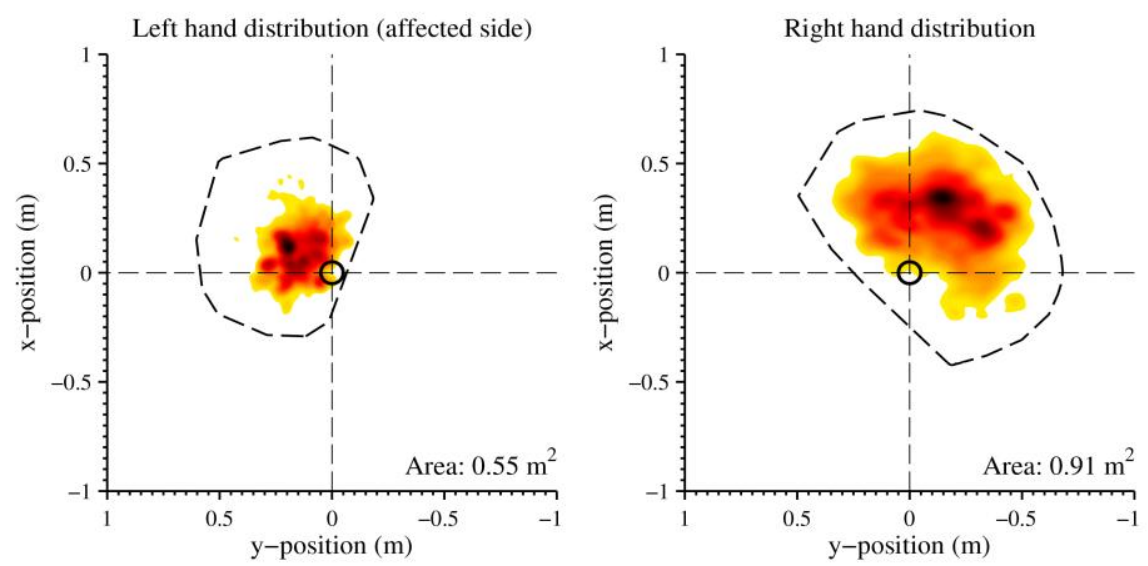

Figure: Distribution of the hand positions relative to the pelvis (origin of the graph, indicated with a black circle) in the transversal plane, of the left (affected side) and right hand

Table: General parameters upper extremity

\begin{tabular}{|l|l|l|l|l|l|r|}
\hline & & Left (A) & \multicolumn{3}{|l|}{ Right (NA) } \\
\hline Metric & Unit & Mean & SD & \multicolumn{1}{l|}{ Mean } & SD \\
\hline Max. reaching distance & $(\mathrm{m})$ & 0.58 & 0.14 & 0.65 & 0.1 \\
\hline Number of reaches & $(\#)$ & 19 & & 25 & \\
\hline Total area & $\left(\mathrm{m}^{\wedge} 2\right)$ & 0.55 & & 0.91 & \\
\hline Shoulder abduction ROM & $(\mathrm{Deg})$ & 15.1 & 6.2 & 38.1 & 17.5 \\
\hline
\end{tabular}

Figure 31. Case report example page 2: A selection of metrics of extremity function from one measurement, as reported in van Meulen and Klaassen et al, 2016 [2] 


\title{
Chapter 6
}

\section{THE DEVELOPMENT AND EVALUATION OF AN ARM USAGE COACH FOR STROKE SURVIVORS}

\author{
B. Klaassen ${ }^{1,2}$, P.G.H. Bartels, B.J.F. van Beijnum ${ }^{1,2}$ and H. J. Hermens ${ }^{1,2,3}$
}

${ }^{1}$ Biomedical Signals and Systems, MIRA - Institute for Biomedical Technology and Technical Medicine, University of Twente, Enschede, Netherlands.

${ }^{2}$ Centre for Telematics and Information Technology, University of Twente, Enschede, Netherlands.

${ }^{3}$ Roessingh Research and Development, Roessingh Rehabilitation Hospital, Enschede, Netherlands.

Published in IEEE, 2015 9th International Conference on Sensing Technology (ICST) 8-10 ${ }^{\text {th }}$ of December, 2015. An extended version will be published in Springer book, Sensors for Everyday Life, in December 2016.

\section{ABSTRACT}

Physicians currently have no objective information about the intensity and quality of a Stroke patient's daily-life activities after returning home from the rehabilitation hospital. Therefore there is a need to unobtrusively monitor patients performing daily life tasks at home. Within the INTERACTION project, a new inertial based sensor suit was developed, which is able to measure stroke patients at home. This research extend the INTERACTION project by developing an Arm Usage Coach (AUC), which stimulates the patients affected arm to be used more often at home. The results of a usability evaluation shows high scores in usability, but some design and wear ability problems were found. An open loop evaluation of stroke patient data showed how different decision criteria parameters, for applying feedback to the patient, resulted in different outcomes of feedback given. Based on both evaluation results, a new prototype is in development, which will be evaluated by stroke patients in clinic. 


\section{INTRODUCTION}

The changes in functional capacity and performance of stroke patients after returning home from a rehabilitation hospital is unknown to a physician. They have no objective information about the intensity and quality of a patient's daily-life activities. Capacity describes what a patient is able to do, this can be measured with clinical tests like the Fugl-Meyer test [1] in a standardized clinical environment. Performance describes what a patient is doing in actual practice (for example, during daily-life, at home). Therefore, there is a need for an unobtrusive and modular system for objectively monitoring the stroke patient's upper and lower extremity motor function in daily-life activities. In the INTERACTION project, a sensor system was developed, based on inertial, strain, goniometer, pressure and EMG sensors, for monitoring stroke patients during daily life activities [2].

Results of earlier studies showed that capacity measurements in clinic do not automatically transfer to the performance of a patient during daily life situations [34]. From the first results of stroke patient measurements, we observed differences over time in arm-usage between the affected and non-affected side. In some patients we saw more use of the non-affected arm at home, which eventually could lead to a loss in arm function over time. Possible causes could be a missing motivational factor, functional need of the arm (ease of use), that the patient feels unsafe in an uncontrolled environment and neglect. Hence, there is a need to assist stroke patients during daily life situations to motivate, or remember them to use his/her affected arm more often.

This can be done by providing VibroTactile (VT) feedback to patients to stimulate the usage of their arm. Other modalities such as visual, auditory or haptic feedback (in multimodal systems) are mostly used in training systems, focusing on capacity, and are too obtrusive within a social context in a home situation. In order to transfer the patient's capacity to daily life situation, this should be minimized [5-6]. Providing VT feedback to patients have been studied, but no research has been done on a realisation of a system that actually provides feedback during daily life [7-13].

This research aims to extend the INTERACTION system to not only monitor and analyse the movement data, but also making a decision whether to give feedback to the patient or not, i.e. the decision component, and how the patient can be stimulated to move the paretic arm more, i.e. the effectuate component. In this paper, we present 
an "Arm Usage Coach" (AUC) that can be used in daily life situations by stroke patients. The AUC will target sufficient arm movement quantity, rather than quality of arm movement and utilizes inertial sensors and VT feedback for providing patient feedback. Section two includes a summary of the requirement analysis which has been done as part of the system development. In section three, the algorithms will be explained and in section four, the final prototype will be presented. User and technical evaluation are described in sections five and six. The discussion and conclusion are presented in sections seven and eight. 


\section{REQUIREMENT ANALYSIS}

First, a Function Analysis System Technique (FAST) [14] was used to formulate the functional requirements the system must have. From this analysis the following function were identified: Stimulate affected-arm-usage is the main function of the system. There is need to stimulate the patient to use his/her affected arm during dailylife, which is based on monitoring the patient's arm movement and to decide whether to give feedback or not. Awareness can be created by providing feedback on arm movement to the patient which can be done by Monitoring the movements of the left and right arm of the patient to make a decision whether to provide a stimulus or not. The final step is to provide the stimulus itself. Interviews were conducted with therapists and vibrotactile experts at Roessingh Research and Development B.V. and the University of Twente respectively. From these interviews, non-functional requirement have been determined, which are described below.

\subsection{Placement of sensors}

Placing tactors on hairy skin, in locations where bone comes closest to the skin and outside joints or areas of movement of use is advisable. When placing multiple tactors it is essential to ensure that the distance between tactors is at least conform the 2point discrimination threshold, which varies over the body, in order to recognize the distinction between tactors [4]. The tactor is placed either on the affected or the nonaffected side, depending on the ability of the patient to feel a sensation on the affected arm.

\subsection{Timing of feedback}

Timing of the VT feedback is an important aspect. During an interview with a Stroke rehabilitation expert, it became evident that feedback is least effective during movement, while providing feedback directly after the movement is significantly more effective. Both types of feedback are called 'knowledge of performance'. Feedback provided after a certain measurement period is most effective. This type feedback is called 'knowledge of result'. Due to the fact that some stroke patients suffer from cognitive impairments, only providing knowledge of result is not desirable. It is therefore suggested to use a combination of knowledge of performance after movement and knowledge of result. 


\section{ARM USAGE COACH ALGORITHM}

For tracking arm movements, two Xsens MTw inertial sensors were used. This solution allows to synchronize multiple Mtw's with each other. The Xsens Awinda protocol ensures real-time sending and receiving of data and handles data packet loss $[15]$.

\subsection{Metric}

In order to detect movement of the arm by using $3 \mathrm{D}$ accelerometers, a certain metric has to be defined. We created a new metric called the Difference Acceleration Vector (DAV). The length of the DAV is calculated by subtracting a reference gravitational acceleration vector $\mathrm{g}(\mathrm{t})$ from the current acceleration vector $\mathrm{a}(\mathrm{t})$ and taking the norm of the resulting vector. The length of the DAV, called " $d(t)$ " is defined as follows:

$$
d(t)=\sqrt{\left(a_{x}(t)-g_{x, t 0}\right)^{2}+\left(a_{y}(t)-g_{y, t 0}\right)^{2}+\left(a_{z}(t)-g_{z, t 0}\right)^{2}}
$$

Finally, the mean DAV is calculated over a time period $\mathrm{T}_{\text {dav }}$ of measurement data, which by default is one second. Figure 32 shows a graphical representation of how the DAV is calculated. With each dashed arrow, there is a switch between the global and sensor frame. The reference acceleration vector, shown in Figure 32b, is subtracted from the acceleration vector at a current time point, shown in Figure 32a. Figure 32c is the result of combining Figure $32 \mathrm{a}$ and $32 \mathrm{~b}$. After the subtraction, the length of the difference acceleration vector can be constructed from the components, shown in Figure 32d.

The DAV metric has been evaluated by measuring daily-life movements in health subjects which performed movements like walking, reaching and simulating stroke patient movements. Clear distinctions in the DAV were found among the different movements and therefore this metric was chosen as a measure for arm usage. [16]

\subsection{Decision making}

The decision criteria are based on three input parameters: 1) a threshold value " $\mathrm{T}_{\text {harm }}$ " for the DAV, 2) amount of desired affected arm movement as a ratio, called desired ratio " $R_{a r m}$ " and 3) time period " $T_{a d l}$ ". Raw acceleration data of both sensors is processed to calculate the length of the DAV, $d(t)$, by subtracting reference data which 
is obtained from a short calibration before each measurement. Next, the amount of samples is counted within a certain time period $T_{\text {adl, }}$, where the DAV is above the threshold value. This is done for both the left and right arm and a ratio between the two counters is determined. If this ratio is smaller than " $R_{a r m}$ ", feedback will be given. The default value for threshold "Tharm" to detect activity is $5 \mathrm{~m} / \mathrm{s}^{2}$, as walking tends to generate values that range between 2 and $4 \mathrm{~m} / \mathrm{s}^{2}$. The desired ratio is determined by a therapist. A desired ratio " $\mathrm{R}_{\mathrm{arm}}$ " of 0.2 means that after five non-affected arm movements, one affected arm movement has to be performed. A flowchart of the Arm Usage Coach algorithm is shown in Figure 33.

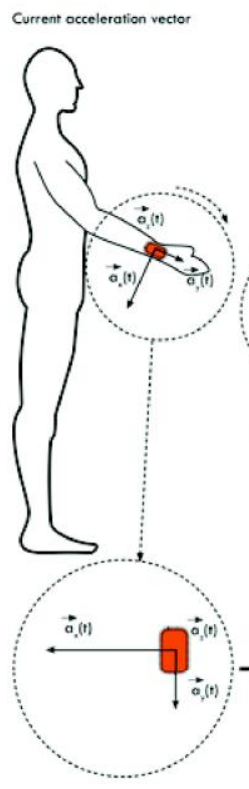

a)

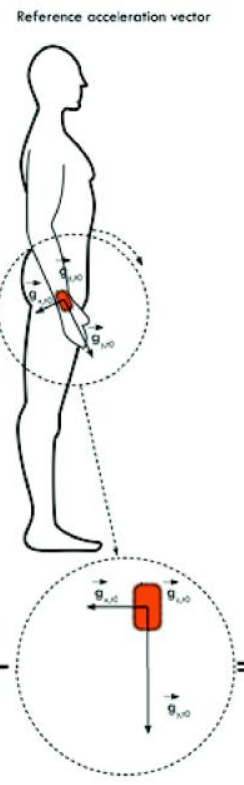

b)

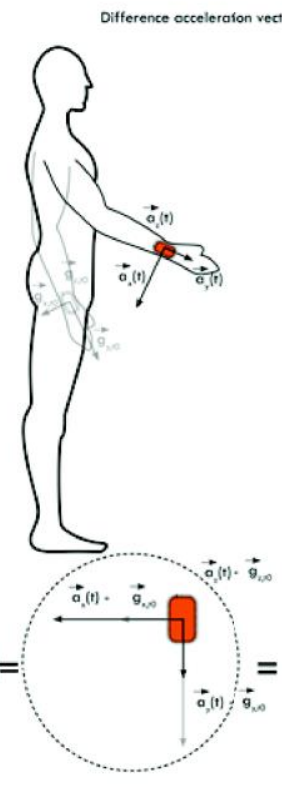

c)

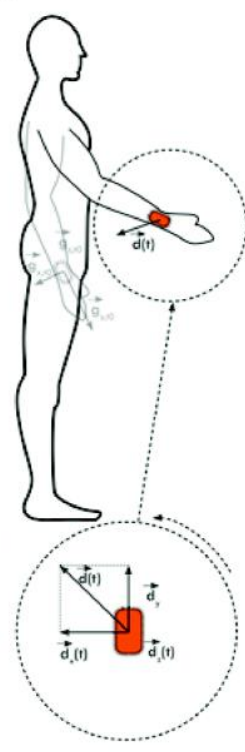

d)

Figure 32. Calculating the DAV 


\section{PROTOTYPE IMPLEMENTATION}

The prototype is shown in figure 34. Two Xsens MTw's (Xsens B.V., the Netherlands) are connected wirelessly via an Xsens dongle to a laptop running Matlab [17]. An Elitac vibrotactile system (Elitac B.V., The Netherlands) is chosen for giving feedback to the patient, because it is easy to control via Matlab and it is already available on the market [18]. Both intensity and frequency pattern of feedback can be adjusted in the Elitac system and together with the final actuation of the tactor are called "Feedback processes". The Elitac system is connected via Bluetooth to the laptop. For development purposes, two algorithms were developed in Matlab: a data acquisition script and a data translation and feedback script. Each is running on a separate Matlab engine. The data acquisition script, used in previous research [2], is customized in order to ensure real-time data streaming from the Xsens sensors to Matlab where triaxial (x,y, z) accelerometer data with corresponding time stamps is logged in a circular buffer with a frequency of $20 \mathrm{~Hz}$. This circular buffer is used to split up the data acquisition process from the data translation and feedback processes. At first, the previously mentioned decision criteria must be entered within the algorithms main user interface. For obtaining the reference acceleration vector, a calibration neutral npose (standing straight with hands alongside the body, feet pointed forward and shoulder width apart) is needed. This vector is acquired during the first 10 seconds of measurement.

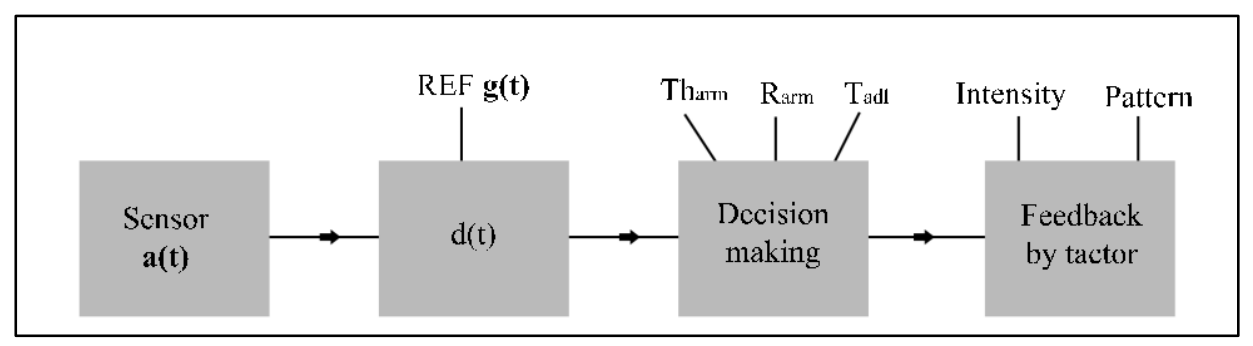

Figure 33. AUC Flow 
Chapter 6: The development and evaluation of an arm usage coach for stroke survivors

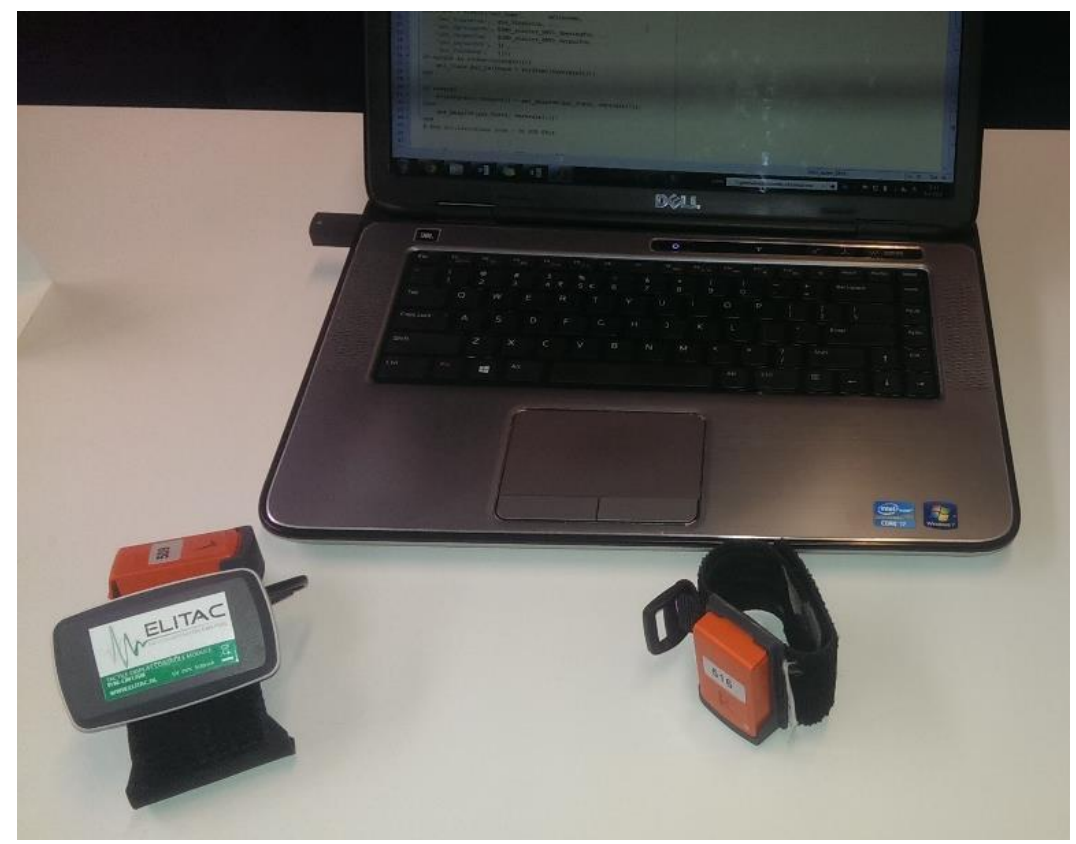

Figure 34. AUC prototype. In the picture, two Xsens MTw (orange boxes) and one Elitac module are shown. 


\section{USABILITY EVALUATION}

\subsection{Methodology}

Five healthy subjects, who have knowledge about cerebrovascular accidents, have been included as part of this study. Subjects were asked to put on the wristband with sensors on each arm. The data acquisition algorithms in Matlab was started on a laptop and a connection with the Xsens MTw and Elitac system was established. After the connection was made, the subject was asked to stand in N-pose for 10 seconds. Next, the data translation and feedback scripts were started on a second Matlab engine. The default set of parameters implemented in Matlab (Tharm $=5$, Rarm $=1$ ) is used for each subject. Subjects were asked to perform a specific set of combined tasks that represents daily-life activities. The complete protocol has been described in van Meulen et al., 2015 [19]. This specific set of tasks are as follows: 1) Sit behind a desk. 2) Stand up and walk to the door. 3) Open the door, walk through it and close it again. 4) Walk to the table. 5) Move object. 6) Pick up object 2. 7) Walk back to the door and open it. 8) Walk through the door and close it again. 9) Take a seat behind the desk.

This set was performed twice per subject, one time while performing as a healthy subject, one time simulating a stroke patient with a left affected side. After both sets of combined tasks were performed, the subject was asked to fill in the System Usability Scale (SUS) [20], the Computer System Usability Questionnaire (CSUQ), [21] and a short interview was taken to ask about the opinion of the participants. 


\subsection{Results}

The answers from the SUS and CSUQ were analysed and mean and standard deviation were calculated for both questionnaires. These are listed in Table 11 and 12 respectively. According to the subjects, the wristband was not comfortable to wear, the system is large and oversized and the system did not consider different types of movement. However, the vibration is not annoying or obstructive, the system is not harmful and it is easy to learn how to use the system. Finally, according to the subjects, the system had a stimulating effect on the awareness of using the arm more often when simulating a Stroke patients.

Table 11. SUS results

\begin{tabular}{|c|c|c|c|}
\hline & Score of SUS & Mean & Std \\
\hline Overall & & 75.0 & 7.2 \\
\hline
\end{tabular}

Table 12. QSUS results

\begin{tabular}{lll}
\hline \multicolumn{1}{c}{ Score Name of CSUQ } & Mean & Std \\
\hline Overall & 5.5 & 0.8 \\
\hline System use & 5.9 & 0.8 \\
\hline Information quality & 5.8 & 0.2 \\
\hline Interface quality & 5.6 & 0.6 \\
\hline
\end{tabular}




\section{OPEN LOOP EVALUATION}

\subsection{Methodology}

Besides a user oriented evaluation, we want to know to what extend the decision criteria input parameters influence the VT feedback rate and how the system would perform in daily-life stroke patients. Within the INTERACTION project, large amount of stroke patient data was captured with a full body inertial measurement suit. As the data acquisition script was separated from the data translation and feedback scripts, it made it possible to process earlier captured movement data. However, this is an open-loop situation as the patient doesn't get feedback and therefore cannot adapt, but it should give a good insight as to how the decision criteria input parameters influence the feedback repetitions given. For this evaluation, a seven minute measurement session was taken which includes many short daily activities around the house (sitting, standing, walking, grabbing objects, and doing dishes). INTERACTION includes an activity recognition algorithm and the output is shown in Figure 32a. The activity recognition algorithm detects sitting, standing, cyclic walking (defines as walking three steps in the same direction), variable walking (steps in all directions) and arm usage. Four different combinations of $\mathrm{Tr}_{\mathrm{arm}}$ and $\mathrm{R}_{\mathrm{arm}}$ were chosen and the VT feedback with these settings was investigated.

\subsection{Results}

The results are shown in Figure 35. The activity monitor shows a variety of different movements, namely standing with arms in rest, standing with using the arms (can be doing the dishes), walking around the house with variable steps and using the arms (carrying objects) and walking longer distances in a straight line. The patient also sits for a few minutes and uses his arms. The tactile activation are plotted in Figure 35b, c, $\mathrm{d}$ and e, where each subplot is generated by different decision criteria input parameters. There are three key points in the timeline (highlighted in green) where each of the settings gave VT feedback. The activity monitor shows that this is a period of more non-affected arm usage then affected arm. In Figure 35b, a low threshold of 3.5 with a ratio of 1 seems to activate the tactor several times after each other, where a slight increase of the threshold greatly reduces the number of activations as shown in Figure $35 \mathrm{~d}$. Increasing the threshold from 5 to 8 doesn't influence the amount of activations a lot. Decreasing the ratio from 1 to 0.5 as seen in Figure $35 \mathrm{~d}$ and $35 \mathrm{e}$ respectively, reduces the number of feedback given. 
Chapter 6: The development and evaluation of an arm usage coach for stroke survivors

a)

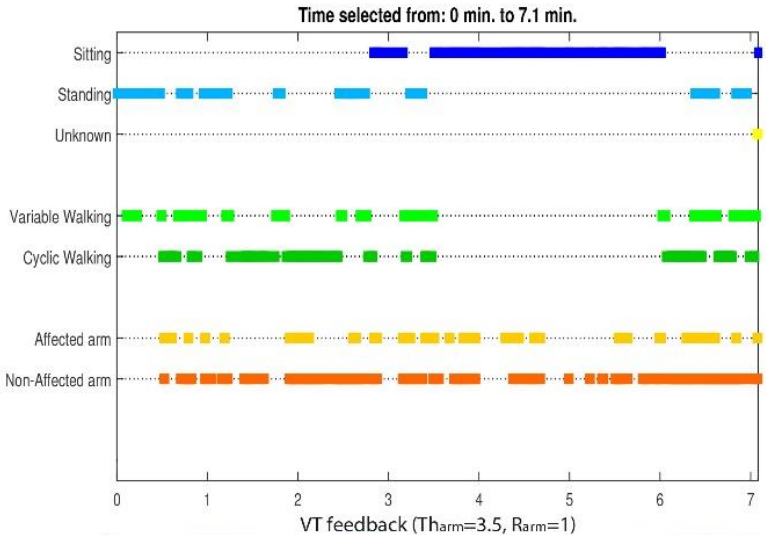

b)

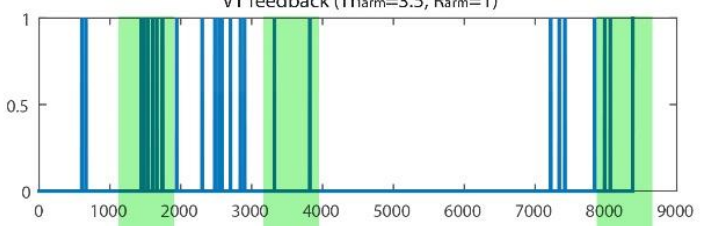

c)

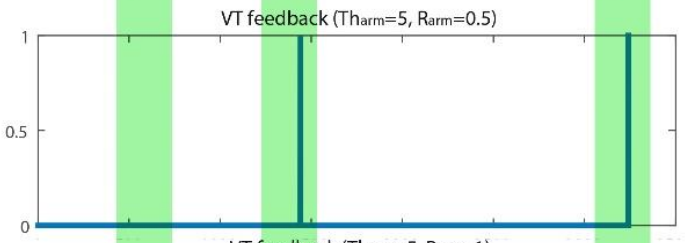

d)



e)

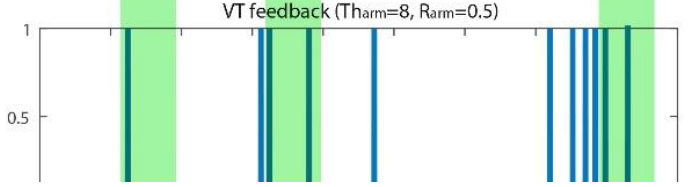

Figure 35. Results of the open-loop evaluation.

4a) Activity monitor results.

4b) vibrotactile results ( $1=$ activated, $\mathrm{o}=$ not) with Tharm $=3.5$ and Rarm=1.

4c) vibrotactile results ( $1=$ activated, $\mathrm{O}=$ not) with Tharm $=5$ and $\operatorname{Rarm}=0.5$.

4d) vibrotactile results ( $1=$ activated, $o=$ not) with Tharm $=5$ and Rarm $=1$.

4e) vibrotactile results ( $1=$ activated, $\mathrm{o}=$ not) with Tharm $=8$ and Rarm $=0.5$. 


\section{DISCUSSION}

The results from the SUS and QSUQ questionnaires showed high scores in usability. The system is safe and easy to use, the vibrotactile (VT) feedback provided was felt and easy to interpret according to the included healthy subjects. A default set of decision criteria input were used during the usability evaluation. People differ in mobility and their own interpretation of how a stroke patient handles daily-life tasks. Therefore, results could be influenced while the system was not personally configured. A protocol for determining those input parameters should be developed, ideally in an automatic way.

The open loop evaluation shows that the algorithms were able to process stroke patient data, captured at home. By changing the decision criteria input parameters, the (simulated) VT feedback could be visualized over time. This, however, was an open-loop situation as the patient was not able to respond and thereby change his or her behaviour. The results showed large differences in VT feedback with different input parameter. By inspecting Figure 35, a $T h_{a r m}=5$ and $R_{a r m}=0.5$ seems to be a plausible setting specifically for this patient, with two feedback moments within seven minutes, as frequency and predictability are two important factors in giving feedback $[22]$.

To make a good assumption about optimal settings for stroke patients, we need to do actual patient measurements. However, what can be seen is that by only using two input parameters, the system can be influenced in such a way that the amount of feedback can be changed significantly. It therefore seems promising to start clinical measurements with the plausible setting mentioned earlier. Simulating the VT feedback in this way could be the starting point for automatic determination of the optimal decision criteria input parameters, to make the input parameters patient specific.

In the current prototype, a laptop is used to process data. When building a system for stroke patients to use in an ambulatory setting, it has to be self-supportive and completely wearable. Therefore there is a need to prototype a new system, which should, according to the user evaluation results, be easier to wear and self-supporting at home without the need of a care-professional. 


\section{CONCLUSION}

The main goal of this research was to "develop and evaluate an on-body vibrotactile feedback system for stroke survivors to stimulate the use of the affected arm during daily life. In this paper a system was developed and evaluated to coach stroke patients at home in using their affected arm more often. The system was evaluated on healthy subjects and on offline data of stroke patients in daily life situations. Future research must conclude whether the system stimulates stoke patients to use their affected arm during daily-life.

Most of the decision criteria input parameters of the system must be patient specific, i.e. the 'desired ratio', the location at which sensations can be experienced in the affected and/or non-affected side and feedback preference. An early prototype of the proposed system is composed of two Xsens MTw sensors, which were placed on the wrists to track arm movements. A difference acceleration vector (DAV) was calculated for both arms. Feedback is given via an Elitac vibrotactile actuator. A user evaluation protocol was set up to test the system on five healthy subjects and assess the systems usability for future development. They have rated the system with a score of $75.0( \pm 7.2)$ at the System Usability Scale and mean of $5.5( \pm 0.8)$ for the overall system at the Computer System Usability Questionnaire. The first impression by the participants of the prototype is promising.

In the usability evaluation, subjects noted that the prototype is large and oversized, and that it does not distinguish different types of movement. However, they also noted that one can easily learn how to use the prototype, that it creates awareness on arm movement and that it has a stimulating effect. An open loop evaluation was done by using accelerometer data of arm movements during daily life activities of stroke patients. The results show that the algorithms were able to process stroke patient data and how different decision criteria input parameters resulted in different activation times of the tactor. Interestingly, in this particular dataset, different settings had three key time points in common where feedback was given.

Based on the results of the usability evaluation, a new prototype of the system is currently in development. It includes smaller accelerometers, smaller tactors and batteries that last longer than the current ones, all integrated in an appealing wristband by utilizing ${ }_{3} \mathrm{D}$ printing technology and the Bitalino platform [23]. Instead of a laptop, a small tablet will be used for testing. These steps also reduce the costs of 
Chapter 6: The development and evaluation of an arm usage coach for stroke survivors

the system significantly. Evaluations with stroke patients in clinic are planned for the end of 2015. We would like to measure them in clinic for two weeks daily and take baseline measurements before and resulting measurements the week after this intervention. We aim to help stroke patients in using their affected arm more often during daily-life tasks and that this eventually leads to a larger increase in their arm function and better performance at home. 
Chapter 7: The usability evaluation of sensing system combined with vibrotactile feedback in stroke survivors

\section{Chapter 7}

\section{THE USABILITY EVALUATION OF SENSING SYSTEM COMBINED WITH VIBROTACTILE FEEDBACK IN STROKE SURVIVORS}

B.Klaassen ${ }^{* 1,3}$, J.P. Held ${ }^{* 1,2,4}$, B.J.F. van Beijnum, 3, A.R. Luft ${ }^{2,4}$, P.H. Veltink ${ }^{1}$

${ }^{1}$ Biomedical Signals and Systems, MIRA - Institute for Biomedical Technology and Technical Medicine, University of Twente, Enschede, the Netherlands.

${ }^{2}$ Division of Vascular Neurology and Neurorehabilitation, Department of Neurology, University Hospital of Zurich, Zurich, Switzerland.

${ }^{3}$ Centre for Telematics and Information Technology, University of Twente, Enschede, The Netherlands.

${ }^{4}$ Cereneo A.G., Centre for Neurology and Rehabilitation, Vitznau, Switzerland.

**Bart Klaassen and Jeremia P. Held have contributed equally to this work.

\section{ABSTRACT}

Background: To increase the functional capabilities of stroke survivors during activities of daily living, patients receive rehabilitative training to recover adequate motor control. With the goal to motivate self-training by use of the arm in daily life tasks, a sensor system (Arm Usage Coach, AUC) was developed that provides VibroTactile (VT) feedback if the patient does not move the affected arm above a certain threshold level. The objective here is to evaluate VT feedback with regard to patient acceptance and effectiveness to increase daily-live arm usage in stroke survivors.

Method: The study was designed as a pilot trial to investigate the usability and the acceptance of feedback modalities. Stroke survivors, with mild to moderate arm impairments were enrolled. The subjects wore two AUC devices one on each wrist. VT feedback was given by the device on the affected arm. A semi-structured interview was performed before and after a measurement session with the AUC. In addition, the 
Chapter 7: The usability evaluation of sensing system combined with vibrotactile feedback in stroke survivors

System Usability Scale (SUS) questionnaire was given with scores of $71 \%$ indicating good usability.

Results: Ten ischemic chronic stroke patients (39 \pm 38 months after stroke) were recruited. Four out of ten subjects have worn the VT feedback on their dominant, affected arm. In the pre-measurement interview, eight participants indicated a preference for acoustic or visual over VT feedback. In the post evaluation interview, nine of ten participants preferred VT over visual and acoustic feedback. On average, the AUC gave VT feedback six times during the measurement session. All participants, with the exception of one, used their dominant arm more than the non-dominant. For the SUS, eight participants responded above 80, one between 70 and 80 and one participant responded below 50\%.

Discussion: More patients accepted and valued VT feedback after the test period, hence VT is a feasible feedback modality. The AUC can be used as a tele-rehabilitation device to train and maintain upper extremity use in daily-life tasks. 
Chapter 7: The usability evaluation of sensing system combined with vibrotactile feedback in stroke survivors

\section{INTRODUCTION}

To gain independence and increase the quality of life, inpatient neurorehabilitation is usually necessary for hemi paretic stroke survivors [1]. The functional capabilities of these patients are assessed using standardized tests, which are intended to predict functional performance after discharge. However, the power of this prediction is poor [2]. Therefore, daily-life monitoring of movement quality and quantity would help in guidance of therapy. We previously developed a monitoring solution using a full body inertial sensor suit [4-5], with resulting metrics capable of objectifying the quality of movement of stroke survivors. Monitoring in post-stroke patients demonstrated that while patients are capable of performing movements during the clinical assessments, they often do not use their affected arm in daily-life [6]. These results suggest that capability and arm training does not automatically translate into usage of the affected arm. An unobtrusive coaching system for arm-usage during daily-life might be able to motivate arm movement in these patients.

In addition to the INTERACTION project, a reduced sensor system was developed to coach and motivate stroke survivors in remembering to use their affected-arm during daily-live activities. This Arm Usage Coach (AUC) includes two inertial sensors and one VibroTactile (VT) device. The objective in this study is to investigate if VT feedback is accepted and helps to enhance arm movement in stroke survivors during daily-live activities with the AUC. 
Chapter 7: The usability evaluation of sensing system combined with vibrotactile feedback in stroke survivors

\section{METHODS}

\subsection{Study overview}

This study was designed as a usability study, conducted at the University Hospital Zurich, to investigate the usability and the acceptance of the AUC. Stroke survivors, with mild to moderate arm impairments were enrolled. A semi-structured interview was performed at enrolment, including a questionnaire, to assess the preference of different types of feedback modalities, e.g. vibrotactile, visual and acoustic feedback among stroke survivors. Then, a measurement session was performed using the AUC to let subjects experience vibrotactile feedback, responsive to their arm activity and the overall usage of the device. Afterwards another semi-structured interview was done and the System Usability Scale (SUS) [17] questionnaire was applied to evaluate the systems usability. An overview is shown in Figure 36.

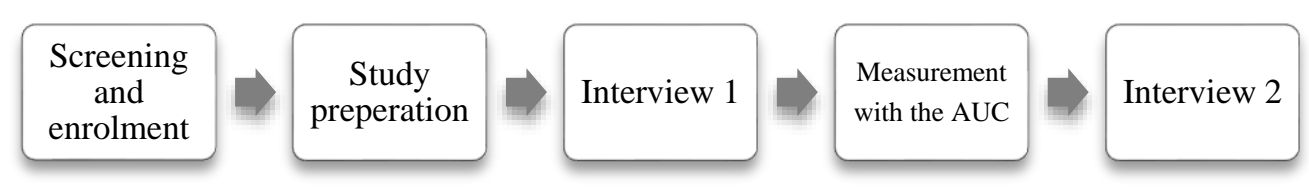

Figure 36: Flowchart of the study.

\subsection{Participant selection}

Stroke survivors (above 18 years old) with a unilateral ischaemic or haemorrhagic stroke and residual hemiparesis after completion of inpatient rehabilitation were enrolled between March and April 2016. Stroke survivors were required to have a mild to moderate arm impairment with a Fugl-Meyer Assessment upper extremity (FMAUE) score higher than 22 [15]. Additional exclusion criteria were as follows: if the participant has: 1) a major untreated depression, 2) a major cognitive or communication deficits, 3) a major comprehension or memory deficits, 4) major medical comorbidity, 5) severely impaired sensation, 6) sever neglect and 7) suffering from comprehensive aphasia 
Chapter 7: The usability evaluation of sensing system combined with vibrotactile feedback in stroke survivors

\subsection{Preparation of the study}

The participants gave written informed consent in accordance with the declaration of Helsinki. Approval in using the VT feedback system was given by the cantonal ethics in Zurich (Nr. 06-2016). Demographic data of the participant (including: age, gender, stroke event, work status, technical background, left or right handed, affected side and arm-dimensions) was documented. Furthermore, vibration sense on the affected arm was assessed using the Revised Nottingham sensory assessment (on the wrist) [16].

\subsection{Pre-interview}

A semi-structured interview was performed with each participant before the measurement intervention. The questions, with multiple answering options, are listed in Table 13 .

Table 13 Questions during pre-interview

\begin{tabular}{|c|c|c|}
\hline \# & Question & Answering options: \\
\hline & & Yes/No. If yes, what type? \\
\hline 1 & Do you use a self-tracking device? & $\begin{array}{l}\text { Smartphone, wrist band, walking } \\
\text { tracker, sleeping mat, other.... }\end{array}$ \\
\hline 2 & $\begin{array}{l}\text { Do you have any experience with getting } \\
\text { feedback? }\end{array}$ & $\begin{array}{l}\text { Yes/No. If yes, by whom? Therapist, } \\
\text { doctor, relatives, friends, other...) }\end{array}$ \\
\hline 3 & Do you get therapy for the upper extremities? & Yes/No \\
\hline 4 & What kind of feedback do you prefer? & Visual, acoustic, vibrotactile, none \\
\hline 5 & When should the feedback be applied? & $\begin{array}{l}\text { Every } 15 \text { minutes, per hour, every } \\
\text { second hour, if the arm is not } \\
\text { moving, one time per day, none... }\end{array}$ \\
\hline 6 & $\begin{array}{l}\text { Should the information about the feedback be } \\
\text { send to the clinician? }\end{array}$ & Yes/No \\
\hline
\end{tabular}


Chapter 7: The usability evaluation of sensing system combined with vibrotactile feedback in stroke survivors

\subsection{Arm Usage Coach Overview}

The Arm Usage Coach (AUC) is composed of two inertial sensors (Xsens B.V. xsens.com) (each weights 27 gram), an Elitac (Elitac B.V. Elitac.nl) VibroTactile (VT) actuator (weighting 200 gram) and a laptop [7]. Both sensors are wirelessly connected via an Xsens dongle, utilizing the Awinda protocol, and the Elitac system via Bluetooth. The inertial sensors are worn on each wrist of the participant. The Elitac VT actuator is placed on the affected-arm of the participant (Figure 37). The laptop is operating a software program for providing feedback, including: analysis of the sensor data, a decision feature and feedback as explained in Klaassen et al, 2016 [7]. There are three input parameters for the software, namely: 1) threshold of arm activities (between o and 9), 2) the time in which both arms should be compared to give feedback (average duration of a activity done by the participant) and 3) the ratio between the affected and non-affected arm usage (o-1, where 1 means the affected side should be used in the same amount as the non-affected side). The outcome parameters of the algorithms are: amount of arm-usage (when exceeding the threshold mentioned above, for the left and right arm as percentage of combined arm-usage) and the amount of feedback provided over time. A default set of input parameters is used for the software for each participant (threshold $=8 \mathrm{~m} / \mathrm{s}^{2}$ time $=20$ seconds and ratio $=1$ ). The VT feedback is given at $158.3+/-2.4$ Hertz and is given for only $489 \mathrm{~ms}$ (300 ms duration, and 189 spin-up and down time of the vibration motor to reach the vibration intensity). 
Chapter 7: The usability evaluation of sensing system combined with vibrotactile feedback in stroke survivors

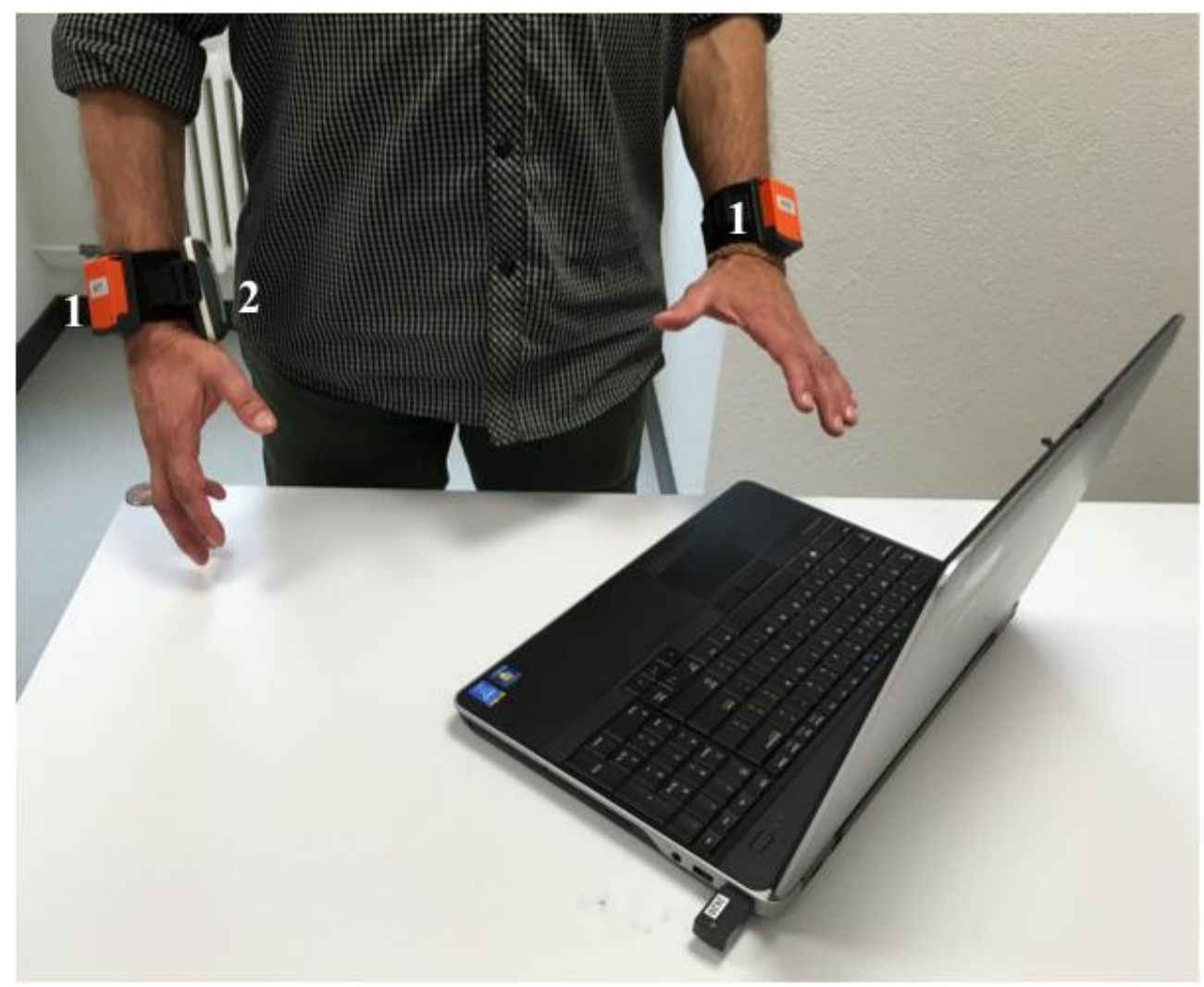

Figure 37. Right impaired stroke subject with AUC prototype. 1. Inertial sensors; 2. Elitac VT actuator.

\subsection{Measurement protocol}

At the start of the measurement, the participant was asked to stand in a comfortable neutral position. This will be the reference position in which arm-activity is detected [7]. Next, a selection of tasks, listed in Table 14, is performed by the participant twice in a specific measurement area. This measurement area consists of one room $\left(18 \mathrm{~m}^{2}\right)$ including a table and a chair, with a door leading to a 15 meter long hallway. This set of tasks is performed twice, one time where the VT feedback device is OFF and a second time where the device is turned $\mathrm{ON}$ for later comparison. 
Chapter 7: The usability evaluation of sensing system combined with vibrotactile feedback in stroke survivors

Task 1-3, 7, 8 and 10 are based on the protocol presented by van Meulen et al, 2015 [17]. The tasks were specifically designed for measuring stroke survivors performing simulated activities of daily living. Participants were instructed to stand up from the chair, walk to a door, open the door, walk through the door and close the door. Then, the participant was instructed to walk in the hallway for 15 meters, turn around and walk 15 meters back to the door, open, walk through the door, close the door and walk to a table. On this table (height $75 \mathrm{~cm}$ ), four blocks $\left(10 \mathrm{~cm}^{3}, 2.5 \mathrm{~cm}^{3}, 5 \mathrm{~cm}^{3}, 7 \cdot 5 \mathrm{~cm}^{3}\right)$, a cricket ball, a sharpening stone, a drinking glass and a marble were placed. Participants were asked to grasp each object and place them on a shelf. This combined set is part of the ARAT [18] assessment while standing. After all items were placed on the shelf, the participant was instructed to sit down in a chair. After the measurement, arm-usage and the amount of feedback that is given were presented, as shown in Figure 38.

Percentage of time of arm usage
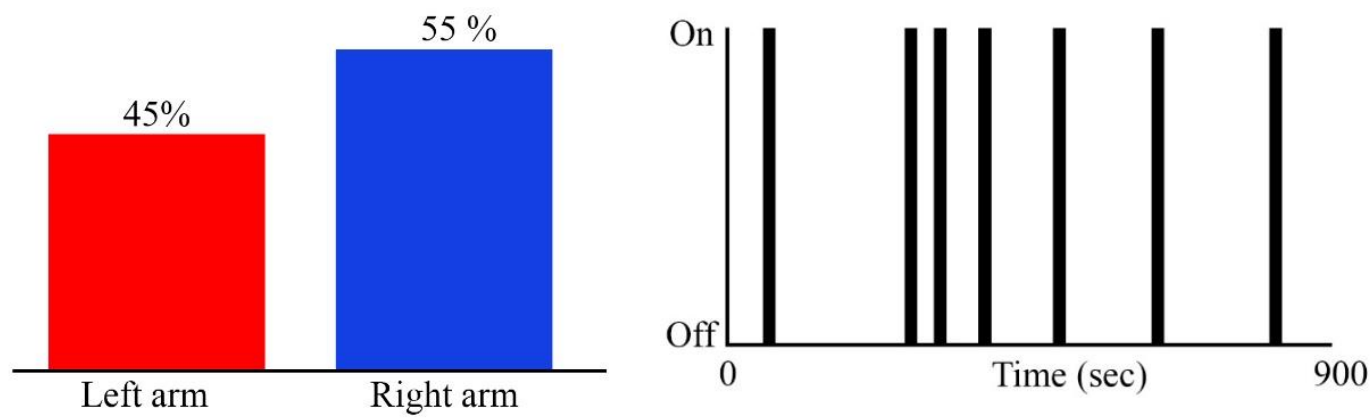

Figure 38. Examples of arm-usage and VT feedback results. Left) Percentage of time of arm usage, Right) VT Feedback over time 
Chapter 7: The usability evaluation of sensing system combined with vibrotactile feedback in stroke survivors

Table 14. Activity protocol

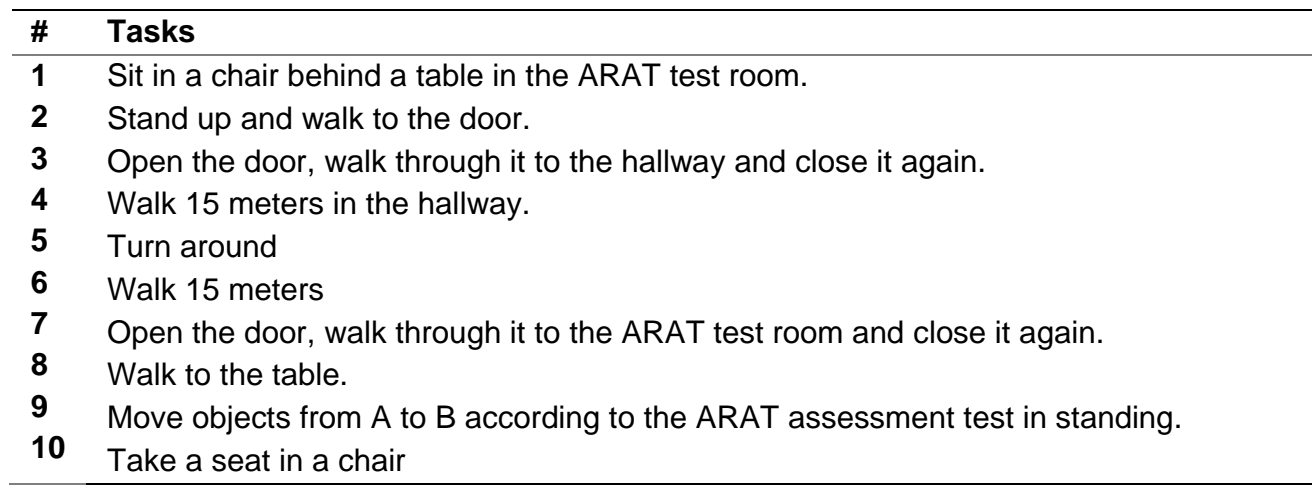

\subsection{Post-interview}

A semi-structured interview was done after the measurements. Two questionnaires were presented to the participants: 1) a custom made questionnaire as listed in Table 15 and 2) the System Usability Scale (SUS) [19]. The SUS is a well-established ten-item scale, designed to evaluate usability (effectiveness, efficiency and satisfaction) of technical devices. Questions are scored on a five-point Likert-type scale ranging from 'strongly agree' to 'strongly disagree'. Combined scores are translated to a range between 0-100, with a higher score meaning better usability [19]. SUS scores above 9os reflect best imaginable usability, 85 excellent, 71 good and 50 suggest fair usability. Scores below 50 indicate that using the product or intervention in practice with be will limited due to low compliance [20-21]. An additional customized questionnaire (Table 15) was designed to gain more insight into the patient's preferences in terms of feedback after using the AUC and if they would like to use the AUC at home to increase arm function in daily life. 
Chapter 7: The usability evaluation of sensing system combined with vibrotactile feedback in stroke survivors

Table 15. Custom questionnaire during the post interview

\begin{tabular}{|c|c|c|}
\hline \# & Question & Answering options: \\
\hline 1 & $\begin{array}{l}\text { What kind of feedback would you } \\
\text { prefer? }\end{array}$ & Visual, acoustic, vibrotactile, none \\
\hline 2 & When should the feedback be applied & $\begin{array}{l}\text { Every } 15 \text { minutes, per hour, every second } \\
\text { hour, if the arm is not moving, one time per } \\
\text { day, none... }\end{array}$ \\
\hline 3 & $\begin{array}{l}\text { Should the information about the } \\
\text { feedback be send to the clinician }\end{array}$ & Yes/No \\
\hline 4 & Would you use a device like the AUC & Yes/No \\
\hline 5 & When would you use the AUC & Daily, Weekly \\
\hline 6 & $\begin{array}{l}\text { Do you think the AUC could } \\
\text { compliment your standard therapy }\end{array}$ & Yes/No \\
\hline
\end{tabular}


Chapter 7: The usability evaluation of sensing system combined with vibrotactile feedback in stroke survivors

\section{RESUlTS}

\subsection{Participant enrolment}

Ten survivors of an ischemic stroke (39 \pm 38 months after the event) were recruited in the University Hospital Zurich. Four out of ten participants wore the AUC on the dominant, impaired arm. Six participants had arm FMA-UE score of larger or equal to 48 points; four participants showed poor to limited arm function (FMA-UE $\leq 47$ points). Details of each participant are listed in Table 16. Eight participants had impairments in vibration sense $(>64 \mathrm{~Hz})$ on the wrist, at the radial and ulnar styloid process and between the processes. Six participants reported to have a technical occupational background. Seven participants have used self-tracking devices before, for example a pulse-watch and walking trackers. One participant used an activity tracker worn on the wrist to monitor his arm movements during daily-life. 
Chapter 7: The usability evaluation of sensing system combined with vibrotactile feedback in stroke survivors

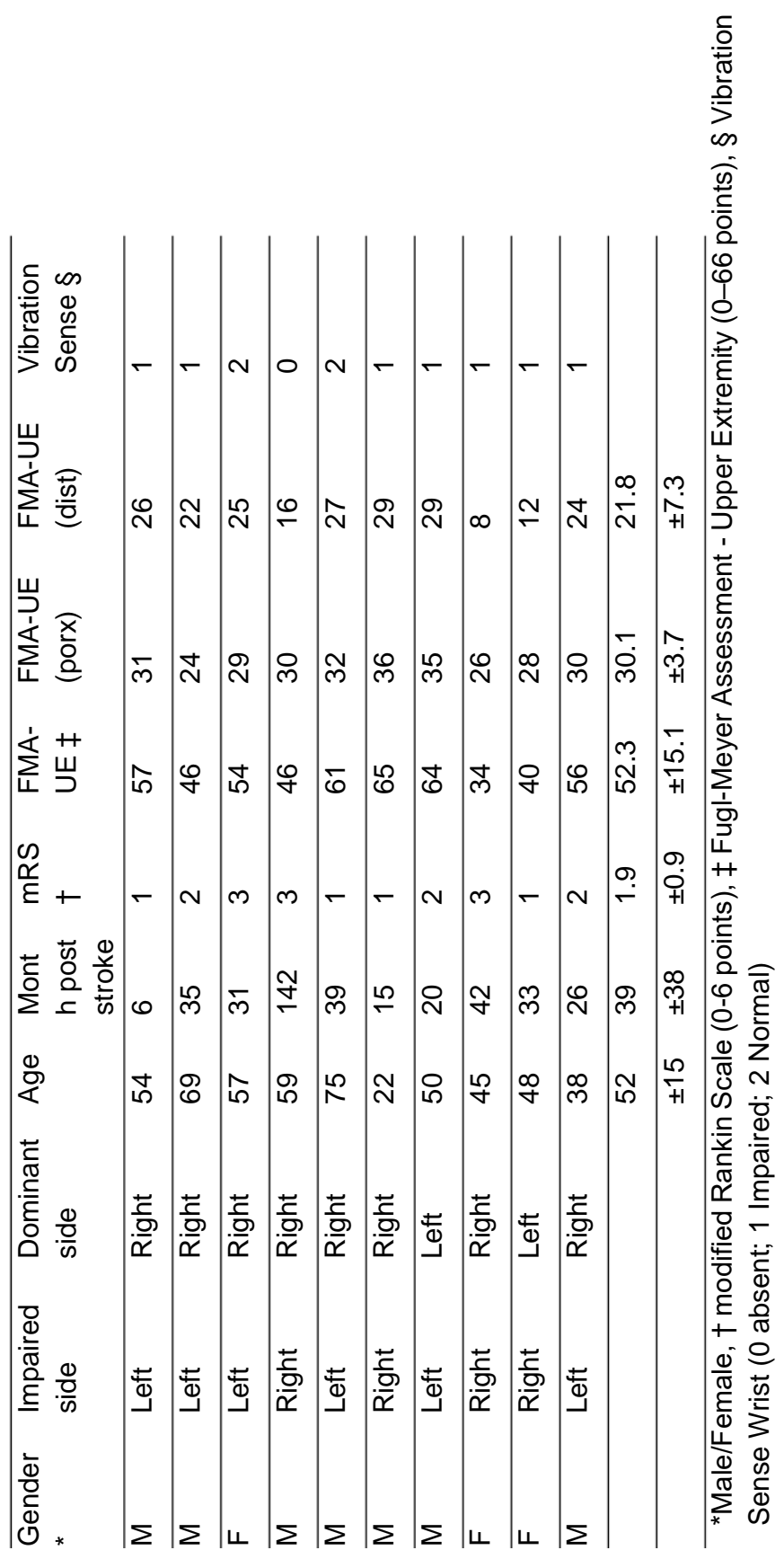

126
a 
Chapter 7: The usability evaluation of sensing system combined with vibrotactile feedback in stroke survivors

\subsection{Pre interview results}

The results from the questionnaire given during the pre-interview, are listed in Table 17. Seven participants had experience with self-tracking devices, e.g. wrist-band, walking-trackers or chest strap to measure heart rate. Seven participants mentioned they have experience with feedback on arm-movement provided by relatives, friends, and therapists or by self-tracking devices. Eight participants preferred acoustic or visual over VT feedback. Four participants mentioned that they would like to receive feedback hourly or when the arm is not moving, one participant every 15 minutes and one patient once daily. All participants agreed on sharing the feedback information with a clinician.

Table 17. Results interview 1

\begin{tabular}{|c|c|c|}
\hline \# & Question & Results: \\
\hline 1 & Do you use a self-tracking device? & Yes: 7; No: 3 \\
\hline 2 & $\begin{array}{l}\text { Do you have any experience with getting } \\
\text { feedback? }\end{array}$ & Yes: 7; No: 3 \\
\hline 3 & Do you get therapy for the upper extremities? & Yes: 5 ; No: 5 \\
\hline 4 & What kind of feedback would you prefer? & $\begin{array}{l}\text { Visual: } 2 \text {; acoustic: } 6 \text {; vibrotactile: } 3 \text {; } \\
\text { none: } 0\end{array}$ \\
\hline 5 & When should the feedback be applied? & $\begin{array}{l}\text { Every } 15 \text { minutes: } 1 \text {; per hour: } 4 \text {; every } \\
\text { second hour: } 0 \text {; if the arm is not moving: } \\
4 \text {; ones a day: } 1 \text {; none: } 0\end{array}$ \\
\hline 6 & $\begin{array}{l}\text { Should the information about the feedback be } \\
\text { send to the clinician? }\end{array}$ & Yes: $10 ;$ No: 0 \\
\hline
\end{tabular}

\subsection{Measurement results with Arm Usage Coach}

Table 18 shows arm-usage (in percentage of time of combined left/right arm-usage) for the impaired and non-impaired arm when the VT feedback was turned on or off. When the VT feedback was turned on, the amount of feedback given (\#FB) was reported. The difference (D) between the impaired and the non-impaired arm is shown for each feedback condition and the difference in arm-usage (AUD) is shown as either positive or negative (+ or -). Participant 3, 9 and 10 showed an increase in arm-usage on the impaired side when VT feedback was turned on. The other participants showed a decrease in arm movement. On average, the VT feedback device gave feedback six times during the measurement session. All participants, with the exception of participant 9, had a higher arm- usage for their dominant side. 
Chapter 7: The usability evaluation of sensing system combined with vibrotactile feedback in stroke survivors

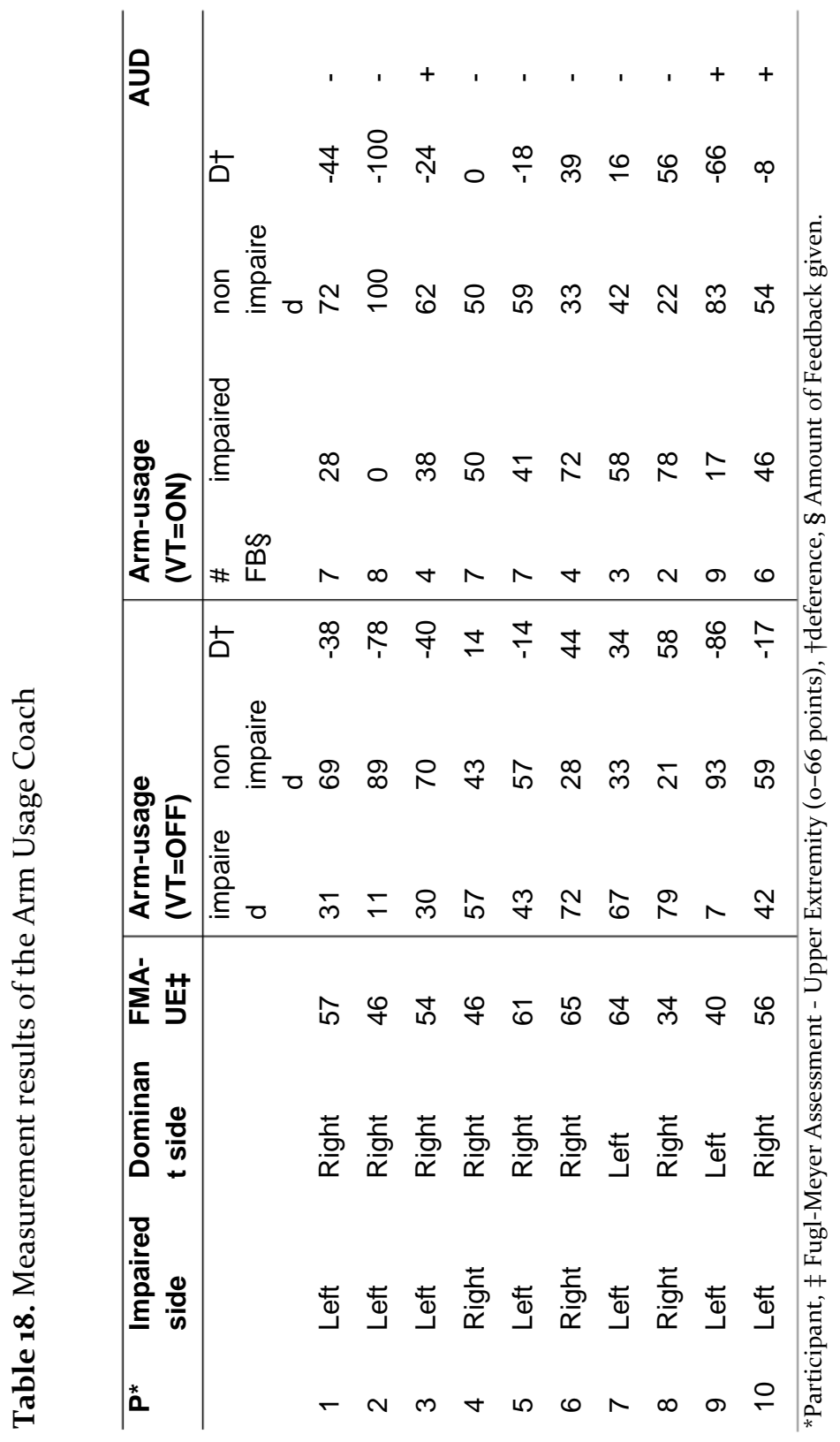


Chapter 7: The usability evaluation of sensing system combined with vibrotactile feedback in stroke survivors

\subsection{Post-interview}

\subsubsection{Custom questionnaire}

Nine out of to participants gave a preference for VT feedback above visual and acoustic feedback (Table 19). More so, seven participants liked the feedback when the affectedarm was not moving. In total, nine participants would utilize the AUC on a daily basis. All participants would share data generated by the system with a clinician. All participants indicated that they would use the Arm Usage Coach as an addition to their routine therapy.

Table 19. Results custom questionnaire during interview 2

\begin{tabular}{|c|c|c|}
\hline \# & Question & Results: \\
\hline 1 & $\begin{array}{l}\text { What kind of feedback would you } \\
\text { prefer? }\end{array}$ & $\begin{array}{l}\text { Visual: 3; Acoustic: 0; Vibrotactile: } 9 \text {, } \\
\text { none:0 }\end{array}$ \\
\hline 2 & When should the feedback be applied & $\begin{array}{l}\text { Every } 15 \text { minutes: } 0 \text {; per hour: } 3 \text {; every } \\
\text { second hour: } 0 \text {; if the arm is not moving: } 7 \text {; } \\
\text { one time per day: } 1 \text {; none: } 0\end{array}$ \\
\hline 3 & $\begin{array}{l}\text { Should the information about the } \\
\text { feedback be send to the clinician? }\end{array}$ & Yes: 10 ; No: 0 \\
\hline 4 & Would you use a device like the AUC? & Yes: $10 ;$ No: 0 \\
\hline 5 & When would you use the AUC? & Daily: 9; Weekly: 1 \\
\hline 6 & $\begin{array}{l}\text { Do you think the AUC could } \\
\text { compliment your standard therapy }\end{array}$ & Yes: 10; No: 0 \\
\hline
\end{tabular}

\subsubsection{System Usability Scale results}

On average, patients reported a SUS score of $84( \pm 20.7)$ out of 100 points, seen in Figure 39, indicating excellent usability [20]. Eight participants scored above 8o, one between 70 and 80 and one participant reported poor usability below 50 . This individual had the worst FMA-UE score $(\leq 40)$. 
Chapter 7: The usability evaluation of sensing system combined with vibrotactile feedback in stroke survivors
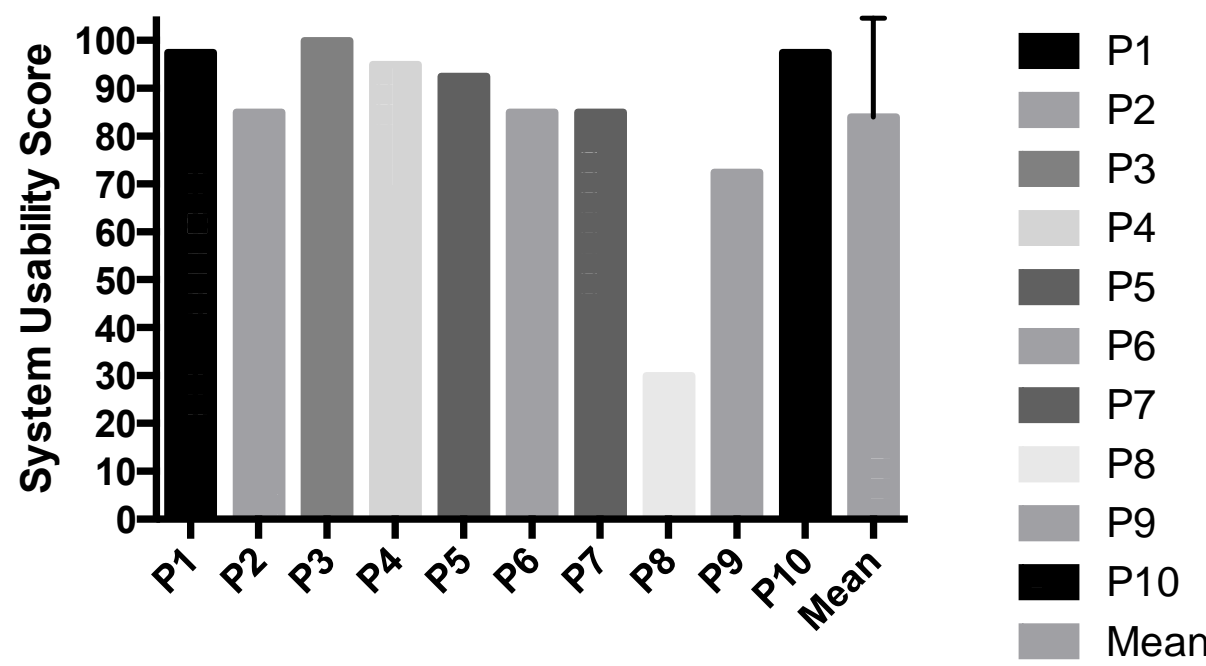

Figure 39. System Usability Scale results 
Chapter 7: The usability evaluation of sensing system combined with vibrotactile feedback in stroke survivors

\section{DISCUSSION}

The objective of this study was to investigate if VT feedback is accepted and usability of the AUC in stroke subjects during a daily-life activities simulation. In total, $70 \%$ of the participants said they would like to obtain feedback when the impaired arm was not moving during certain activities. This indicates good acceptance of the device. In total, nine out of ten participants were able to feel the vibration on their impairedarm. Therefore, it appears that participants accepted VT feedback. All participants reported they would like to use the device, that it complements their current therapy and that they prefer to share the data with a clinician.

As we were mainly interested in their opinion on VT feedback and AUC usage, we did not let participants experience other feedback modalities (except for visual), which might have positively influenced the post evaluation results in favour of VT feedback. Patients agree to send the data from the AUC to a care-professional to check on their progress and address this during therapy sessions, this could help to adapt the rehabilitation for upper extremity to the patient's needs. This indicates that AUC could be used as a telemonitoring and rehabilitation devices for upper extremity

Systems to train the upper extremity function with VT feedback in stroke patients have been previously developed [23-24]. It is known that intensive training after stroke has a positive effect in clinical outcome [24], but the effect of VT feedback on arm function is unclear [25]. The AUC could provide the opportunity to increase the armusage in daily-life by providing VT feedback. However, in this study we did not observe an effect of the AUC on arm-usage of the impaired side. This is due to the short observation period. Because the main objective here was to test the usability and acceptance of the system, hence a short measurement time was selected. Alternatively, feedback intensity may have been insufficient especially in patients with sensory deficits (although we did test whether or not participants felt the VT feedback before starting the measurement).

The usability reported with the AUC was high, with 84 out of 100 points on average for all participants. The usability of the AUC is therefore classified as excellent according to Bangor et al, 2009. The AUC however could, according to patients, be improved by being smaller and waterproof. The combination of monitoring and training stroke patients in daily-life with VT feedback is new and could be realized by using the AUC. Future versions need to include smaller and waterproof sensors. 
Chapter 7: The usability evaluation of sensing system combined with vibrotactile feedback in stroke survivors

Computational tasks should be performed by a smartphone, rather than on a laptop.

Based on the results of this usability study, an efficacy study, with extended protocol and pre-defined outcome parameter, could evaluate the impact of VT feedback on the stroke subjects arm movements in daily life activities.

\section{Conflict of Interest Statement}

Andreas R. Luft is scientific advisor for Hocoma AG (Volketswil, Switzerland), which develops rehabilitation technology. The remaining authors declare that the research was conducted in the absence of any commercial or financial relationships that could be construed as a potential conflict of interest.

\section{Authors and Contributors}

$\mathrm{BK}$ and $\mathrm{JH}$ drafted the manuscript and analysed the data. JH performed patient measurements inside the hospital with remote supervision of BK. BK prepared, tested and optimized the measurement system. BJVB helped in drafting the manuscript and assisted with data interpretation. AL, PV and BJVB supervised the research. All authors read, corrected/commented and approved the final manuscript.

\section{Funding}

This work was partially supported by the supported by the INTERACTION project, which was partially funded by the European Commission under the 7 th Framework Programme (FP7-ICT-2011-7-287351). 


\section{Chapter 8}

\section{CONCLUSION}

In this chapter we first conclude the research in this thesis and address each objective with included sub goals in detail (as presented in Chapter 1). Following, the contributions to science and society are mentioned and perspectives on future research are given.

\subsection{Conclusions}

Daily-life monitoring of the Quality of Movement (QoM) of stroke survivors during functional activities is essential for the optimal guidance of rehabilitation therapy after being discharged from the hospital. However, the performance of stroke survivors in a home environment is currently unknown, having no objective information about their QoM over time. In this thesis, we address two main objectives that focus on that problem. The first objective was to develop and evaluate a tele-supervision system and intelligent on-body feedback technology for monitoring and coaching stroke survivors in a home environment, which is addressed in Chapters 2,3,6 and 7. The second objective was to develop and evaluate new QoM metrics in stroke survivors, where a metric is defined as a measure of some property. This research is presented in Chapters 4 and 5 .

Due to our research, we gained new insights in how to develop and evaluate, by means of usability techniques, a new telemonitoring system capable of measuring ${ }_{3} \mathrm{D}$ motions of stroke survivors during daily-life activities. A full body inertial motion capture system, named INTERACTION, was successfully developed and implemented for monitoring stroke survivors during daily-life. A literature survey on usability of telemonitoring systems provided the foundations of implementing methods for usability evaluations on our system and its components. Stroke survivors were measured at home and in clinic and we were able to show differences in QoM by metrics that are clinically relevant. INTERACTION generates vast amounts of data with long measurement sessions during daily-life. Therefore, new methods for processing this data, from a higher perspective concerning the flow of data to detailed structures like activity monitors, were needed. During the evaluation of our inertial sensing system and associated metrics, we found that care-professionals prefer metrics that present a visual overview of certain movements, compared to metrics that 
only express e.g. angles or distances, during daily-life monitoring. To motivate patients in using their impaired side more during daily-life activities, a reduced sensing device, called the Arm Usage Coach (AUC), was developed that measures arm activity of stroke survivors at home and gave vibrotactile (VT) feedback. The device was working and positively accepted by stroke survivors. In addition, VT feedback was found useful by many as a method for reminding them in using their affected arm during daily-life activities. In total, our research shows new techniques to determine what happens with stroke survivors after discharge during daily-life. Although progress has been made, no definitive confirmation can be given on evidence of optimal guidance of rehabilitation. Therefore, additional research is needed. New projects, for example MiniSens [1] and NeuroCIMT [2], might push this type of technology even further into actual practice by continuing on the results from INTERACTION. To further elaborate on our conclusions, we address the sub goals associated with each main objective, as presented in Chapter 1, in more detail below. The first objective includes sub goal 1 till 3 and the second objective includes sub goals 4 and 5 .

\section{Identify relevant usability evaluation approaches currently used in tele monitoring devices.}

In Chapter 2, usability evaluation strategies were investigated in a literature survey in which we related different types of telemonitoring systems to, for example, patient condition and usability methods applied. We found that questionnaires are the most applied method to evaluate usability across different types of telemedicine systems and end-users. By using information from Chapter 2, we gained new insight in how to evaluate telemedicine systems, which we applied in Chapters 3, 5 and 7 . We found that interview and logging techniques were preferred for measuring usability among stroke survivors. We applied that knowledge throughout the design of the INTERACTION system (Chapter 3) and it was also part of the evaluation of the AUC with stroke survivors (Chapter 7). The knowledge gained in Chapter 2 enabled us to construct an approach to evaluate the INTERACTION system and its metrics with care-professionals (Chapter 5). 


\section{Develop and evaluate a tele-supervision system to be able to monitor stroke patients during daily-life tasks}

In Chapter 3, the development of the INTERACTION motion capture system is described, with particular focus on the telemonitoring aspect. We developed, implemented and evaluated our sensor system in close collaboration with designers, engineers, care-professionals and patients. In the development process an iterative design approach was adopted, where system complexity was gradually increased. After a series of test measurements in the Netherlands with stroke survivors, the system was stable and robust enough for long-term daily-life measurements in Switzerland. During those patient measurements, we found that, even though the technological concept of INTERACTION was fully implemented in daily-life, the quality of the capture movement data was depending on many aspects. In short measurements (like in clinic) a calibration is performed for each session to prevent sensor drift due to e.g. magnetic disturbances. Home measurements often took longer, up-to three hours without calibration, resulting in a reduction of the $3 \mathrm{D}$ reconstruction quality. During the evaluation (Chapter 5), the largest drawbacks care-professionals mentioned for such systems are the set- up time of the sensor suit (donning and doffing, connecting the sensors) and that data processing might take long. They reason that as this type of assistive technology is still in addition to regular therapy, limited time is available in clinic. Reducing the setup time might be possible with a reduced sensor set, however a strap-based system instead of a system integrated into shirt and trousers might become too obtrusive to wear during daily live, unless the sensor and strap size can be reduced. In sum, we showed that it is possible to monitor these patients on an ambulatory, outpatient basis for longer periods of time by unobtrusively wearing a sensor system, where patients did more than just basic activities, including shopping at the mall, drive their car, bike, and physical exercise training.

\section{Develop and evaluate on-body feedback technology able to motivate stroke survivors in using their impaired arm in daily-life tasks}

In Chapter 6, a new feedback system was designed named the Arm Usage Coach (AUC), to motivate stroke survivors to use their affected arm more often during dailylife tasks. The device was evaluated on usability by healthy subjects and we found that changes in the design in terms of size were needed. To further evaluate the AUC, a study with 10 stroke survivors was performed in Chapter 7 . We found that most patients would like to use a VT feedback device, such as the AUC, as it was found to be intuitive and unobtrusive and that the system complements their current therapy. We applied the System Usability Scale (SUS) questionnaire to objectively capture the 
usability of the AUC. The SUS method was found in many publications within the literature survey of Chapter 2 and provides a quick objective method for measuring usability. It provides a validated measure to judge the usability of the AUC for future research. We found high scores among most patients, which is an excellent starting point for further development towards actual daily-life use. The combination of monitoring and coaching stroke survivors in daily-life for the upper extremities with VT feedback is new and could be realized by the system we designed.

\section{Develop new metrics of extremity function which are able to show differences in the QoM of stroke patients in clinic and home environment}

In Chapter 4, we presented a coherent set of metrics for measuring the QoM in stroke survivors. We showed that these can be used for the objective evaluation of intrapatient differences in movement quality between in-clinic measurements (structured measurements in a controlled environment) and measurements in a daily-life setting (where the patient movements are free). The metrics were constructed for the upper and lower extremities separately, so that the modularity of the sensing system was kept intact. It was part of an early requirement of the system as certain patients only need upper or lower extremity recovery or training. There are some factors that should be considered related to the metrics and clinical relevancy. First, differences between assessed movements during in- clinic measurements and measurements during daily-life might be the result of the different circumstances in which the data are captured. In-clinic, patients were instructed to perform a specific task which might force them to, for instance, use their affected side or walk at a specific speed. While during daily-life measurements, with no specific instructions, it can be expected that patients will perform tasks in the most comfortable way to them. Therefore, intrapatient differences might be expected. The proposed metrics in Chapter 4 can be used to describe relative differences between a stroke survivor's affected and non-affected side for different measurements, although the above reasons have to be accounted for when comparing in-clinic with daily-life measurements.

\section{Evaluate QoM metrics with care-professionals}

In Chapter 5, the usability of the QoM metrics (as presented in Chapter 4) and their clinical relevance were evaluated by 23 care- professionals from outside the INTERACTION project. Care-professionals were able to understand and interpret most of these metrics. Most care-professionals were interested in higher-level metrics such as the movement visualisation of the hand over time in a so-called hand 
distribution plots, compared to more basic metrics like shoulder abduction. This was due to the absence of the patient's state (e.g. feels tired), intentions (e.g. does the patient wants to grab a piece of paper or a heavy cooking pan) or surroundings (e.g. is he walking indoors or outdoors, on what type of surface, etc.).

\subsection{Contributions to science and society}

The research presented in this thesis has contributed to both fundamental and applied areas of science and also has an important (potential) societal impact regarding diagnostics and treatment of (stroke) survivors by enabling quantitative monitoring during daily-life activities:

- An extensive literature survey on usability evaluations of telemonitoring systems was performed (Chapter 2). The study presents new insights in usability techniques for evaluating telemonitoring systems. These insights can help researches in optimizing their usability strategies during the development of a specific type of system for a specific patient condition. The survey also presents an overview of the amount of publications (including its features, such as what type of usability strategy the study included) per year and per continent, which in turn could help in predicting future trends in usability evaluation strategies.

- $\quad$ Realized, in a multidisciplinary team with particular focus on the telemonitoring aspects, a full-body inertial sensing system, unobtrusive to wear by stroke survivors during daily-life (Chapter 3). The system enables telemonitoring capabilities by constructing an architecture capable of capturing movement data, storing data remotely, processing the data and finally, visualising patient data in a report form. This system was used to monitor stroke survivors at home to gain new insights into the performance of these patients during daily-life activities.

- Clinically relevant QoM metrics were developed, implemented and evaluated (Chapter 4 and 5), enabling new insights into the differences between in-clinic and outpatient measurements of stroke survivors over longer periods of time. This in turn might assist care-professionals in understanding what is happening with stroke survivors after discharge from the hospital to their homes.

- We have designed, implemented and evaluated a reduced sensor system (the AUC, Chapter 6 and 7), capable of monitoring and coaching stroke survivors and giving feedback based on arm movement activity. This, in turn might engage patients in using their impaired arm more often during daily-life activities. We also found that stroke survivors prefer vibrotactile feedback as a feedback method, which sets the foundation for other researchers in developing assistive 
technological devices for stroke survivors.

- An in-depth view on the opinions by care-professionals in using inertial motion capture as an assistive technology, including working with QoM metrics as opposed to traditional clinical assessments, was given (Chapter 5). Developers in assistive devices for healthcare still face the problem that many care-professionals do not, cannot or slowly adapt new technology into their daily-practices. The findings we present might help other developers in understanding why this is, in our case related to an inertial motion capture system and associated metrics, and take new approaches in designing and introducing assistive devices into daily practices.

\subsection{Challenges and future research}

The knowledge obtained in this thesis can be advanced into different directions. This section presents research challenges and new ideas for future research.

- We were able to extract vast amounts of data from our literature survey (Chapter 2) on usability in telemonitoring systems. What we did not address was to objectively assess the acceptability of each usability method per publication and comparing them among each other. Each publication employed different usability assessment metrics and targets different end-users. Therefore, comparing publications for acceptability is quite a challenge due to the many techniques and usability techniques applied.

- $\quad$ The INTERACTION system can only be used for measuring daily-life movements up to three hours due to battery-life (Chapter 3). Within this limited time window, no significant change in movement performance was to be expected. When measuring for longer periods of time, physical activity may change as activity levels may vary during the day. It would be very interesting to compare early morning and evening results of stroke survivors, to see potential changes of physical activity and related QoM, as increased levels of physical activity are associated with a reduced risk for stroke and cardiovascular disease and enhanced physical and psychosocial performance [3].

- More research should be conducted in the motivational aspects of the patient (Chapter 4 and 5), which is prominent when a patient trains in clinic compared to at home [4-5]. If the patient receives proper feedback at home and feels he or she is being coached remotely, it might have a similar effect but that is not yet clear. 
- In addition to stroke survivors, the INTERACTION system and data analysis methods (Chapter 2, 4 and 6) might be useful for other groups of patients, e.g. elderly people, or people with Parkinson's disease, multiple sclerosis, and other neurological diseases. Daily-life assessment of their quality of movement might give more insight on the influence of the patient's condition at performing activities of daily living.

- For the AUC (Chapter 6), a next step would be to develop a new version, with smaller and waterproof sensors and the computation of the data should be moved to a smartphone, rather than on a laptop. Then, a long term effect study on stroke survivors can be performed to investigate the effect of the AUC on arm activity levels of their affected side, and resulting QoM over time. Therefore, more research has to be done to confirm if there is a positive effect in motivating stroke survivors in using their impaired side more often in daily-life.

- A few advances have to be made in order to reduce the complexity of the INTERACTION system and increase it robustness. The number of sensors has to be reduced to become less invasive for patients at home and the system needs to be personalized for each patient. For example, if a patient only needs upper extremity training he or she might wear two sensors on the wrists and perhaps one on the sternum only. By using a motion estimation framework and deep neural networks, only data from a small amount of sensors have to be uploaded via e.g. a phone to a secure database, where full body reconstruction and activity recognition can be realised based on an existing high quality motion capture database [6-8]. If a reduced version of the sensor system can be implemented on a larger scale, we can gain more knowledge from a wider variety of stroke survivors. We can use big data approaches to analyse the data, to see trends over time, and we can present digital usability questionnaires for user-feedback to gain more insights into the usage of the system. Further improvements can be achieved by reducing the sensor size and processing time for near-real-time visualisation on a web-portal. Many companies are successful in implementing this strategy with only a few sensors (e.g. Fitbit [9] and ValedoMotion [10]). If so, it might result in a change in therapy of stroke survivors and outpatient, ambulant monitoring and coaching will increase. 


\section{REFERENCES}

\section{References Chapter 1}

1 Sacco, R. L., Kasner, S. E., Broderick, J. P., Caplan, L. R., Culebras, A., Elkind, M. S., ... \& Janis, L. S. (2013). An updated definition of stroke for the 21st century a statement for healthcare professionals from the American Heart Association/American Stroke Association. Stroke, 44(7), 2064-2089.

2 Kochanek KD, Xu JQ, Murphy SL, Arias E. Mortality in the United States, 2013. NCHS Data Brief, No. 178. Hyattsville, MD: National Center for Health Statistics, Centers for Disease Control and Prevention, US Dept. of Health and Human Services; 2014.

3 Mozzafarian D, Benjamin EJ, Go AS, et al. Heart disease and stroke statistics2015 update: a report from the American Heart Association. Circulation. 2015:e29322.

4 Kelly-Hayes, M., Beiser, A., Kase, C. S., Scaramucci, A., D’Agostino, R. B., \& Wolf, P. A. (2003). The influence of gender and age on disability following ischemic stroke: the Framingham study. Journal of Stroke and Cerebrovascular Diseases, 12(3), 119-126.

5 Godwin, K. M., Wasserman, J., \& Ostwald, S. K. (2011). Cost associated with stroke: outpatient rehabilitative services and medication. Topics in stroke rehabilitation, 18(sup1), 676-684.

6 Taylor, T. N., Davis, P. H., Torner, J. C., Holmes, J., Meyer, J. W., \& Jacobson, M. F. (1996). Lifetime cost of stroke in the United States. Stroke, 27(9), 1459-1466.

7 Chen, Q., Kane, R. L., \& Finch, M. D. (2000). The cost effectiveness of post-acute care for elderly Medicare beneficiaries. Inquiry, 359-375.

8 Lafosse, C., Kerckhofs, E., Troch, M., \& Vandenbussche, E. (2003). Upper limb exteroceptive somatosensory and proprioceptive sensory afferent modulation of hemispatial neglect. Journal of clinical and experimental neuropsychology, 25(3), 308-323

9 Dettmers C, Teske U, Hamzei F, Uswatte G, Taub E, Weiller C. Distributed form of constraint-induced movement therapy improves functional outcome and quality of life after stroke. Arch Phys Med Rehabil 2005;86:204- 9.

10 Lewis GN, Byblow WD. Neurophysiological and behavioural adaptations to a bilateral training intervention in individuals following stroke. Clin Rehabil 2004;18:48-59. 
11 Dickstein R, Dunsky A, Marcovitz E. Motor imagery for gait rehabilitation in poststroke hemiparesis. Phys Ther 2004;84:1167-77.

12 Altschuler EL, Wisdom SB, Stone L. Rehabilitation of hemiparesis after stroke with a mirror. Lancet 1999;353:2035-6.

13 Sütbeyaz S, Yavuzer G, Sezer N, Koseoglu F. Effect of mirror therapy on lower extremity motor recovery and activity level after stroke. Arch Phys Med Rehabil 2007:88:555-9.

14 Page SJ, Levine P, Leonard AC. Effects of mental practice on affected limb use and function in chronic stroke. Arch Phys Med Rehabil 2005;86:399-402.

15 Colborne GR, Olney SJ, Griffin MP. Feedback of ankle joint angle and soleus electromyography in the rehabilitation of hemiparetic gait. Arch Phys Med Rehabil 1993;74:1100-6.

16 Moreland JD, Thomson MA, Fuoco AR. Electromyographic biofeedback to improve lower extremity function after stroke: a meta-analysis. Arch Phys Med Rehabil 1998;79:134-40.

17 Kahn LE, Zygman ML, Rymer WZ, Reinkensmeyer DJ. Robot-assisted reaching exercise promotes arm movement recovery in chronic hemiparetic stroke: A randomized controlled pilot study. J Neuroeng Rehabil 2006; 21:12.

18 Kawahira K, Higashihara K, Matsumoto S, Shimodozono M, Etoh S, Tanaka N, Sueyoshi Y. New functional vibratory stimulation device for extremities in patients with stroke. Int J Rehabil Res 2004;27:335-7.

19 Johansson BB, Haker E, von Arbin M, Britton M, Langstrom A, Terent A et al. Acupuncture and transcutaneous nerve stimulation in stroke rehabilitation. Stroke 2001;32:707-13.

20 Yavuzer G, Geler-Kulcu D, Sonel-Tur B, Kutlay S, Ergin S, Stam HJ. Neuromuscular electric stimulation effect on lower-extremity motor recovery and gait kinematics of patients with stroke: a randomized controlled trial. Arch Phys Med Rehabil 2006;87:536-40.

21 Pollock, A., Baer, G., Campbell, P., Choo, P. L., Forster, A., Morris, J., ... \& Langhorne, P. (2014). Physical Rehabilitation Approaches for the Recovery of Function and Mobility After Stroke Major Update. Stroke, 45(10), ezo2-e2o2.

22 Winstein, C. J., Stein, J., Arena, R., Bates, B., Cherney, L. R., Cramer, S. C., ... \& Lang, C. E. (2016). Guidelines for Adult Stroke Rehabilitation and Recovery A Guideline for Healthcare Professionals From the American Heart Association/American Stroke Association. Stroke.

23 Putman, K., \& De Wit, L. (2009). European comparison of stroke rehabilitation. Topics in stroke rehabilitation, 16(1), 20-26. 
24 Stuart, M., Ryser, C., Levitt, A., Beer, S., Kesselring, J., Chard, S., \& Weinrich, M. (2005). Stroke rehabilitation in Switzerland versus the United States: a preliminary comparison. Neurorehabilitation and neural repair, 19(2), 139-147.

25 Eurostat - Statistics explained. Statistical Office of the European Union. Online available at http://ec.europa.eu/eurostat/statisticsexplained/index.php/Main_Page [Last visited: 29-02-2016]

26 Donnan GA, Fisher M, Madeod M, Davis SM. Stroke (20o8) [Seminar]. The Lancet , Volume 371 , Issue $9624,1612-1623$

27 Mozaffarian D, Benjamin EJ, Go AS, et al. Heart disease and stroke statistics-2015 update: a report from the American Heart Association. Circulation. 2015 ;e29-322.

28 Di Carlo, A. (2009). Human and economic burden of stroke. Age and ageing, 38(1), 4-5.

29 Priority Medicines for Europe and the World: A Public Health Approach to Innovation. World Health Organization, 2004.

30 Peleg, M., Shahar, Y., \& Quaglini, S. (2014). Making healthcare more accessible, better, faster, and cheaper: the MobiGuide Project. Eur J e-Practice., 20, 5-20.

31 Fung, N. L., Jones, V. M., Broens, T. H., Larburu, N., Bults, R. G., Shalom, E., \& Hermens, H. J. (2016). The Conceptual MADE Framework for Pervasive and Knowledge-Based Decision Support in Telemedicine. International Journal of Knowledge and Systems Science (IJKSS), 7(1), 25-39.

32 Roetenberg, D., Luinge, H., \& Slycke, P. (2009). Xsens MVN: full 6DOF human motion tracking using miniature inertial sensors. Xsens Motion Technologies BV, Tech. Rep.

33 Diaz, K. M., Krupka, D. J., Chang, M. J., Peacock, J., Ma, Y., Goldsmith, J., ... \& Davidson, K. W. (2015). Fitbit: An accurate and reliable device for wireless physical activity tracking. Intl J Cardiol, 185, 138-40.

34 Jezernik, S., Colombo, G., Keller, T., Frueh, H., \& Morari, M. (2003). Robotic orthosis lokomat: a rehabilitation and research tool. Neuromodulation: Technology at the neural interface, 6(2), 108-115.

35 Colomer, C., Baldovi, A., Torrome, S., Navarro, M. D., Moliner, B., Ferri, J., \& Noe, E. (2013). Efficacy of Armeo ${ }^{\circledR}$ Spring during the chronic phase of stroke. Study in mild to moderate cases of hemiparesis. Neurologia (English Edition), 28(5), 261267.

36 Burke, J. W., McNeill, M. D. J., Charles, D. K., Morrow, P. J., Crosbie, J. H., \& McDonough, S. M. (2009). Optimising engagement for stroke rehabilitation using serious games. The Visual Computer, 25(12), 1085-1099. 
37 Deutsch, J. E., Brettler, A., Smith, C., Welsh, J., John, R., Guarrera-Bowlby, P., \& Kafri, M. (2011). Nintendo wii sports and wii fit game analysis, validation, and application to stroke rehabilitation. Topics in stroke rehabilitation, 18(6), 701-719.

38 Qualisys, A. B. (2008). Qualisys motion capture systems. URL: http://www. qualisys. se/, accessed on, 04-04.

39 Kadaba, M. P., M. E. Wootten, H. K. Ramakrishnan, D. Hurwitz, and G. V. B. Cochran. "Assessment of human motion with VICON." In Proc. Biomechanics Symp. ASME, pp. 335-338. 1987.

40 Zhuang, Y., Liu, X., \& Pan, Y. (1999). Video motion capture using feature tracking and skeleton reconstruction. In Image Processing, 1999. ICIP 99. Proceedings. 1999 International Conference on (Vol. 4, pp. 232-236). IEEE.

41 González, A., Hayashibe, M., \& Fraisse, P. (2012, October). Estimation of the Center of Mass with Kinect and Wii balance board. In Intelligent Robots and Systems (IROS), 2012 IEEE/RSJ International Conference on (pp. 1023-1028). IEEE.

42 Bruce Greenfield, P. T., \& Musolino, G. M. (2012). Technology in rehabilitation: ethical and curricular implications for physical therapist education. Journal of Physical Therapy Education, 26(2), 81.

43 Peterson, D. B., Peterson, D. B., \& Murray, G. C. (2006). Ethics and assistive technology service provision. Disability and rehabilitation: assistive technology, 1(1-2), 59-67.

44 Isern, D., \& Moreno, A. (2008). Computer-based execution of clinical guidelines: a review. International journal of medical informatics, 77(12), 787-8o8.

45 Vollenbroek-Hutten, M. M., \& Hermens, H. J. (2010). Remote care nearby. Journal of telemedicine and telecare, 16(6), 294-301.

46 Research2guidance (2015) - EU mHealth Market Conditions Benchmarking 2015. Online available at http://research2guidance.com/ [Last visited 29-02-2016]

47 Clark et al. Telemonitoring or structured telephone support programmes for patients with chronic heart failure: systematic review and meta-analysis. BMJ. 2007 Apr 10;334:942. doi:10.1136/bmj.39156.536968.55

48 Noel et al. Home Telehealth reduces healthcare costs. Telemedicine J E Health. 2004;10:170-183. doi:10.1089/tmj.2004.10.170

49 Sanjay Sood, Victor Mbarika, Shakhina Jugoo, Reena Dookhy, Charles R. Doarn, Nupur Prakash, and Ronald C. Merrell. Telemedicine and e-Health. November 2007, 13(5): 573-590. doi:10.1089/tmj.2006.0073.

50 A health telematics policy in support of WHO's Health-For-All strategy for global health development: report of the WHO group consultation on health telematics, 11-16 December, Geneva, 1997.Geneva, World Health Organization, 1998. Online 
available here: http://www.who.int/goe/publications/goe_telemedicine_2010.pdf [Last visited 29-02-2016]

51 ISO 9241-11 Ergonomic requirements for office work with visual display terminals (VDTs) -- Part 11: Guidance on usability. International Organization for Standardization, Switzerland

52 Schwamm, L. H., Holloway, R. G., Amarenco, P., Audebert, H. J., Bakas, T., Chumbler, N. R., ... \& Mayberg, M. (2009). A review of the evidence for the use of telemedicine within stroke systems of care A scientific statement from the American Heart Association/American Stroke Association. Stroke, 40(7), 26162634 .

53 Kollen B, Kwakkel G, Lindeman E. Functional recovery after stroke: a review of current developments in stroke rehabilitation research. Reviews on recent clinical trials 1 (2006) 75-80.

54 Bussmann J.B.J, Ebner-Priemer UW, Fahrenberg J. Ambulatory activity monitoring: progress in measurement of activity, posture, and specific motion patterns in daily life. European Psychologist 14 (2009) 142-152.

55 Lo AC, Guarino PD, Richards LG, Haselkorn JK, Wittenberg G F, Federman DG, et al. Robot-assisted therapy for long-term upper-limb impairment after stroke. The New England Journal of Medicine 2010;362(19):1772-83. NCToo372411. Robotic assisted upper-limb neurorehabilitation in stroke patients. http:// clinicaltrials.gov/ct2/show/NCToo372411 


\section{References Chapter 2}

$1 \quad$ ISO 9241-11 Ergonomic requirements for office work with visual display terminals (VDTs) -- Part 11: Guidance on usability. International Organization for Standardization, Switzerland

2 Bevan, N. (1991). What is Usability. Proceedings of the $4^{\text {th }}$ International Conference on HCI, Stuttgart, September 1991

3 ETSI (1993). Human Factors; guideline for usability evaluations of telecommunication systems and services. ETR 095. DTR/HF-3001, ICS: 33.020, 33.040.40. European Telecommunication standards institute (ETSI). [Available online] http://www.etsi.org/deliver/etsi_etr/oo1_099/095/o1_6o/etr_o95eo1p.pdf [last visited: 18-07-2015]

4 Macleod, M., Bowden,R (1997). The MUSiC performance measurement method. Behavior and Information technology, 1997, vol. 16, 4/5, 279-293

5 Sanjay Sood, Victor Mbarika, Shakhina Jugoo, Reena Dookhy, Charles R. Doarn, Nupur Prakash, and Ronald C. Merrell. Telemedicine and e-Health. November 2007, 13(5): 573-590. doi:10.1089/tmj.2006.0073.

6 A health telematics policy in support of WHO's Health-For-All strategy for global health development: report of the WHO group consultation on health telematics, 11-16 December, Geneva, 1997.Geneva, World Health Organization, 1998. Online available here: http://www.who.int/goe/publications/goe_telemedicine_2010.pdf [Last visited 29-02-2016]

7 Gillham B. Developing a Questionnaire (Real World Research). Bloomsbury Academic; 2 edition (March 10, 2008). ISBN-13: 978-0826496317

8 Sackett DL, Richardson WS, Rosenberg W, Haynes RB (1997). Evidence-based medicine: How to practice and teach EBM. Evid Based Med 2000;5:136 doi:10.1136/ebm.5.5.136

9 Witkin, K. B. (Ed.). (2013). Clinical Evaluation of Medical Devices: principles and case studies. Springer Science \& Business Media.

10 Lewis,J.R.(1995). IBM computer usability satisfaction questionnaires: Psychometric evaluation and instructions for use, Int. J. Hum. Comput. Interact. 7 (1) (1995) 57-78

11 Kirakowski, J. (2011). Software Usability Measurement Inventory (SUMI). Available online at http://sumi.ucc.ie/index.html [last visited: 18-o8-2015]

12 Hart, S. G. (2006). NASA-Task Load Index (NASA-TLX); 20 Years Later. Proceedings of the Human Factors and Ergonomics Society 5oth Annual Meeting, 904-908. Santa Monica: HFES. 
13 Brook, J (1996). SUS - A quick and Dirty usability scale. Available online at thttp://www.usabilitynet.org/trump/documents/Suschapt.doc [last visited: o9o1-2014]

14 EUnetHTA. Available online at http://www.eunethta.eu/ [last visited: 18-07-2015]

15 Human-Computer Interaction and Assistive Technology Laboratory, Foundation for Research and Technology, Institute of Computer Science, Greece. Available online at http://www.ics.forth.gr/ [Last visited: 18-07-2015]

16 Norman, K.,Shneiderman, B.,Harper,B. QUIS: The Questionnaire for User Interaction Satisfaction. Available online at http://www.cs.umd.edu/hcil/quis/ [Last visited: 18-08-2015]

17 Fruhling, A., and Lee, S., "Assessing the Reliability, Validity and Adaptability of PSSUQ" (2005). AMCIS 2005 Proceedings. Paper 378.

18 Venkatesh V (200o) Determinants of perceived ease of use: integrating control, intrinsic motivation, and emotion into the technology acceptance model. Information System Research 11: 265-342.Doi: 10.1287/isre.11.4.342.11872

19 Venkatesh, Viswanath, and Fred D. Davis. "A theoretical extension of the technology acceptance model: Four longitudinal field studies." Management science 46.2 (2000): 186-204. Doi: 10.1287/mnsc.46.2.186.11926

20 Clark et al. Telemonitoring or structured telephone support programmes for patients with chronic heart failure: systematic review and meta-analysis. BMJ. 2007 Apr 10;334:942. doi:10.1136/bmj.39156.536968.55

21 Inglis SC. Structured Telephone Support or Telemonitoring Programmes for Patients with Chronic Heart Failure (Review). The Cochrane Library. 2010;(8). doi: 10.111//j.1756-5391.2010.01104

22 Klersy C. et al. A Meta-Analysis of Remote Monitoring of Heart Failure Patients. J Am Coll Cardiol. 2009 Oct 27;54(18):1683-94. doi:10.1016/j.jacc.2009.08.017

23 Noel et al. Home Telehealth reduces healthcare costs. Telemedicine J E Health. 2004;10:170-183. doi:10.1089/tmj.2004.10.170

24 Cohen, A. (2010). The New World of Home Telemonitoring. Available online at http://medsmagazine.com/2010/o8/the-new-world-of-home-healthtelemonitoring/ [Last visited: 18-08-2015]

25 Mirel, L.B, Carper,K. (2014). Trends in Health Care Expenditures for the Elderly, Age 65 and Over: 2001, 2006, and 2011. Available online at http://meps.ahrq.gov/mepsweb/data_files/publications/st429/stat429.pdf [Last visited 18-07-2015]

26 Heidenreich, P.A (2011) Forecasting the Future of Cardiovascular Disease in the United States - A Policy Statement From the American Heart Association . 
American Heart Association, Inc. Available online at http://circ.ahajournals.org/content/123/8/933.full.pdf+html doi: o.1161/CIR.obo13e31820a55f5

27 Munro, D. (2012). The year in healthcare charts. Available online at http://www.forbes.com/sites/danmunro/2012/12/30/2012-the-year-in-healthcarecharts/ [Last visited: 18-07-2015]

28 American Diabetes Association - Economic costs of diabetes in the U.S. in 2012. Diabetes Care. 2013 Apr;36(4):1033-46. doi: 10.2337/dc12-2625. Epub 2013 Mar 6.

29 Centre for medicare and Medicaid services. Department of health and human services. Original issuance February $17^{\text {th }}, 2005$, re-evaluated march $27^{\text {th }}, 2008$. Available online at https://www.cms.gov/Research-Statistics-Data-andSystems/CMS-Information

Technology/XLC/Downloads/SelectingDevelopmentApproach.pdf [Last visited: 29-02-2016]

30 Kujala,S. (2003) User involvement: A review of the benefits and challenges, Behaviour \& Information Technology, 22:1, 1-16, DOI: 10.1080/01449290301782

31 Gulliksen,J., Göransson,B., Boivie,I. (2003) Key principles for user-centred systems design , Behaviour \&Information Technology, 22:6, 397-409, DOI: 10.1080/0144929031000162432

The included articles for the literature survey can be found at: http://www.ijmijournal.com/article/S1386-5056(16)30130-7/references 


\section{References Chapter 3}

1 Veltink, P. H., van Meulen, F. B., van Beijnum, B.-J. F., Klaassen, B., Hermens, H., Droog, E., et al. (2014). "Daily-life tele-monitoring of motor performance in stroke survivors," in 13th International Symposium on $3 \mathrm{D}$ Analysis of Human Movement (3D-AHM 2014) (Lausanne), 159-162.

2 Pawar, P., Jones, V., Beijnum van, B-J. F. and Hermens, H. (2012) 'A framework for the comparison of mobile patient monitoring systems'. Journal of biomedical informatics, 45 (3). pp. 544-556.

3 European Data Format (2014) A simple and flexible format for exchange and storage of multichannel biological and physical signals,[ONLINE] Available: http://www.edfplus.info/ [05-o6-2014]

4 Liferay, Inc. (2013) Liferay delivers open source enterprise solutions for portals, publishing, content, and collaboration,[ONLINE] Available: http://www.liferay.com/ [30 Sept 2013]

5 Xsens Technologies B.V. (2014) MTW Development KIT Lite,[ONLINE] Available: http://www.xsens.com/en/mtw-dk-lite [05-06-2014]

6 Highsoft Solutions AS (2014) Highcharts JS, interactive JavaScript charts for your website, [ONLINE] Available: http://www.highcharts.com/ [05-06-2014]

7 Twitter Bootstrap (2014) Sleek, intuitive, and powerful front-end framework for faster and easier web development,[ONLINE] Available: http://getbootstrap.com/ [05-06-2014]

8 MatlabControl (2013) Matlabcontrol API for JAVA,[ONLINE] Available: http://code.google.com/p/matlabcontrol/ [30 Sept 2013]

9 Sumner, B. Mancuso, C and Paradiso, R. "Performances evaluation of textile electrodes for EMG remote measurements" Proceedings of the 35th Annual International Conference of the IEEE Engineering in Medicine and Biology Society: 6510-6513, 2013.

10 Tekscan, Inc.(2014), FlexiForce ${ }^{\oplus}$ [ONLINE] Available: http://www.tekscan.com/flexiforce.html [05-06-2014]

11 Roetenberg, D. Luinge, H. Slycke, P. Xsens MVN: full 6DOF human motion tracking using miniature inertial sensors. Xsens Motion Technologies BV, Tech. Rep. 2009.

12 Berg, K.O. Wood-Danphinee, S. Williams, J.T. Measuing balance in the elderly: preliminary development of an instrument. Physiotherapy 41(6):304-311, 1989

13 Vicon Motion Systems Ltd (2014), Oxfort, England. 


\section{References Chapter 4}

1 Kollen, B., Kwakkel, G., and Lindeman, E. (2006). Functional recovery after stroke: a review of current developments in stroke rehabilitation research. Rev. Recent Clin. Trials 1, 75-8o. doi:10.2174/157488706775246111

2 Bussmann, J. B., Ebner-Priemer, U. W., and Fahrenberg, J. (2009). Ambulatory activity monitoring: progress in measurement of activity, posture, and specific motion patterns in daily life. Eur. Psychol. 14, 142-152. doi:10.1027/1016-9040. 14.2 .142

3 Bergmann, J., and McGregor, A. (2011). Body-worn sensor design: what do patients and clinicians want? Ann. Biomed. Eng. 39, 2299-2312. doi:10.1007/s10439-011- 03399

4 Moe-Nilssen, R. (1998). A new method for evaluating motor control in gait under real-life environmental conditions. Part 1: the instrument. Clin. Biomech. 13, 320327. doi:10.1016/So268-0033(98)ooo89-8

5 Gebruers, N., Vanroy, C., Truijen, S., Engelborghs, S., and De Deyn, P. P. (2010). Monitoring of physical activity after stroke: a systematic review of accelerometrybased measures. Arch. Phys. Med. Rehabil. 91, 288-297. doi:10. 1016/j.apmr.2009.10.025

6 de los Reyes-Guzmán, A., Dimbwadyo-Terrer, I., Trincado-Alonso, F., MonasterioHuelin, F., Torricelli, D., and Gil-Agudo, A. (2014). Quantitative assessment based on kinematic measures of functional impairments during upper extremity movements: a review. Clin. Biomech. 29, 719-727. doi:10.1016/j.clinbiomech. 2014.06.013

7 Veltink, P. H., van Meulen, F. B., van Beijnum, B.-J. F., Klaassen, B., Hermens, H., Droog, E., et al. (2014). "Daily-life tele-monitoring of motor performance in stroke survivors," in 13th International Symposium on $3 \mathrm{D}$ Analysis of Human Movement (3D-AHM 2014) (Lausanne), 159-162.

8 van Meulen, F. B., Reenalda, J., Buurke, J. H., and Veltink, P. H. (2015). Assessment of daily-life reaching performance after stroke. Ann. Biomed. Eng. 43, 478-486. doi:10.1007/s10439-014-1198-y

9 Klaassen, B., van Beijnum, B.-J., Weusthof, M., Hofs, D., van Meulen, F., Luinge, H., et al. (2014). "A system for monitoring stroke patients in a home environment," in International Conference on Health Informatics (HEALTHINF 2014) (Angers), 125132.

10 Paradiso, R., Mancuso, C., De Toma, G., and Caldani, L. (2014). “Textile sensing platforms for remote monitoring of physical interaction with the environment," in 
Medical Information and Communication Technology (ISMICT), 8th International Symposium on (Firenze: IEEE), $1-5$.

11 Huis in 't Veld, R. M., Widya, A., Bults, R. G., Sandsjö, L., Hermens, H. J., Vollenbroek-Hutten, M. M., et al. (2010). A scenario guideline for designing new teletreatments: a multidisciplinary approach. J. Telemed. Telecare 16, 302-307. doi:10.1258/jtt.2010.006003

12 Jackson, M. (1997). The meaning of requirements. Ann. Software Eng. 3, 5-21. doi:10.1023/A:1018990005598

13 Clegg, D., and Barker, R. (1994). Case Method Fast-Track: A RAD Approach. Boston, MA: Addison-Wesley Longman Publishing Co., Inc.

14 Roetenberg, D., Luinge, H., and Slycke, P. (2009). Xsens mvn: full 6dof human motion tracking using miniature inertial sensors. Xsens Motion Technol. BV Tech. Rep.

15 Skog, I., Handel, P., Nilsson, J.-O., and Rantakokko, J. (2010). Zero-velocity detection - an algorithm evaluation. IEEE Trans. Biomed. Eng. 57, 2657-2666. doi:10. 1109/TBME.2010.2060723

16 Donovan, K., Lord, S. E., McNaughton, H. K., and Weatherall, M. (2008). Mobility beyond the clinic: the effect of environment on gait and its measurement in community-ambulant stroke survivors. Clin. Rehabil. 22, 556-563. doi:10.1177/ 0269215507085378

17 Fulk, G. D., Reynolds, C., Mondal, S., and Deutsch, J. E. (2010). Predicting home and community walking activity in people with stroke. Arch. Phys. Med. Rehabil. 91, 1582-1586. doi:10.1016/j.apmr.2010.07.005

18 Dickstein, R. (2007). Rehabilitation of gait speed after stroke: a critical review of intervention approaches. Neurorehabil. Neural Repair 22, 649-66o. doi:10.1177/ 1545968308315997

19 Kuo, A. D., and Donelan, J. M. (2010). Dynamic principles of gait and their clinical implications. Phys. Ther. 90, 157-174. doi:10.2522/ptj.20090125

20 Von Schroeder, H. P., Coutts, R. D., Lyden, P. D., Billings, E., and Nickel, V. L. (1995). Gait parameters following stroke: a practical assessment. J. Rehabil. Res. Dev. 32, 25-25.

21 Evans, M. D., Goldie, P.A., and Hill, K. D. (1997). Systematic and random error in repeated measurements of temporal and distance parameters of gait after stroke. Arch. Phys. Med. Rehabil. 78, 725-729. doi:10.1016/Sooo3-9993(97)90o8o-o

22 Haggard, P., and Cockburn, J. (1998). Concurrent performance of cognitive and motor tasks in neurological rehabilitation. Neuropsychol. Rehabil. 8, 155-170. doi:10.1080/713755565 
23 Bowen, A., Wenman, R., Mickelborough, J., Foster, J., Hill, E., and Tallis, R. (2001). Dual-task effects of talking while walking on velocity and balance following a stroke. Age Ageing 30, 319-323. doi:10.1093/ageing/30.4.319

24 Cockburn, J., Haggard, P., Cock, J., and Fordham, C. (2003). Changing patterns of cognitive-motor interference ( $\mathrm{cmi}$ ) over time during recovery from stroke. Clin. Rehabil. 17, 167-173. doi:10.1191/0269215503cr5970a

25 Brach, J. S., Studenski, S., Perera, S., VanSwearingen, J. M., and Newman, A. B. (2008). Stance time and step width variability have unique contributing impairments in older persons. Gait Posture 27, 431-439. doi:10.1016/j.gaitpost.2007. 05.016

26 Balasubramanian, C. K., Neptune, R. R., and Kautz, S. A. (2009). Variability in spatiotemporal step characteristics and its relationship to walking performance post-stroke. Gait Posture 29, 408-414. doi:10.1016/j.gaitpost.2008.10.061

27 Belda-Lois, J.-M., Mena-del Horno, S., Bermejo-Bosch, I., Moreno, J. C., Pons, J. L., Farina, D., et al. (2011). Rehabilitation of gait after stroke: a review towards a topdown approach. J. Neuroeng. Rehabil. 8, 66. doi:10.1186/1743-0003-8-66

28 Hausdorff, J. M., Rios, D. A., and Edelberg, H. K. (2001). Gait variability and fall risk in community-living older adults: a 1-year prospective study. Arch. Phys. Med. Rehabil. 82, 1050-1056. doi:10.1053/apmr.2001.24893

29 Verghese, J., Holtzer, R., Lipton, R. B., and Wang, C. (2009). Quantitative gait markers and incident fall risk in older adults. J. Gerontol. Series A Biol. Sci. Med. Sci. 64, 896-901. doi:10.1093/gerona/glpo33

30 Maki, B. E. (1997). Gait changes in older adults: predictors of falls or indicators of fear? J. Am. Geriatr. Soc. 45, 313-320. doi:10.1111/j.1532-5415.1997.tboo946.x

31 Zariffa, J., Kapadia, N., Kramer, J. L., Taylor, P., Alizadeh-Meghrazi, M., Zivanovic, V., et al. (2012). Relationship between clinical assessments of function and measurements from an upper-limb robotic rehabilitation device in cervical spinal cord injury. IEEE Trans. Neural Syst. Rehabil. Eng. 20, 341-350. doi:10. 1109/TNSRE.2011.2181537

32 Rönnqvist, L., and Rösblad, B. (2007). Kinematic analysis of unimanual reach- ing and grasping movements in children with hemiplegic cerebral palsy. Clin. Biomech. 22, 165-175. doi:10.1016/j.clinbiomech.2006.09.004

33 Ellis, M. D., Sukal, T., DeMott, T., and Dewald, J. P. (2008). Augmenting clinical evaluation of hemiparetic arm movement with a laboratory-based quantitative measurement of kinematics as a function of limb loading. Neurorehabil. Neural Repair 22, 321-329. doi:10.1177/1545968307313509 
34 Jaspers, E., Desloovere, K., Bruyninckx, H., Klingels, K., Molenaers, G., Aertbeliën, E., et al. (2011). Three-dimensional upper limb movement characteristics in children with hemiplegic cerebral palsy and typically developing children. Res. Dev. Disabil. 32, 2283-2294. doi:10.1016/j.ridd.2011.07.038

35 de los Reyes-Guzmán, A., Dimbwadyo-Terrer, I., Trincado-Alonso, F., MonasterioHuelin, F., Torricelli, D., and Gil-Agudo, A. (2014). Quantitative assessment based on kinematic measures of functional impairments during upper extremity movements: a review. Clin. Biomech. 29, 719-727. doi:10.1016/j.clinbiomech. 2014.06.013

36 Young, R. P., and Marteniuk, R. G. (1997). Acquisition of a multi-articular kicking task: jerk analysis demonstrates movements do not become smoother with learning. Hum. Mov. Sci. 16, 677-701. doi:10.1016/So167-9457(97)ooo10-9

37 Song, R., Tong, K. Y., and Hu, X. L. (2008). Evaluation of velocity-dependent performance of the spastic elbow during voluntary movements. Arch. Phys. Med.Rehabil. 89, 1140-1145. doi:10.1016/j.apmr.2007.10.035

38 Hogan, N., and Sternad, D. (2009). Sensitivity of smoothness measures to movement duration, amplitude, and arrests. J. Mot. Behav. 41, 529-534. doi:10.3200/35-09-004-RC

39 Vega-González, A., and Granat, M. H. (2005). Continuous monitoring of upperlimb activity in a free-living environment. Arch. Phys. Med. Rehabil. 86, 541-548. doi:10.1016/j.apmr.2004.04.049

40 de Niet, M., Bussmann, J. B., Ribbers, G. M., and Stam, H. J. (2007). The stroke upper-limb activity monitor: its sensitivity to measure hemiplegic upper-limb activity during daily life. Arch. Phys. Med. Rehabil. 88, 1121-1126. doi:10.1016/ j.apmr.2007.06.005

41 Preece, S. J., Goulermas, J. Y., Kenney, L. P., Howard, D., Meijer, K., and Crompton,

42 Yang, C.-C., and Hsu, Y.-L. (2010). A review of accelerometry-based wearable motion detectors for physical activity monitoring. Sensors 10, 7772-7788. doi: 10.3390/s10o807772

43 Weenk, D., Roetenberg, D., van Beijnum, B.-J. F., Hermens, H. J., and Veltink, P. H. (2015). Ambulatory estimation of relative foot positions by fusing ultrasound and inertial sensor data. IEEE Trans. Neural Syst. Rehabil. Eng. 23, 817-826. doi:10.1109/TNSRE.2014.2357686

44 Wade, D. T., Wood, V. A., Heller, A., Maggs, J., \& Langton, H. R. (1986). Walking after stroke. Measurement and recovery over the first 3 months. Scandinavian journal of rehabilitation medicine, 19(1), 25-30. 


\section{References Chapter 5}

1 Klaassen B, van Beijnum BJ, Weusthof M, Hofs D, van Meulen F, Droog E, et al. A full body sensing system for monitoring stroke patients in a home environment. (2015) Communications in Computer and Information Science 511, pp. 378-393.

2 van Meulen FB, Klaassen B, Held J, Reenalda J, Buurke JH, van Beijnum BJF, et al. Objective evaluation of the quality of movement in daily life after stroke. Frontiers in Bioengineering and Biotechnology 3 (2016).

3 Lorussi F, Carbonaro N, De Rossi D, Paradiso R, Veltink P, Tognetti A. Wearable textile platform for assessing stroke patient treatment in daily life conditions. Frontiers in Bioengineering and Biotechnology 4 (2016).

4 Kollen B, Kwakkel G, Lindeman E. Functional recovery after stroke: a review of current developments in stroke rehabilitation research. Reviews on recent clinical trials 1 (2006) 75-8o.

5 Qualisys, A. B. (2008). Qualisys motion capture systems. URL: http://www. qualisys. se/, accessed on, 04-04.

6 Burridge JH, Hughes AM. Potential for new technologies in clinical practice. Current opinion in neurology 23 (2010) 671-677.

7 Bergmann J, McGregor A. Body-worn sensor design: what do patients and clinicians want? Annals of biomedical engineering 39 (2011) 2299-2312.

8 Hughes, A. M., Burridge, J., Demain, S., Ellis-Hill, C., Meagher, C., TedescoTriccas, L., ... \& Swain, I. (2014). Translation of evidence-based Assistive Technologies into stroke rehabilitation: users' perceptions of the barriers and opportunities. BMC Health Services Research, 1(14), 1-12.

9 Podsiadlo D, Richardson S. The timed up \& go: a test of basic functional mobility for frail elderly persons. Journal of the American geriatrics Society 39 (1991) 142148.

10 Gladstone CD DJ, Black S. The fugl-meyer assessment of motor recovery after stroke: a critical review of its measurement properties. Neurorehabil Neural Repair 16 (2002) 232-240.

11 Allen IE, Seaman CA. Likert scales and data analyses. Quality Progress 40 (2007), $\mathrm{p}: 65-65$.

12 Muhr T. Atlas. ti: The Knowledge Workbench: V5. o User's Guide and Reference (Scientific Software Development) (2004).

13 Bailey RR, Klaesner JW, Lang CE. Quantifying real-world upper-limb activity in nondisabled adults and adults with chronic stroke. Neurorehabilitation and neural repair 29 (2015) 969-978.

14 Xsens B.V. Introducing the new xsens mvn biomech (2015). 
15 Noitom B.V. Perception neuron full body mocap systems (2016).

16 Bianchi M, Carbonaro N, Battaglia E, Lorussi F, Bicchi A, De Rossi D, et al. Exploiting hand kinematic synergies and wearable under-sensing for hand functional grasp recognition. Wireless Mobile Communication and Healthcare (Mobihealth), 2014 EAI 4th International Conference on (IEEE) (2014), 168-171.

17 MacLellan MJ, Patla AE. Adaptations of walking pattern on a compliant surface to regulate dynamic stability. Experimental brain research 173 (2006) 521-530.

18 Bang DH, Shin WS, Noh HJ, Song MS. Effect of unstable surface training on walking ability in stroke patients. Journal of physical therapy science 26 (2014) 1689 .

19 Hermsdorfer J, Bienkiewicz M, Cogollor JM, Russel M, Jean-Baptiste E, Parekh M, et al. Cogwatch-automated assistance and rehabilitation of stroke-induced action disorders in the home environment. Engineering Psychology and Cognitive Ergonomics. Applications and Services (Springer) (2013), 343-350.

20 Liu L, Stroulia E, Nikolaidis I, Miguel-Cruz A, Rincon AR. Smart homes and home health monitoring technologies for older adults: A systematic review. International Journal of Medical Informatics 91 (2016) 44-59.

21 Klaassen B, Bartels P, van Beijnum B, Hermens H. The development and evaluation of an arm usage coach for stroke survivors. 2015 9th International Conference on Sensing Technology (ICST) (IEEE) (2015), 514-519. 


\section{References Chapter 6}

1. Fugl-Meyer, A. R., L. Jääskö, I. Leyman, S. Olsson, and S. Steglind. The post-stroke hemiplegic patient. A method for evaluation of physical performance. Scand. J. Rehabil. Med. 7:13-31, 1975.

2. B. Klaassen, B.J.F van Beijnum, M.H.H. Weusthof, D.H.W Hofs,. F.B van Meulen,. H.J Luinge,. F. Lorussi, H.J. Hermens, and P.H. Veltink, (2014) A System for Monitoring Stroke Patients in a Home Environment. In: Proceedings of the International Conference on Health Informatics, 3-6 march 2014, Angers, France. pp. 125-132. International Conference on Health Informatics (HEALTHINF 2014) 2014. SCITEPRESS. ISBN 978-989-758-010-9

3. M. E. Michielsen, R.W. Selles, H. J. Stam, G. M. Ribbers, ,J. B. Bussmann, "Quantifying Nonuse in Chronic Stroke Patients: A Study Into Paretic, Nonparetic, and Bimanual Upper-Limb Use in Daily Life".Archives of Physical Medicine and Rehabilitation. Volume 93, Issue 11, November 2012, Pages 1975-1981

4. M. de Niet, J. B. Bussmann, G. M. Ribbers, H. J. Stam, "The Stroke Upper-Limb Activity Monitor: Its Sensitivity to Measure Hemiplegic Upper-Limb Activity during Daily Life". Archives of Physical Medicine and Rehabilitation. Volume 88, Issue 9, September 2007, Pages 1121-1126

5. B. e. a. Molier, "Nature, timing, frequency and type of augmented feedback; does it influence motor relearning of the hemiparetic arm after stroke?," Disability and rehabilitation, vol. 32(22), pp. 1799-1809, 2010

6. K. e. a. Sienko, "The effect of vibrotactile feedback on postural sway during locomotor activities," Journal of neuroengineering and rehabilitation, vol. 10, 2013

7. K. Bark, P. Khanna, R. Irwin, P. Kapur, S. Jax A., L. Buxbaum J. and K. Kuchenbecher J., "Lessons in Using Vibrotactile Feedback to Guide Fast Arm Motions," Istanbul, 2011

8. Causo, T. L. Dung, S. H. Yeo, Chen and I-Meng, "Visual Cue and Vibrotacitle in Series Configuration: Multimodal Feedback Desing for Arm Posture Correction," Journal of Medical Imaging and Health Information, no. 2, pp. 430-437, 2012

9. Houwink, L. D. Roorda, W. Smits, I. W. Molenaar and A. C. Geurts, "Measuring upper limg capacity in patients after stroke: reliability and validity of the stroke upper limb capacity scale," Arch Phys Med Rehabil, no. 92, pp. 1418-1422, 2011

10. O. A. V. v. H. Jansen, "Vibrotactile movement initiation," in Proceedings of EuroHaptics, Munich, 2004

11. P. Kapur, S. Premakumar, S. A. Jax, L. J. Buxbaum, A. M. Dawson and K. J. Kuchenbecker, "Vibrotactile Feedback System for Intuitive Upper-Limb Rehabilitation," in Third Joint Eurohaptics Conference and Symposium on Haptic 
Interfaces, Salt Lake City, 2009

12. J. E. N. Rosenthal, "Design, Implementation, and Case Study of a Pragmatic Vibrotactile Belt," IEEE transaction on instrumentation and measurement, vol. 6o, 2011

13. R. e. a. Sigrist, "Augmented visual, auditory, haptic and multimodal feedback in motor learning: A review," Psuchonomic Bulletin \& review, no. 20(1), pp. 21-53, 2013

14. Canadian society of value analysis, [Online]. Available: http://www.scavcsva.org/. [Accessed on 31-08-2015]

15. Xsens MTW CE [online]. Available: https://www.xsens.com/products/mtwdevelopment-kit/ [Accessed on 18-06-2015]

16. P.G.H. Bartels, "The development and evaluation of an on-body feedback system for stroke patients in which vibrotactile feedback contributes to the stimulation of using the affected arm during daily life" Biomedical Signals and systems, BSS15-03, 2015.

17. MATLAB Release 2014b, The MathWorks, Inc., Natick, Massachusetts, United States.

18. Elitac vibrotactile display [online] Available: http://www.elitac.nl/ [Accessed on 18-06-2015]

19. FB. van Meulen, J.Reenalda , JH Buurke, PH Veltink."Assessment of daily-life reaching performance after Stroke". Ann Biomed Eng. 2015 Feb;43(2):478-86. doi: 10.1007/s10439-014-1198-y. Epub 2014 Dec2

20. J.Brook, "SUS: A Quick and dirty Usability scale". [Online] Available: http://www.usability.gov/how-to-and-tools/methods/system-usabilityscale.html [Accessed on 18-06-2015].

21. J.R. Lewis, (1995) IBM Computer Usability Satisfaction Questionnaires: Psychometric Evaluation and Instructions for Use. International Journal of Human-Computer Interaction, 7:1, 57-78

22. H. op den Akker, M. Cabrita, R. op den Akker, V. M. Jones, H. J. Hermens, "Tailored motivational message generation: A model and practical framework for real-time physical activity coaching." Journal of Biomedical Informatics 55 (2015) pages 104-115.

23. Bitalino circuit boards [online] Available: http://www.bitalino.com/ [Accessed on 28-06-2015] 


\section{References Chapter 7}

1. Kollen B, Kwakkel G, Lindeman E. Functional recovery after stroke: a review of current developments in stroke rehabilitation research. Reviews on recent clinical trials 1 (2006) 75-8o.

2. Bussmann JB, Ebner-Priemer UW, Fahrenberg J. Ambulatory activity monitoring: progress in measurement of activity, posture, and specific motion patterns in daily life. European Psychologist 14 (2009) 142-152.

3. Lo AC, Guarino PD, Richards LG, Haselkorn JK, Wittenberg G F, Federman DG, et al. Robot-assisted therapy for long-term upper-limb impairment after stroke. The New England Journal of Medicine 2010;362(19):1772-83. NCToo372411. Robotic assisted upper-limb neurorehabilitation in $\mathrm{s}$ troke patients. http:// clinicaltrials.gov/ct2/show/NCToo372411

4. B. Klaassen, B.J.F van Beijnum, M.H.H. Weusthof, D.H.W Hofs, F.B van Meulen, E. Droog, H.J. Luinge, L.Slot, A. Tognetti, F. Lorussi, R. Paradiso, J. Held, A. Luft, J. Reenalda, C.Nikamp, J. Buurke, H.J. Hermens, and P.H. Veltink, (2016) A Full Body Sensing System for Monitoring Stroke Patients in a Home Environment. Springer chapter Biomedical Engineering Systems and Technologies Volume 511 of the series Communications in Computer and Information Science pp 378-393, ISBN: 978-3-319-26129-4, DOI: 10.1007/978-3-319-26129-4_25

5. Veltink PH, van Meulen FB, van Beijnum BJF, Klaassen B, Hermens H, Droog E, et al. Ambulatory 370 gait analysis in stroke patients using ultrasound and inertial sensors. 13th International Symposium on 3D Analysis of Human Movement (3DAHM 2014), Lausanne, Switserland (2014), 159-162.

6. van Meulen FB, Klaassen B, Held J, Reenalda J, Buurke JH, van Beijnum B-JF, Luft A and Veltink PH (2016) Objective Evaluation of the Quality of Movement in Daily Life after Stroke. Front. Bioeng. Biotechnol. 3:210. doi: 10.3389/fbioe.2015.00210K. Bark, P. Khanna, R. Irwin, P. Kapur, S.

7. Klaassen, B., Bartels, P. G. H., van Beijnum, B. J. F., \& Hermens, H. (2015, December). The development and evaluation of an arm usage coach for Stroke survivors. In 2015 9th International Conference on Sensing Technology (ICST) (pp. 514-519). IEEE.

8. Jax A., L. Buxbaum J. and K. Kuchenbecher J., "Lessons in Using Vibrotactile Feedback to Guide Fast Arm Motions," Istanbul, 2011

9. Causo, T. L. Dung, S. H. Yeo, Chen and I-Meng, "Visual Cue and Vibrotacitle in Series Configuration: Multimodal Feedback Desing for Arm Posture Correction," Journal of Medical Imaging and Health Information, no. 2, pp. 430-437, 2012 
10. Houwink, L. D. Roorda, W. Smits, I. W. Molenaar and A. C. Geurts, "Measuring upper limg capacity in patients after stroke: reliability and validity of the stroke upper limb capacity scale," Arch Phys Med Rehabil, no. 92, pp. 1418-1422, 2011

11. O. A. V. v. H. Jansen, "Vibrotactile movement initiation," in Proceedings of EuroHaptics, Munich, 2004

12. P. Kapur, S. Premakumar, S. A. Jax, L. J. Buxbaum, A. M. Dawson and K. J. Kuchenbecker, "Vibrotactile Feedback System for Intuitive Upper-Limb Rehabilitation," in Third Joint Eurohaptics Conference and Symposium on Haptic Interfaces, Salt Lake City, 2009

13. J. E. N. Rosenthal, "Design, Implementation, and Case Study of a Pragmatic Vibrotactile Belt," IEEE transaction on instrumentation and measurement, vol. 6o, 2011

14. R. e. a. Sigrist, "Augmented visual, auditory, haptic and multimodal feedback in motor learning: A review,” Psuchonomic Bulletin \& review, no. 20(1), pp. 21-53, 2013

15. Fugl-Meyer, A. R., L. Jaasko, I. Leyman, S. Olsson, and S. Steglind The post-stroke hemiplegic patient. 1. A method for evaluation of physical performance. Scand. J. Rehabil Med. 7:13-31, 1975

16. F. Stolk-Hornsveld, MSc. \& J.L. Crow, MSc. Meetinstrument voor onderzoek van tastzin en propriocepsis bij patienten met niet aangeboren hersenletsel. EmNSA september 2014 / Erasmus Nottingham Sensory Assessment

17. van Meulen FB, Reenalda J, Buurke JH, Veltink PH. Assessment of daily-life reaching performance after stroke. Annals of biomedical engineering 43 (2015) $478-486$.

18. Lyle, R. C. (1981). "A performance test for assessment of upper limb function in physical rehabilitation treatment and research." Int J Rehabil Res 4(7333761): 483492

19. J.Brook, "SUS: A Quick and dirty Usability scale”.[Online] Available: http://www.usability.gov/how-to-andtools/methods/system-usability-scale.html [Accessed on 18-06-2015].

20. Bangor A, Kortum P, Miller J. Determining what individual SUS scores mean: adding an adjective rating scale. J Usability Stud. 2009;4(3):114-23.

21. Bangor A, Kortum PT, Miller JT. An empirical evaluation of the system usability scale. Int J Hum Comput Interact. 2008;24(6):574-94. doi:10.1080/10447310802205776.

22. Hoonhorst MH, Nijland RH, van den Berg JS, Emmelot CH, Kollen BJ, Kwakkel G. How Do Fugl-Meyer Arm Motor Scores Relate to Dexterity According to the 
Action Research Arm Test at 6 Months Poststroke? Arch Phys Med Rehabil. 2015 Oct;96(10):1845-9. doi: 10.1016/j.apmr.2015.06.009. Epub 2015 Jul 2.

23. Acuna, M., Amasay, T., \& Karduna, A. R. (2010). The reliability of side to side measurements of upper extremity activity levels in healthy subjects. BMC Musculoskeletal Disorders, 11, 168. http://doi.org/10.1186/1471-2474-11-168

24. Hung, C. T., Croft, E. A., \& Machiel Van der Loos, H. F. (2015, August). A wearable vibrotactile device for upper-limb bilateral motion training in stroke rehabilitation: A case study. In Engineering in Medicine and Biology Society (EMBC), 2015 37th Annual International Conference of the IEEE (pp. 3480-3483). IEEE.

25. Kato, N., Tanaka, T., Sugihara, S., \& Shimizu, K. (2015). Development and evaluation of a new telerehabilitation system based on VR technology using multisensory feedback for patients with stroke. Journal of physical therapy science, $27(10)$, 3185 . 


\section{References Chapter 8}

1. MiniSens, STW (13917) project, University of Twente (2015-2019). [Online] http://www.stw.nl/nl/content/minisens-3d-full-body-movement-tracking-usingminimal-wearable-sensing (last visited 28-08-2016)

2. NeuroCIMT (2016). Neuromodulation by Continuous and Integrated Monitoring and Treatment. [Online available at neurocontrol.nl]

3. Gordon, N. F., Gulanick, M., Costa, F., Fletcher, G., Franklin, B. A., Roth, E. J., \& Shephard, T. (2004). Physical activity and exercise recommendations for stroke survivors an American heart association scientific statement from the council on clinical cardiology, subcommittee on exercise, cardiac rehabilitation, and prevention; the council on cardiovascular nursing; the council on nutrition, physical activity, and metabolism; and the stroke council. Stroke, 35(5), 1230-1240.

4. Maclean, N., Pound, P., Wolfe, C., \& Rudd, A. (2002). The concept of patient motivation a qualitative analysis of stroke professionals' attitudes. Stroke, 33(2), 444-448.

5. Maclean, N., \& Pound, P. (2000). A critical review of the concept of patient motivation in the literature on physical rehabilitation. Soc Sci Med, 5o(4), 495506.

6. Giuberti, M., \& Ferrari, G. (2013). BSN-based Activity Classification: a Low Complexity Windowing-\&-Classification Approach. In Advances in Science and Technology (Vol. 85, pp. 53-58). Trans Tech Publications.

7. K. Cho and X. Chen, "Classifying and visualizing motion capture sequences using deep neural networks", Computer Research Repository (CoRR), vol. 1306, pp. 3874, 2013.

8. S. Ji, W. Xu, M. Yang and K. Yu, "3d convolutional neural networks for human action recognition", IEEE Transactions on Pattern Analysis and Machine Intelligence, vol. 35, no. 1, pp. 221-231, 2013.

9. Takacs, J., Pollock, C. L., Guenther, J. R., Bahar, M., Napier, C., \& Hunt, M. A. (2014). Validation of the Fitbit One activity monitor device during treadmill walking. Journal of Science and Medicine in Sport, 17(5), 496-500.

10. Hocoma, A. G. (2016). Back pain therapy with the Valedo THERAPY Concept. 


\section{LIST OF PUBLICATIONS}

\section{Journal papers}

- Klaassen, B., van Beijnum, B.J.F., \& Hermens, H.J. (2016). Usability in telemedicine systems- A literature survey. International Journal of Medical Informatics. Vol 93, Pages 57-69, Elsevier

- Klaassen, B., Meulen, F. B., Held, J.P., Reenalda, J., Buurke, J. H., Beijnum, B. J. F., \& Veltink, P. H. (2016). Objective evaluation of the quality of movement in daily life after stroke. Frontiers in bioengineering and biotechnology, 3(210), 1-11.

- Klaassen, B, Held, J.P, van Beijnum, B.J.F., Luft' A. R., Veltink' P. H. (2016) The evaluation of a sensing system combined with vibrotactile feedback in stroke survivors . Submitted to Frontiers in Bioengineering and Biotechnology October 2016 (first revision).

- Klaassen, B., van Beijnum, B.J.F., Held, J.P., Reenalda, J., Meulen, F. B., Veltink' P. H., Hermens, H.J. (2016) Usability evaluations of a full body sensing system and resulting metrics for stroke survivors. Submitted to Frontiers, Bioengineering and Biotechnology, October 2016 (first revision).

\section{Book chapters}

- Klaassen B, van Beijnum B.J.F, Weusthof M.H.H., Hofs D, van Meulen F, Droog E, Luinge H, Slot L, Tognetti A, Lorussi F, Paradiso R, Held J, Luft A.R, Reenalda J, Nikamp C, Buurke J.H, Hermens H,J. Veltink P.H. (2015) A full body sensing system for monitoring stroke patients in a home environment. Springer, Commun Comput Inf Sci. 2015; 511:378-93.

- Klaassen B, van Beijnum B.J.F., Bartels, P.G.H, Hermens H.J (2016). The development and evaluation of a vibrotactile arm coach for stroke survivors. Springer, Sensors for Everyday Life volume 2, to be published in December 2016. 


\section{Peer reviewed conference papers}

- Klaassen,B., Van Beijnum, B.J.F., Weusthof, M.H.H. ., Hofs, D., Van Meulen, F.B., Luinge, H.J. et al., "(2014) A System for Monitoring Stroke Patients in a Home Environment. (HealthINF, Angers, France) 2014, pp. 125-132, ISBN 978989-758-010-9.

- $\quad$ Klaassen, B., Bartels, P. G. H., van Beijnum, B. J. F., \& Hermens, H.J. (2015). The development and evaluation of an arm usage coach for Stroke survivors. In 2015 9th International Conference on Sensing Technology (ICST Auckland, New Zealand) (pp. 514-519). IEEE.

\section{Conference abstracts / demonstrations / workshops (1th / $2^{\text {nd }}$ author)}

- Klaassen, B., Held, J.P., van Beijnum, B.J.F., Luft, A.R., Veltink, P.H. The Evaluation of Feedback Modalities in Stroke Survivors (2016). Accepted for ICNR 2016, Spain.

- Held, J.P., Klaassen, B., Eenhoorn, A., Buurke, J.H., van Beijnum, B.J.F., Luft, A.R., Veltink, P.H (2016) Monitoring stroke patients in hospital and home environment (2016). Accepted for ICNR 2016, Spain.

- Veltink, P. H., Klaassen, B., Hermens, H. J., Droog, A., Weusthof, M. H. H., Lorussi, F., ... \& Buurke, J. H. (2014). Daily-life tele-monitoring of motor performance in stroke survivors. Ecole Polytechnique Federale de Lausanne

- Meulen, F.B. van, Klaassen, B., Reenalda, J., Buurke, J.H., Veltink, P.H., Assessment and visualisation of daily-life arm movements after stroke, poster,

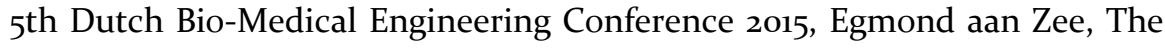
Netherlands, 22-23 January 2015

- Klaassen, B., INTERACTION for Stroke: a full body sensing system for daily life performance monitoring, invited oral presentation, Lehrstuhl für Bewegungswissenschaft, Fakultät für Sport- und Gesundheitswissenschaft Technische Universität München, Lead by: Prof. Dr. Joachim Hermsdörfer, http://www.bewegungswissenschaft.sg.tum.de/startseite/, 8 May 2014

- Klaassen, B, Weusthof, M.H.H., Van Beijnum, B.J.F., INTERACTION demonstration, INRS2013 Congress Zürich, 11-13 September 20 


\section{INTERACTION}

This thesis is part of the INTERACTION project, which was funded by the European Commission under the 7 th Framework Program (FP7-ICT-2011-7-287351) and coordinated by the University of Twente. In a joint collaboration with over 30 researchers, engineers and care-professionals, a new system for monitoring stroke patients at home was developed and evaluated in four years' time.

Xsens technologies B.V. provided the inertial motion capture solutions, while Smartex B.V. delivered the fabrics and integrated additional stretch and EMG sensors to the etextile sensor suit. The University of Pisa explored the possibilities for shoulder movement and hand grasping reconstructions by using new sensing technologies. The University of Twente developed the telemonitoring architecture for the system and investigated the outcome metrics of the sensing system and feedback strategies. The University of Zürich and Roessingh Research and Development B.V. conducted the first patient measurements, both in clinic and at home. Together with researchers from the University of Twente, they tested the prototypes, conducted measurements and evaluated the system. The Cereneo A.G. neurorehabilitation clinic and the University Hospital Zurich in Switzerland directed the long-term patient measurements in clinic and at home. Overall, 10 stroke patients were measured for an extended period of time.

The INTERACTION consortium made an important (potential) impact on society and on the theoretical and applied areas of science regarding the diagnostics and treatment of stroke survivors. Over 45 publications have resulted from this project, and the findings have also been presented at many conferences, meetings and workshops worldwide. The EU committee considered the project as "completed" and gave an overall assessment of "good progress". It resulted in a number of new successor projects under the Horizon 2020 program of the European Union. 
THANK YOU FOR READING

BART 


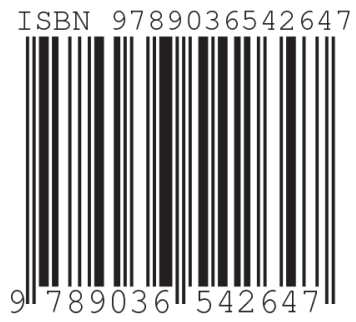

